
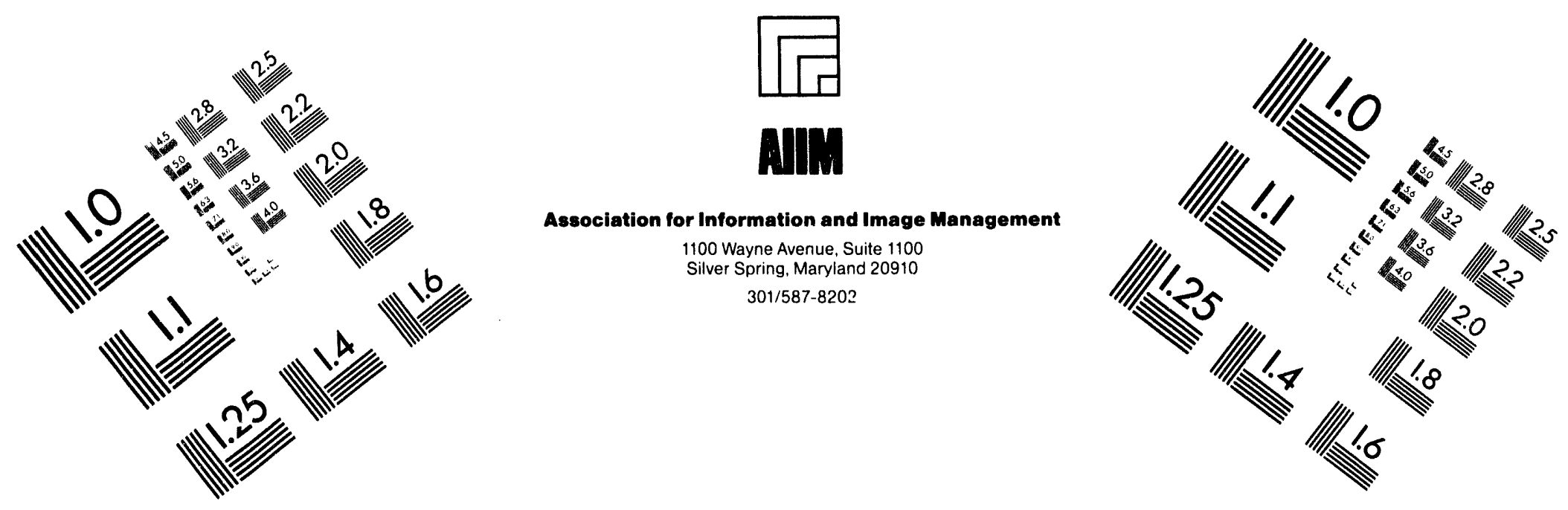

\title{
Centimeter
}

10

Inches
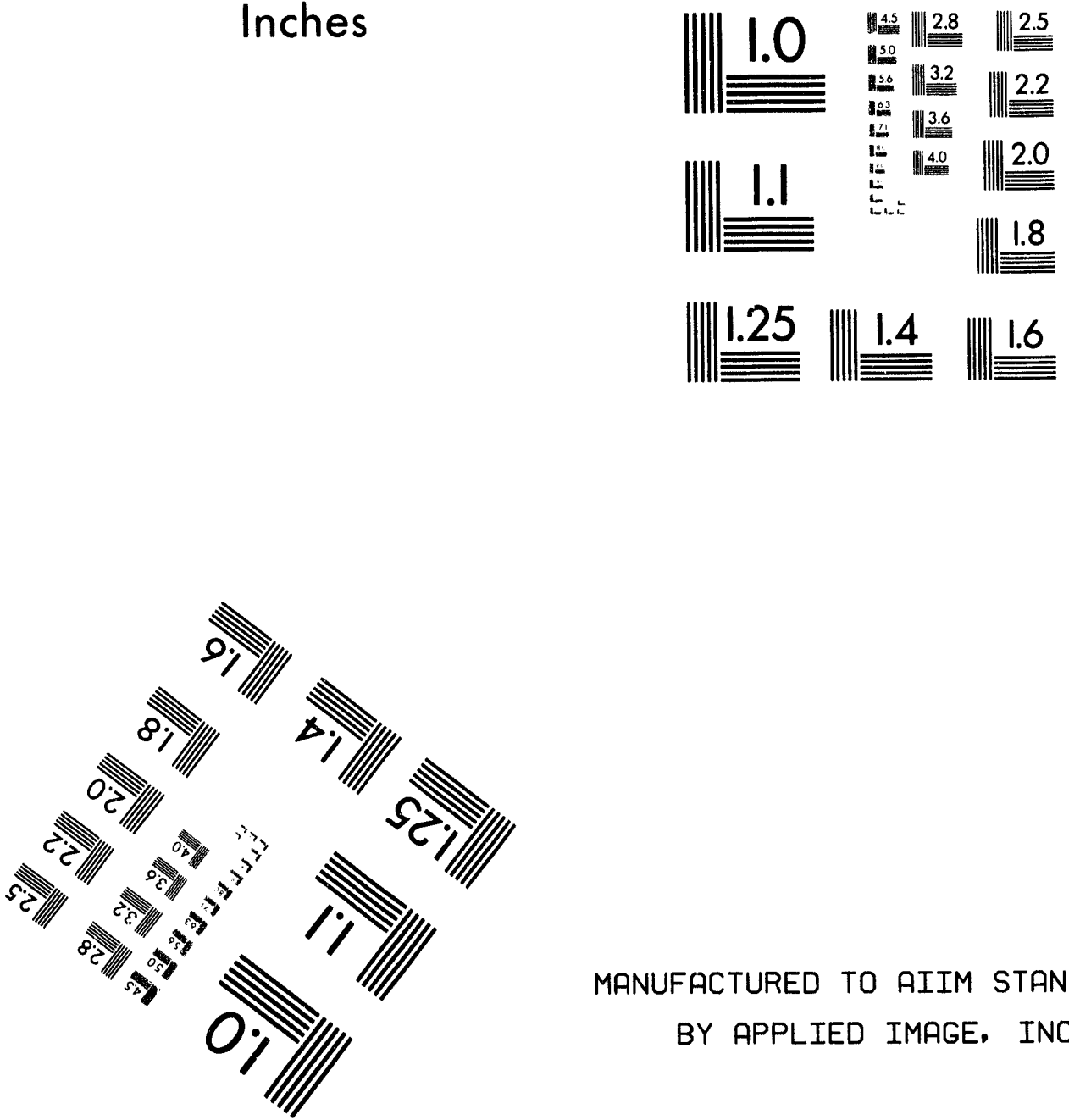

MANUFACTURED TO AIIM STANDARDS

BY APPLIED IMAGE, INC.

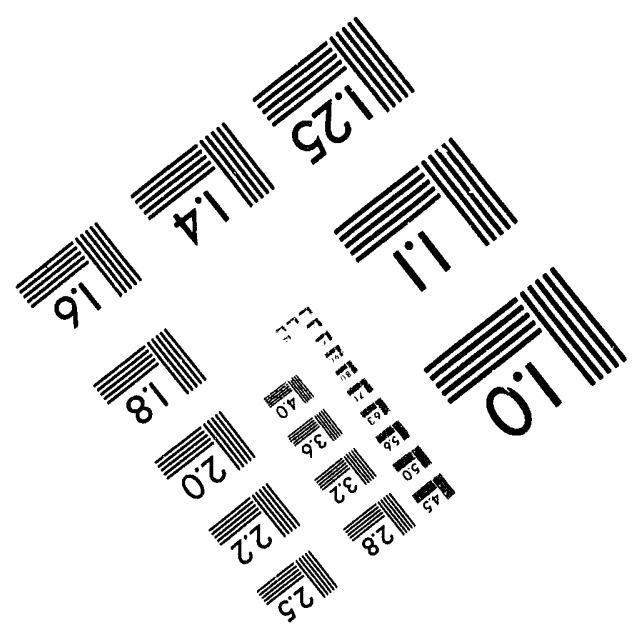



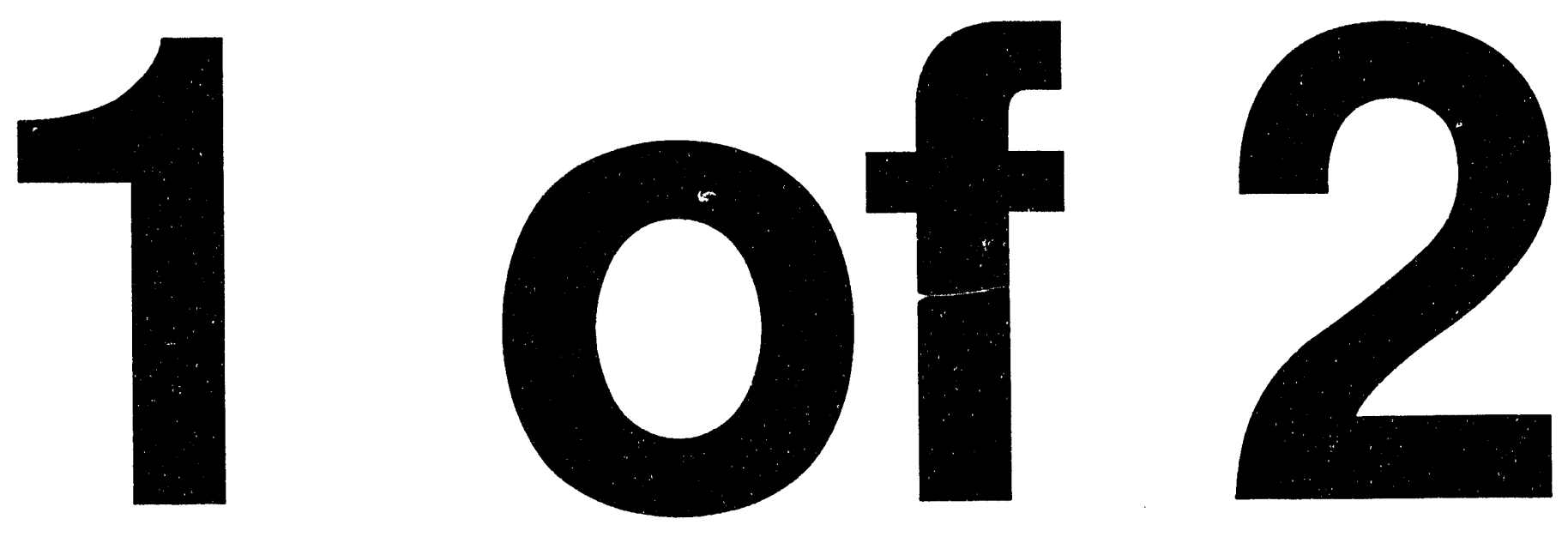


\section{Environmental Geophysics at Beach Point, Aberdeen Proving Ground, Maryland}

by L.D. McGinnis, C.R. Daudt, M.D. Thompson, S.F. Miller, W.A. Mandell," and J. Wrobel*

Reclamation Engineering and Geosciences Section, Energy Systems Division, Argonne National Laboratory, 9700 South Cass Avenue, Argonne, Illinois 60439

July 1994

Work sponsored by United States Department of Defense, United States Army, Aberdeen Proving Ground, Maryland 


\section{Preface}

This report provides administrative and technical staff, responsible for environmental planning and remediation at Beach Point, with the final results and conclusions drawn from geophysical studies begun in May 1993. During the course of the study, the work scope was expanded from that outlined in the Geophysics Work Plan, which emphasized the hydrogeologic framework beneath Beach Point, to include several technologies designed to determine the presence or former presence of contaminants, including surface spills, buried tanks, pipes, and trenches. In addition, the relationship between current aquifer contaminants and disposed liquid wastes was investigated. The work scope and its objectives were guided by staff at Aberdeen Proving Ground, Directorate of Safety, Health, and the Environment; Jacobs Engineering Group, Inc.; and Argonne National Laboratory, Reclamation Engineering and Geosciences Section. Field assistance was provided by Lisa Sachnoff and Robert Pell. Reviews of early versions of the manuscript were provided by Michelle Lorah-Devereux, U.S. Geological Survey; Dennis T. Burton, University of Maryland; and David Diodato, Pennsylvania State University. 


\section{Contents}

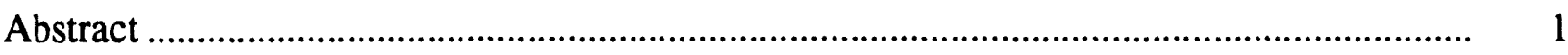

1 Introduction ............................................................................................................

1.1 Physiographic Setting and Site Survey .................................................................... 3

1.2 Site Geology and Hydrogeology ............................................................................. 8

1.3 Outcrops ........................................................................................................... 11

1.4 Instrumentation and Software ...................................................................... 13

2 Magnetic Surveys .......................................................................................................... 15

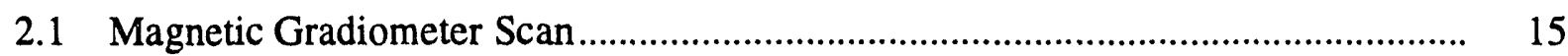

2.2 Continuous Profiling Magnetometry ……………................................................ 15

3 Electrical Surveys ............................................................................................... 19

3.1 Horizontal Conductivity Profiling - EM31 ……….............................................. 21

3.2 Horizontal Conductivity Profiling - EM34 ………............................................... 25

3.3 Horizontal Resistivity Profiling - Octapod ............................................................... 25

3.4 Vertical Resistivity Sounding ……………............................................................. 27

4 Ground Penetrating Radar Surveys ...................................................................................... 30

4.1 Monostatic Ground Penetrating Radar ..................................................................... 30

4.2 Bistatic Ground Penetrating Radar ................................................................... 33

5 High-Resolution Seismic Surveys ............................................................................. 38

5.1 Seismic Refraction Profiling ................................................................................ 38

5.2 Seismic Reflection Profiling ………………….............................................. 43

5.2.1 Shallow Reflection Analysis .................................................................. 44

5.2.2 Deep Reflection Analysis................................................................... 44

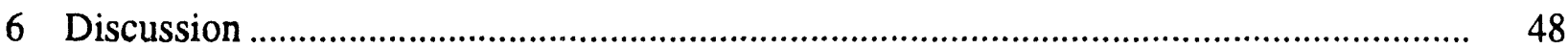

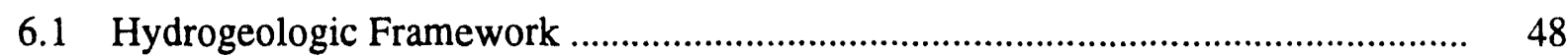

6.2 Possible Point Sources of Contaminants................................................................ 48

6.3 Possible Contaminant Plume ........................................................................... 50

7 Summary and Conclusions .................................................................................... 52

8 References ......................................................................................................... 53

Appendix A: Resistivity Depth Sounding Curves ……...................................................... 57

Appendix B: Ground Penetrating Radar Profile Line Coordinates........................................ $\quad 79$

Appendix C: Seismic Reflection Profiles ........................................................................ 85

Appendix D: Area Magnetic Maps ............................................................................... 95 


\section{Tables}

1 Activities, Time-Frame, and Effort ............................................................................ 3

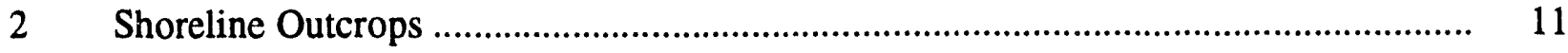

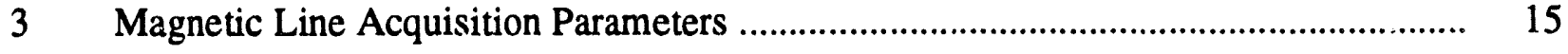

$4 \quad$ Magnetic Anomalies with Nonsurface Source …..................................................... 17

$5 \quad$ EM31 Line Acquisition Parameters............................................................................... 23

$6 \quad$ Vertical Electrical Soundings at Beach Point .................................................................. 28

$7 \quad$ Refraction Profiles at Beach Point ............................................................................ 39

$8 \quad$ Reflection Profiles at Beach Point ............................................................................... 43

Figures

1 Beach Point Location Map in the Canal Creek Area,

Aberdeen Proving Ground

2 Topography, Roads, and Major Buildings at Beach Point and Land

Areas West of Beach Point.

3 Location of Geophysical Survey Area for the Southern Portion of Beach Point.

4 Location of Geophysical Survey Area for the Central Portion of Beach Point.

5 Location of Geophysical Survey Area for the Northern Portion of Beach Point.

6 Hydrogeologic Cross Section beneath the Canal Creek Area, Aberdeen Proving Ground

$7 \quad$ Lithology from Well Data in the Canal Creek Area ..................................................... 10

8 Beach Point Stratigraphy of the Upper 12 Feet from Outcrop Mapping....................... 12

9 Beach Point Base Line Resistivity Profiles from ABEM/Octapod Resistivity and EM31 Data

10 Beach Point EM31 Anomalies................................................................................. 22

11 Beach Point EM34 Anomalies with 20-Meter Coil Spacings ..................................... 24 


\section{Figures (Cont.)}

12 Overlay Map of EM31 and EM34 Data Showing the Shift of Anomaly

Minima to the East with Increasing Depth

13 Regional Resistivity Map Constructed from Horizontal Resistivity Data

Collected with the Octapod .............................................................................. 26

14 Resistivity Cross Section beneath the Beach Point Base Line ................................. 29

15 GPR Profile over a Dune-Shaped Reflector Containing Strong

Internal Reflectors

16 GPR Profile over a Possible Buried Pit or Trench ................................................

17 GPR Anomaly Produced by a Buried Tank East of the Concrete Slab ...................... 33

18 GPR Profile at the North End of the Base Line .....................................................

19 GPR Profile between 250S and 600S along the Base Line ..................................... 34

20 GPR Profile between 600S and 800S along the Base Line ................................... 36

21 GPR Profile between 800S and 1050S along the Base Line ................................... 36

22 Relationship between EM31 Anomalies and GPR Reflectors ................................. 37

23 Location of Seismic Survey Lines at Beach Point................................................ 39

24 Seismic Refraction Interpretation along the Access Road to Beach Point .................. 40

25 Seismic Refraction Interpretation along the Beach Point Base Line .......................... 41

26 Facies below Beach Point Peninsula on the Basis of Seismic Data .......................... 42

27 Configuration of the Pleistocene-Age Unconformity Developed on

Cretaceous Coastal Pla in Sediments on the Basis of High-Resolution

Seismic Reflection Data

28 Facies below Beach Point Road on the Basis of Seismic Data ................................. 46

29 Magnetic Map of Beach Point with Conductivity Overlay ...................................... 49

30 Conductivity Map of Beach Point with Magnetic Overlay ...................................... 49

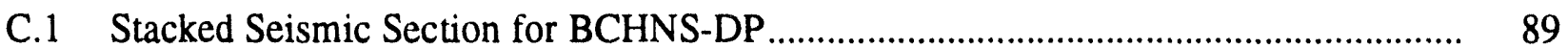

C.2 Stacked Seismic Section for BCHEW-DP ....................................................... 90

C.3 Stacked Seismic Section for BCHEW-SH ......................................................... 90

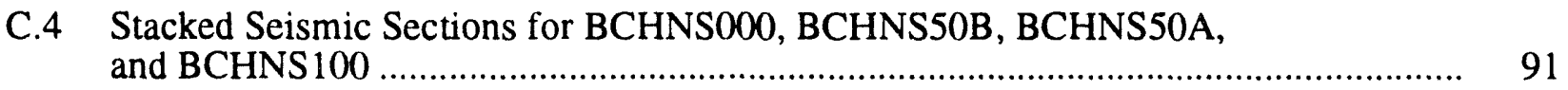




\section{Figures (Cont.)}

C.5 Stacked Seismic Sections for BCHEW450, BCHEW650, and BCHEW 1000 ............ 92

C.6 Stacked Seismic Section for BCHXWELL ...................................................... 93

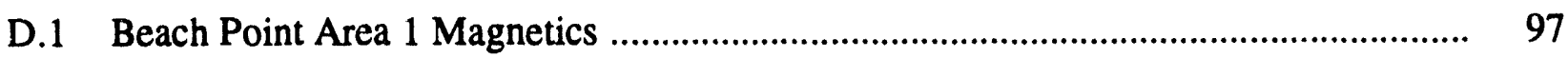

D.2 Beach Point Fine Grid: Southeast ..................................................................... 99

D.3 Beach Point Area 2 Magnetics ................................................................ 101

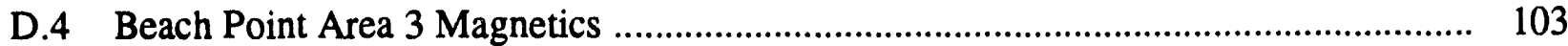

D.5 Beach Point Fine Grid: Northwest ............................................................... 105

D.6 Beach Point Area 4 Magnetics ................................................................. 107

D.7 Beach Point Area 5 Magnetics ................................................................... 109

D.8 Beach Point Area 6 Magnetics .................................................................. 111

D.9 Beach Point Area 7 Magnetics ................................................................... 113

D.10 Beach Point Area 8 Magnetics ..................................................................... 115

D.11 Beach Point Area 9 Magnetics ................................................................. 117 


\title{
Environmental Geophysics at Beach Point, Aberdeen Proving Ground, Maryland
}

\author{
by \\ L.D. McGinnis, C.R. Daudt, M.D. Thompson, \\ S.F. Miller, W.A. Mandell, and J. Wrobel
}

\begin{abstract}
Geophysical studies at Beach Point Peninsula, in the Edgewood area of Aberdeen Proving Ground, Maryland, provide diagnostic signatures of the hydrogeologic framework and possible contaminant pathways. These studies permit construction of the most reasonable scenario linking dense, nonaqueousphase liquid contaminants introduced at the surface with their pathway through the surficial aquifer. Subsurface geology and contaminant presence were identified by drilling, outcrop mapping, and groundwater sampling and analyses. Suspected sources of near-surface contaminants were defined by magnetic and conductivity measurements. Negative conductivity anomalies may be associated with unlined trenches. Positive magnetic and conductivity anomalies outline suspected tanks and pipes. The anomalies of greatest concern are those spatially associated with a concrete slab that formerly supported a mobile clothing impregnating plant. Resistivity and conductivity profiling and depth soundings were used to identify an electrical anomaly extending through the surficial aquifer to the basal Pleistocene unconformity, which was mapped by using seismic reflection methods. The anomaly may be representative of a contaminant plume connected to surficial sources.
\end{abstract}

\section{Introduction}

An environmental geophysical study was conducted at Beach Point, Aberdeen Proving Ground (APG), Edgewood Area (Figure 1), during early summer 1993 in order to define the hydrogeologic framework; to determine the location of near-surface, point-source contaminants; and to determine contaminant pathways. Most of the geophysical surveys were done on Beach Point Peninsula, although seismic reflection and refraction profiles were obtained to the west of the peninsula on Beach Point Road. Activities, time-frame, and effort are detailed in Table 1.

Geophysical activities were spurred by the use history of Beach Point (see Table 7 ID no. 25, Lorah and Clark, in preparation; and Jacobs Engineering Group, Inc., 1992). Major activities in the area included liquid rocket fuel tests, rocket fuel fire suppression tests, pyrotechnic material and smoke generator tests, and the use of solvents at a mobile clothing 


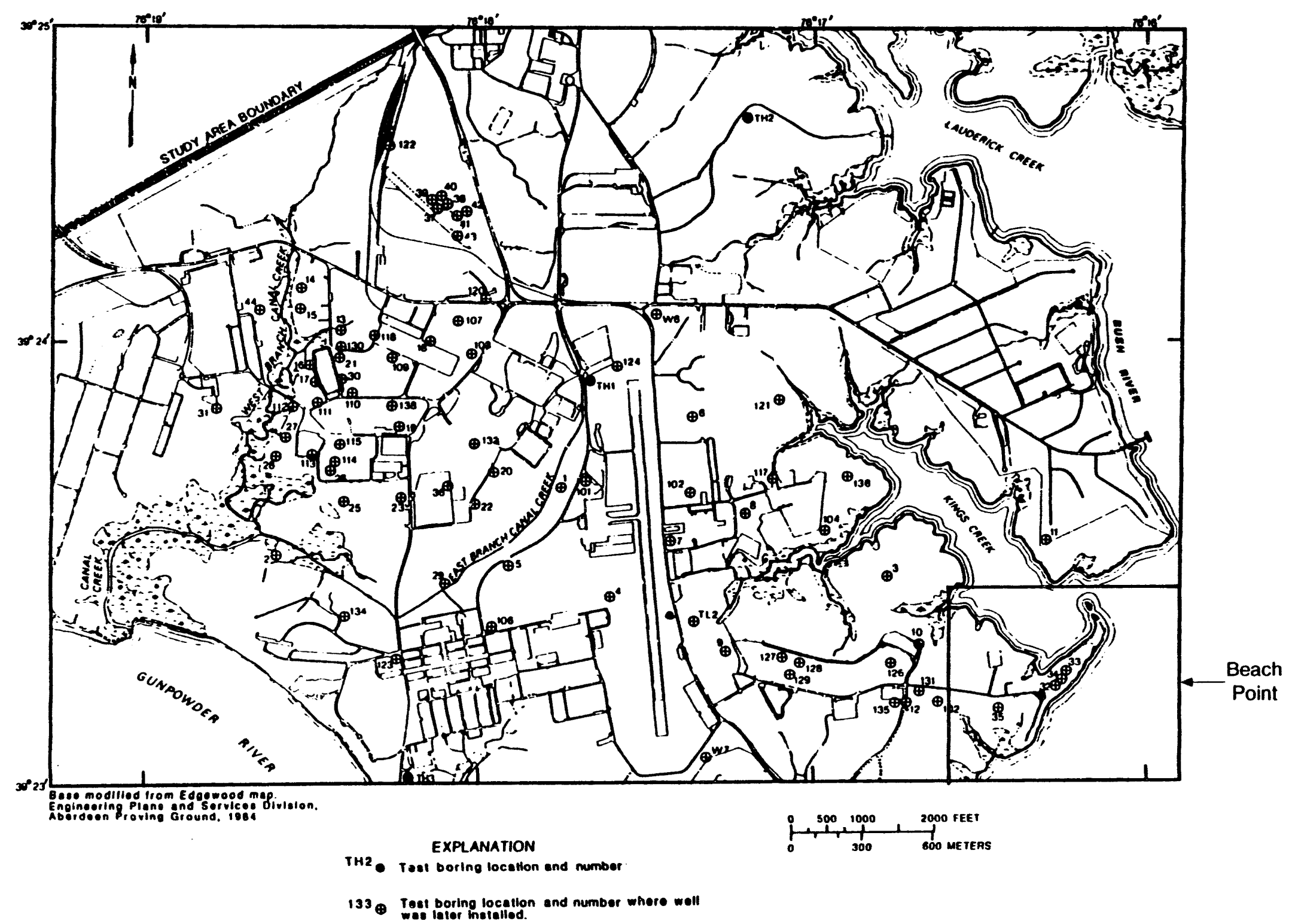

FIGURE 1 Beach Point Location Map in the Canal Creek Area, Aberdeen Proving Ground (Source: Oliveros and Vroblesky 1989) 
TABLE 1 Activities, Time-Frame, and Effort

\begin{tabular}{lll}
\hline \multicolumn{1}{c}{ Activity } & Submitted/Time Window & Comment \\
\hline Geophysics Work Plan & October 1992 & $\begin{array}{c}\text { Includes seismic reflection, } \\
\text { refraction, resistivity } \\
\text { profiling, vertical electrical } \\
\text { sounding, electromagnetic } \\
\text { profiling, magnetics, and } \\
\text { ground penetrating radar. }\end{array}$ \\
$\begin{array}{l}\text { Health and Safety Plan } \\
\text { Mobilization }\end{array}$ & $\begin{array}{l}\text { March 1993 } \\
\text { Transport } \\
\text { Site effort }\end{array}$ & $\begin{array}{l}\text { May 6-12,1993 13-14, 1993 } \\
\text { May 15-16,1993 }\end{array}$ \\
\hline
\end{tabular}

impregnating plant. Some of the wastes were discharged into unlined pits or directly onto the ground surface and either ran off into surface water or percolated into the subsurface. Buildings located at the test site were used for small-scale chemical agent storage (G agents), laboratories, storehouses, offices, and machine shops. Several of these structures were built with sewer systems that discharged directly to Kings Creek and Bush River. A few of the buildings were constructed with septic systems, which allowed septic system effluent to percolate into the subsurface (Lorah and Clark, in preparation).

An original objective of the study was to determine the local hydrogeologic framework down to the crystalline basement beneath Beach Point. Following initiation of the field study, a decision was made, with the concurrence of personnel of the Directorate of Safety, Health, and Environment (DSHE) and Jacobs Engineering Group, Inc., to expand the Geophysics Work Plan to include a search for possible buried tanks, pipes, and trenches.

\subsection{Physiographic Setting and Site Survey}

Beach Point Peninsula lies within the Atlantic Coastal Plain physiographic province of Maryland. The long axis of the peninsula (Figure 2), oriented approximately $45^{\circ}$ east of north, measures $1,200 \mathrm{ft}$. The peninsula is a remnant of subareal erosion that occurred during a low sea level stand followed by sea level rise and estuarine encroachment into Kings Creek, which is a tributary of Bush River. Bush River is one of the major tidal estuarine channels on the western shore: of Chesapeake Bay. Elevations range from $25 \mathrm{ft}$ above sea level in the western approaches to the site, to sea level at the shoreline. Average elevation of the site is approximately $10 \mathrm{ft}$ above mean sea level (Figure 2). 


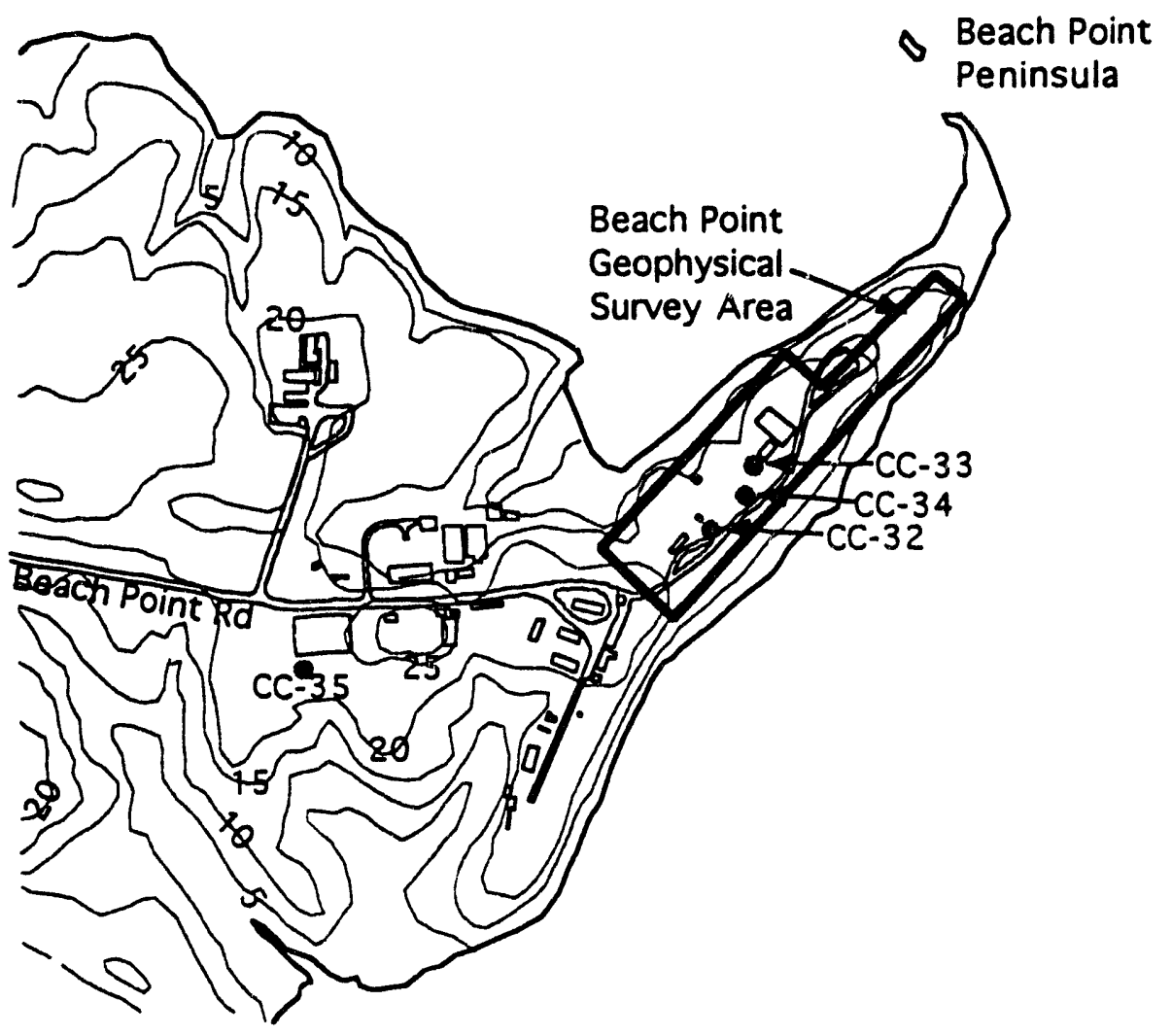

Explanation
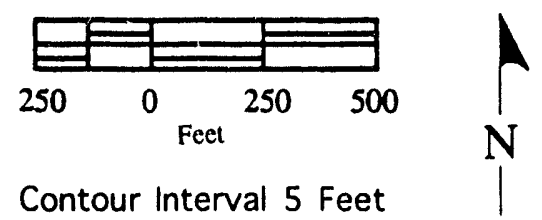

FIGURE 2 Topography, Roads, and Major Buildings at Beach Point and Land Areas West of Beach Point

The area surveyed covers approximately $70 \%$ of Beach Point Peninsula, measuring approximately $1,250 \mathrm{ft}$ along the axis of the peninsula with a maximum width of $250 \mathrm{ft}$. The geophysical survey coordinate $00 \mathrm{~N}-00 \mathrm{~W}$ is located $150 \mathrm{ft}$ south of the northern tip of the peninsula. Figures 3, 4, and 5 show details of the southern, central, and northern sections of the survey area. A 1,050-ft-long north-south geophysical Base Line, extending from $00 \mathrm{~N}-00 \mathrm{~W}$ to $1050 \mathrm{~S}-00 \mathrm{~W}$, was used repeatedly for instrument calibration and to compare results of the various instruments. Reference to the Base Line will occur repeatedly throughout the report.

A 50-ft grid of wooden survey stakes was used to guide the geophysical surveys. The grid was laid out using 300-ft surveyor's tapes and a Brunton compass. Two benchmarks (B) on the peninsula, located at geophysical survey coordinates $250 \mathrm{~S}-0 \mathrm{~W}$ and $983 \mathrm{~S}-0 \mathrm{~W}$, provide location control. (Figures 3 and 5 show the locations of benchmarks.) 


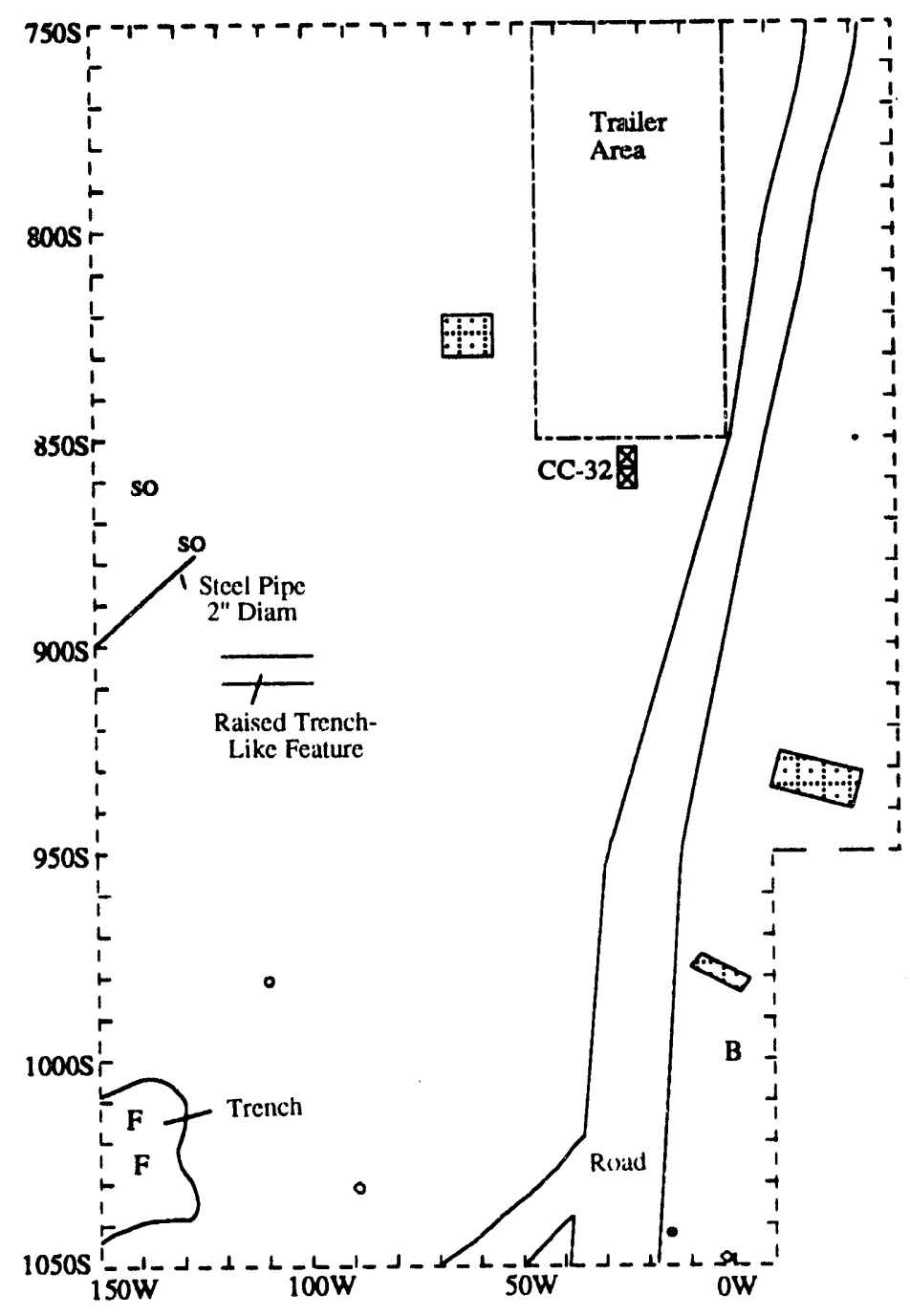

\section{Explanation}

$\begin{array}{clclll}--1 & \text { Geophysical } & \text { B } & \text { Benchmark } & \bigcirc & \text { Rebar } \\ - & \text { Survey Area } & \text { SO } & \text { Steel Object } & \bigcirc & \text { Metal Canister } \\ \square & \text { Test Wells } & \text { F } & \text { Stcel Flag } & & \text { Steel Pole }\end{array}$

FIGURE 3 Location of Geophysical Survey Area for the Southern Portion of Beach Point 


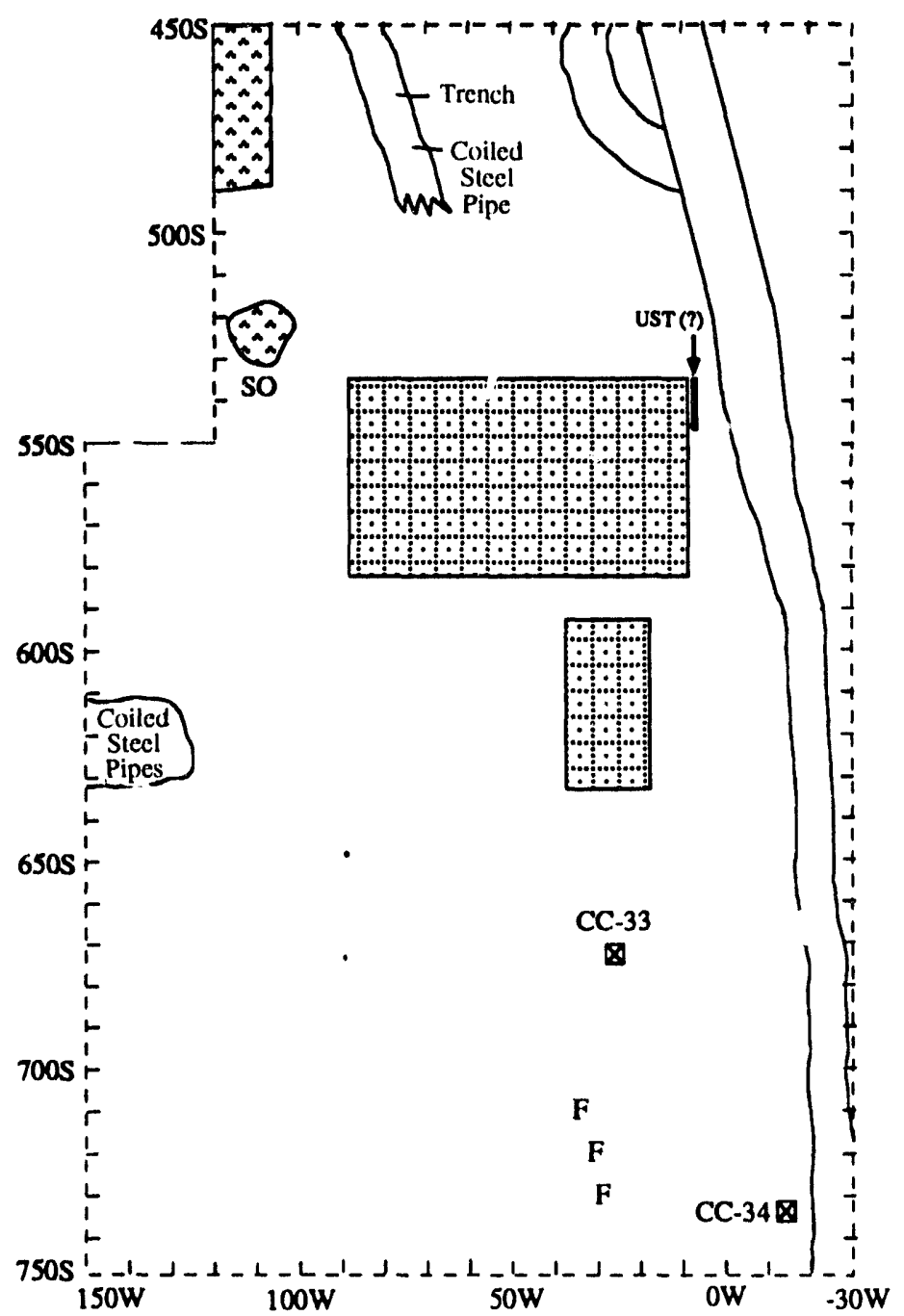

\section{Explanation}

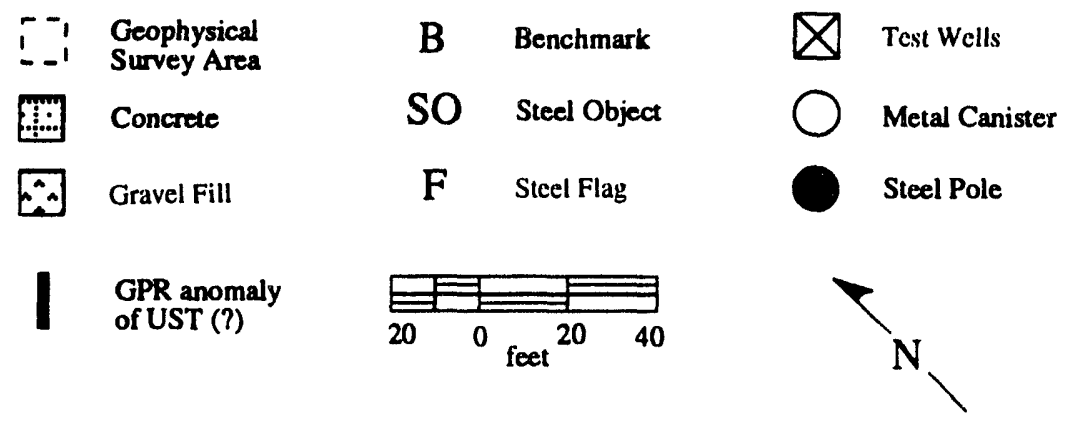

FIGURE 4 Location of Geophysical Survey Area for the Central Portion of Beach Point 


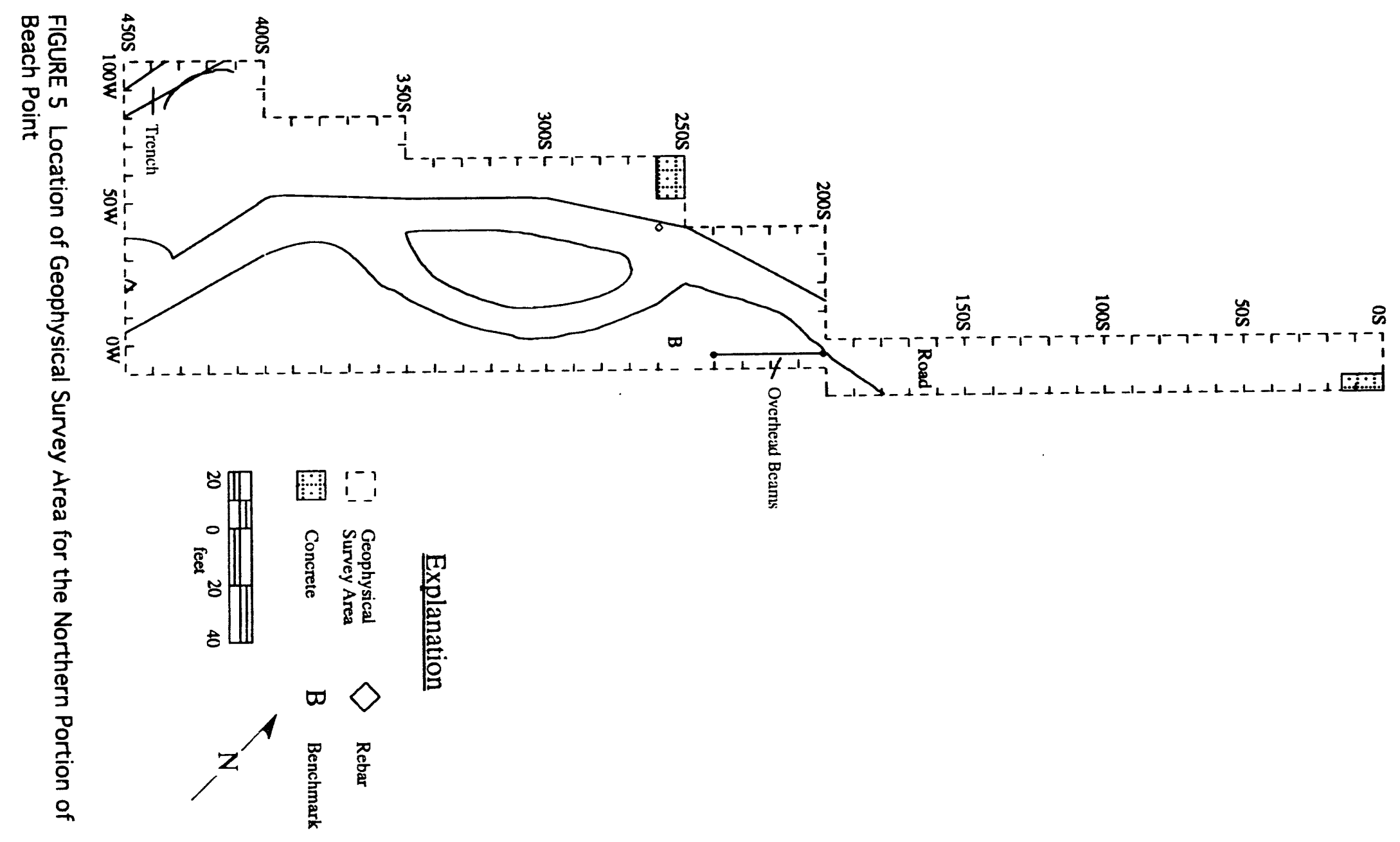




\subsection{Site Geology and Hydrogeology}

A late Precambrian crystalline basement platform, lying approximately $560 \mathrm{ft}$ beneath the northeast tip of Beach Point Peninsula, is composed of rocks similar to those found at the surface in the Piedmont Province northwest of the Fall Line (Oliveros and roblesky 1989). The crystalline basement surface dips to the southeast at an angle of less than one degree (Bennett and Meyer 1952; Dingmen et al. 1956; Southwick and Owens 1969). East of the Fall Line, including all of the area in this report, unconsolidated Atlantic Coastal Plain sediments overlie Piedmont basement rocks.

Atlantic Coastal Plain sediments beneath the Edgewood area of APG were deposited during the Creiaceous Period and the Pleistocene Epoch (Oliveros and Vroblesky 1989). Most of the unconsolidated sediments comprise the Potomac Group, deposited during the Cretaceous Period. Although sediments of the Potomac Group have been further subdivided into formations near Baltimore City, they have not been differentiated beneath APG, where they are referred to collectively as the Potomac Group (Oliveros and Vroblesky 1989).

Sediments that overlie the Potomac Group consist primarily of the Talbot Formation of Pleistocene age with minor amounts of Quaternary alluvium. The Talbot Formation is relatively thin and horizontally discontinuous in the western areas of Edgewood, but it thickens to the east to approximately $60 \mathrm{ft}$ in the area of Aberdeen Proving Ground (Oliveros and Vroblesky 1989). Beneath the Edgewood area, the Talbot Formation is thickest where it occurs as fill in a paleochannel that is cut to a depth of at least $50 \mathrm{ft}$ into the Potomac Group sediments.

A generalized hydrogeologic section beneath the Canal Creek area, taken from Lorah and Vroblesky (1989), is shown in Figure 6. Lorah and Vroblesky (1989) describe the section as follows: "Hydrogeologic units were defined partly on the basis of hydrologic characteristics of the units; therefore, the boundaries between the hydrogeologic units do not necessarily correspond with contacts between geologic units. The surficial aquifer sediments are primarily composed of the Talbot Formation but are a composite of both the Taltot Formation and Potomac Group in some areas. The upper confining unit, the Canal Creek aquifer, the lower confining unit, and the lower confined aquifer are composed of Potomac Group sediments."

Lithologies and gamma logs in three wells on Beach Point Peninsula (and others pertinent to this study) are shown on Figure 7, with locations shown on Figures 1 through 4. Lithologies consist of alternating silty sand and clay layers with interbeds of coarse-grained, sandy gravels, indicative of a fluvial environment. Using our seismic reflection and refraction data, we interpret sediments down to a clay aquitard, at depths ranging from 40-67 ft, as the surficial aquifer of Lorah and Vroblesky (1989).

An angular unconformity of Pleistocene age is developed on the clay aquitard, which is a member of the Potomac Group sediments. The unconformity, referred to here as the P-K 


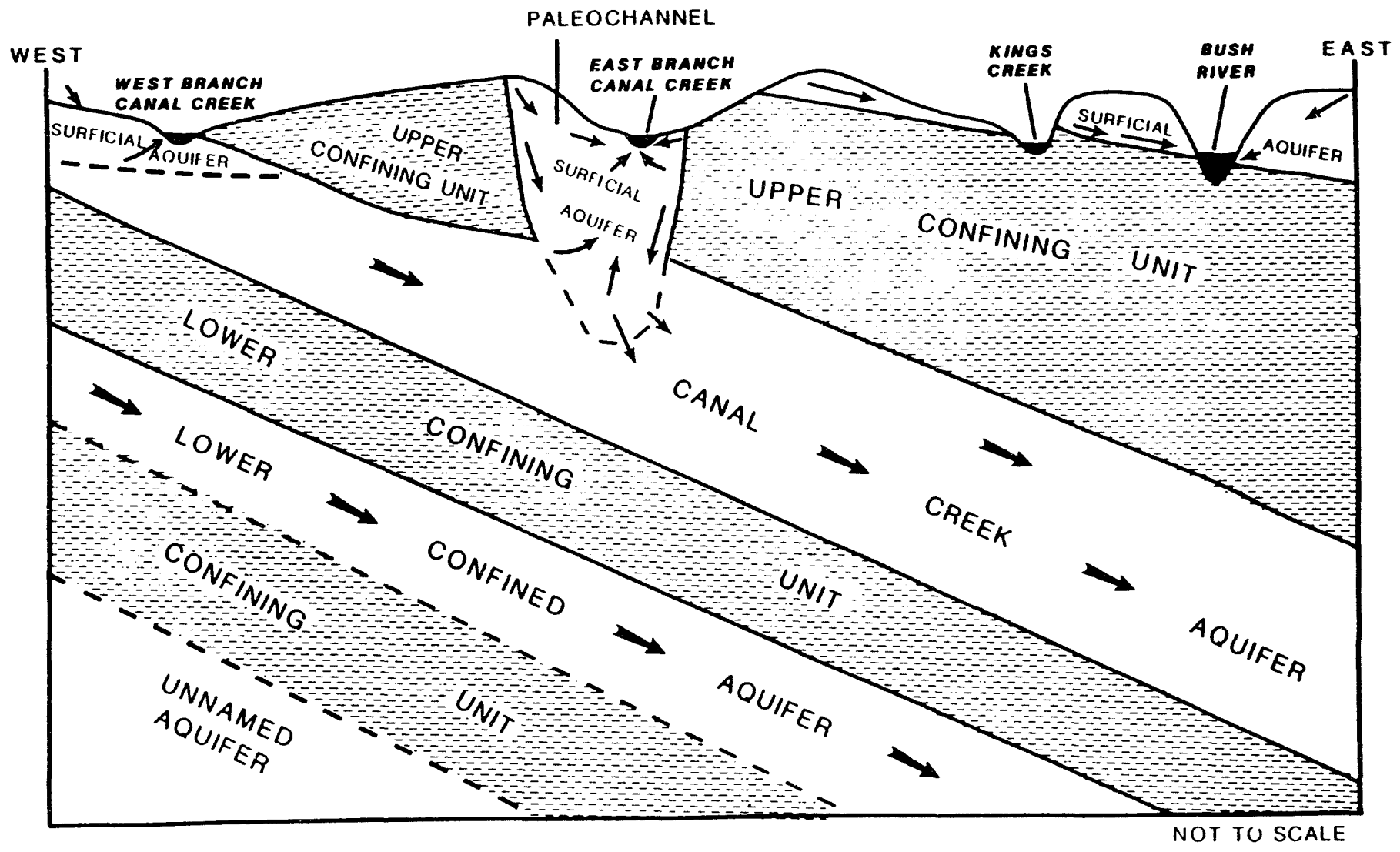

EXPLANATION

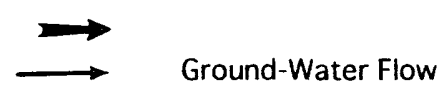

FIGURE 6 Hydrogeologic Cross Section beneath the Canal Creek Area, Aberdeen Proving Ground (Source: Lorah and Vroblesky 1989) 

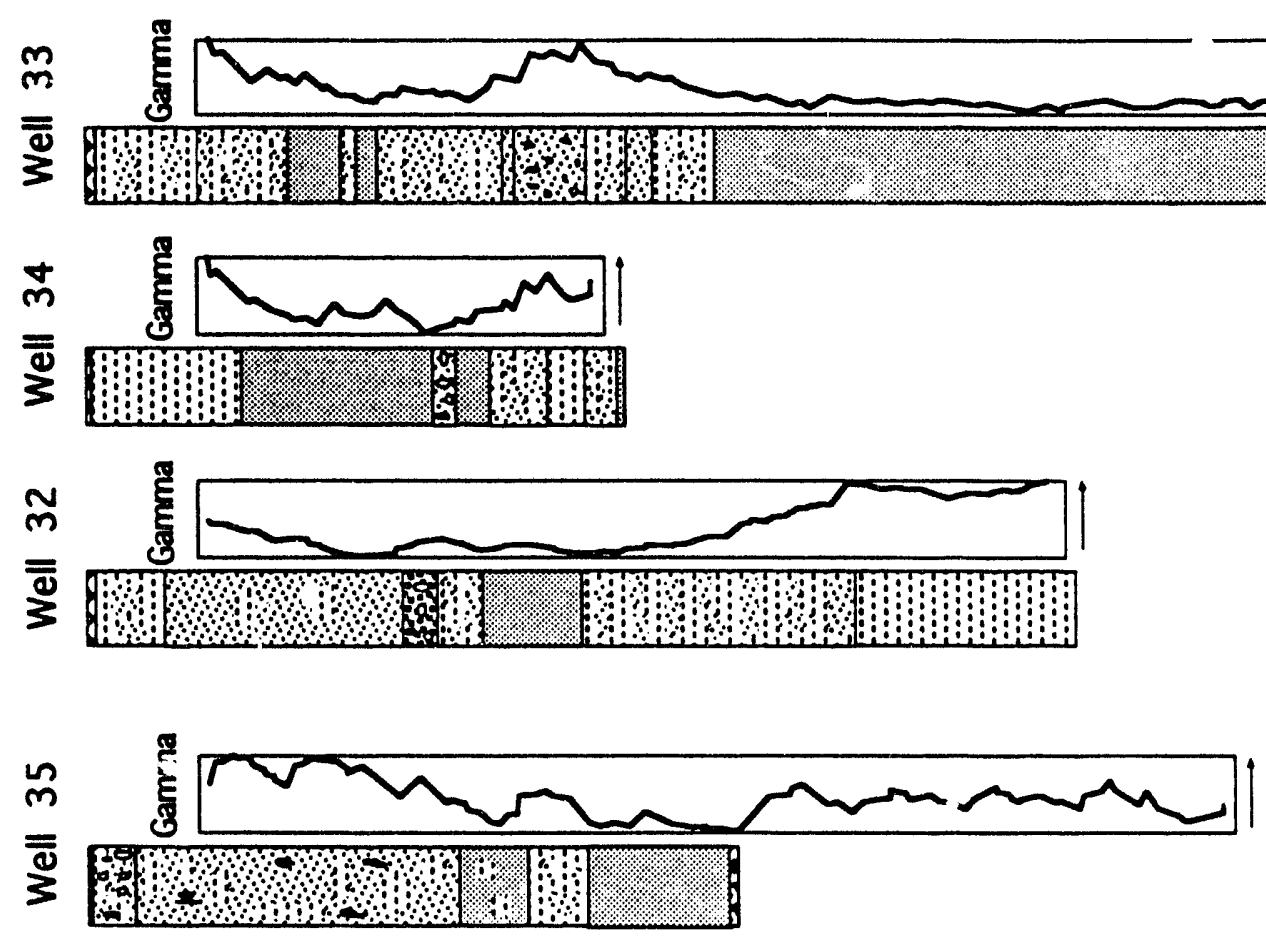

Depth ( $\mathrm{ft}$ )
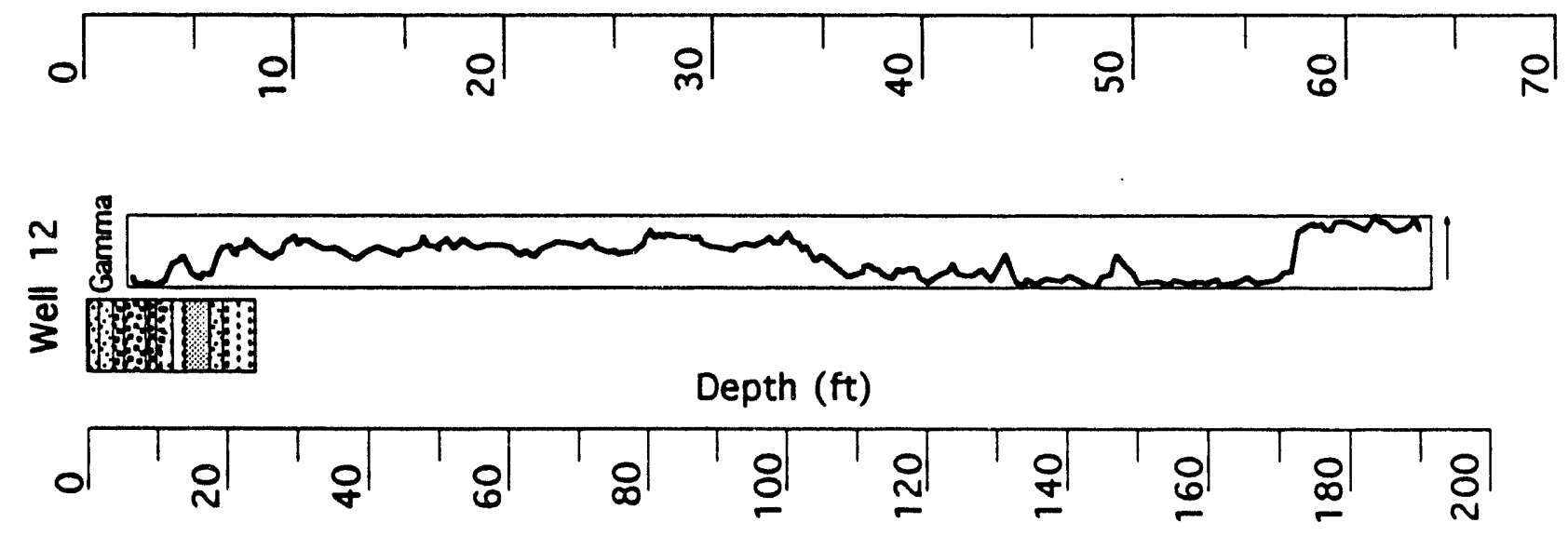

\section{Legend}

$\square$ Gamma Log
Sands Well Sorted Sands
Clays or Silts

FIGURE 7 Lithology from Well Data in the Canal Creek Area (Source: Oliveros and Gernhardt 1989) 
unconformity, will be discussed further in Subsection 5.2.1, Shallow Reflection Analysis. In discussions to follow, the terms "base of the Pleistocene," "P-K unconformity," "base of the surficial aquifer," and "top of the Potomac Group" all refer to the contact at the sand/clay base of the thick sands near the bottom of well CC-33.

From observations at Beach Point and from studies elsewhere in the Canal Creek area, it is evident that a well-integrated tributary system of Pleistocene age was deeply incised into Potomac Group sediments as a result of successive episodes of sea level lowering of $300 \mathrm{ft}$ or more. The tributary system provides the framework for shallow groundwater flow and for potential recharge into Potomac Group aquifers. Mapping the configuration of this system is one of the objectives of geophysical studies at Beach Point.

\subsection{Outcrops}

The peninsula surface slopes gently toward the shoreline bordering the mouth of Kings Creek on the northwest and Bush River on the southeast. Outcrops occur only on the shoreline at the locations indicated in Table 2. Outcrop lengths, generally measuring $12 \mathrm{ft}$ or less, were cleaned of debris, and a cross section was drawn showing the dominant facies (Figure 8).

TABLE 2 Shoreline Outcrops

\begin{tabular}{ccc}
\hline Location & $\begin{array}{c}\text { Length of } \\
\text { Exposed Outcrop } \\
(\mathrm{ft})\end{array}$ & \multicolumn{1}{c}{ Lithologies Present } \\
\hline East Side & & \\
$1750 \mathrm{~S}$ & 12 & Sand, gray-brown clay \\
$1700 \mathrm{~S}$ & 15 & Sand, gray-brown clay \\
$1425 \mathrm{~S}$ & 12 & Sand, gray-brown clay \\
$1225 \mathrm{~S}$ & 12 & Gray-brown clay only \\
$550 \mathrm{~S}$ & 10 & Sand, gray-brown clay \\
$475 \mathrm{~S}$ & 10 & Sand, gray-brown clay \\
$200 \mathrm{~S}$ & 4 & Gray-brown clay only \\
& & \\
West Side & & Sand, gray-brown clay, clayey sand \\
$600 \mathrm{~S}$ & 6 & Sand, gray-brown clay \\
$525 \mathrm{~S}$ & 8 & Sand, gray-brown clay \\
$400 \mathrm{~S}$ & 7 & \\
\hline
\end{tabular}




\section{West Beach}

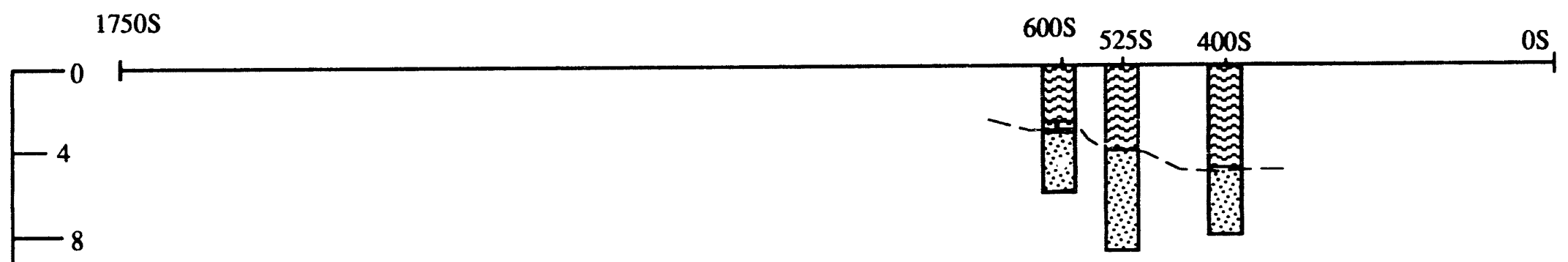

\section{East Beach}

feet

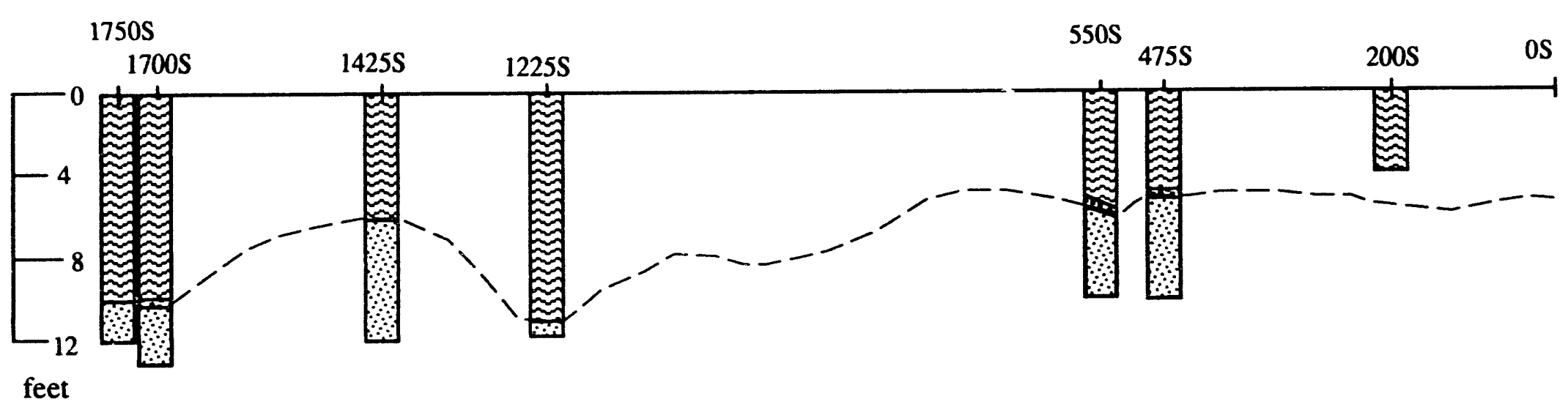

\section{Explanation}

$\begin{array}{ll}\text { Gray-Brown Clay } & -1 \text { Inferred Contact } \\ \text { Uncemented Sand Pebbles and Boulders }\end{array}$

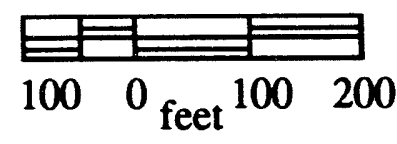

FIGURE 8 Beach Point Stratigraphy of the Upper 12 Feet from Outcrop Mapping 
Outcrops are represented by alternating sands, sandy gravels, clays, and clayey-sands. Thin lenses of well-rounded, boulder-sized igneous rocks, at a sand/clay contact, were also found in outcrops. The coarse clastic sediments suggest an overbank deposit in a fluvial environment of high energy. The upper clay is very dense, hard, and nonorganic. The lower sand is a wellrounded, well-sorted, uncemented, quartz-arenite with clay lenses varying in size. Only one area had no well-defined boundary between the sand and clay, which otherwise was clearly identified.

\subsection{Instrumentation and Software}

The Schonstedt MAC-51B magnetic gradiometer and cable locator is a dual-mode instrument designed for use in detection of shallow buried iron and steel objects and for tracing underground cables and pipes. The system consists of a transmitter and a dual-function receiver designed to detect anomalous magnetic gradients.

Magnetic data were acquired with an EG\&G Geometrics G-822L cesium vapor magnetometer. The magnetometer is a continuously recording, total field, microprocessor-based instrument capable of resolution of anomalies to one nanotesla $(1 \mathrm{nT})$.

Electrical conductivity measurements were made with the Geonics EM31 and EM34 electromagnetic instruments, which provide mean values of condurtivity, in millisiemens per meter $(\mathrm{mS} / \mathrm{m})$, of soils ranging from 0 to approximately $100 \mathrm{ft}$ in depth. Apparent conductivities are averaged over the depth range.

Horizontal electrical resistivity profiling data were acquired with an ABEM Terrameter and Booster interfaced with a modified Wenner electrode array positioned on a rigid frame and towed behind an all-terrain vehicle. The array was designed by Argonne National Laboratory (ANL) staff and is referred to as the Octapod. Data acquired with the Octapod provide mean resistivities in the upper six feet. These data are unaffected by spurious atmospheric electrical noise or by close proximity to metallic buildings. For this reason, resistivity data can be used for quality control of electrical measurements. Wenner a-spacing (electrode separation) was held at a constant two meters.

Electrical depth soundings were also made with the ABEM Terrameter. A Bison BOSS electrode array, an "offset" Wenner technique (Barker 1981), was used in the soundings to enhance data quality. Electrode separations ranged from 0.5 to $64 \mathrm{~m}$ for a maximum current electrode separation of $192 \mathrm{~m}$. All cable arrays for depth soundings were oriented parallel with the long axis of the peninsula. RESIXP software developed by Interpex was used in processing sounding data.

Ground penetrating radar (GPR) surveying was accomplished using a Geophysical Survey Systems, Inc. (GSSI), model SIR-3 unit, with a model 38 video display, connected to either variable-frequency transceivers or to a bistatic antenna system. Data were recorded on a 
digital audio tape through the model 38 system, which was downloaded to a personal computer. The control unit/video display was located in the transport vehicle. An IBM-compatible processing computer was located in a field office, so that radar profiles could be downloaded, data-tape quality checked, and preliminary data processing performed on the profiles Radan III computer software written by GSSI was used for processing the GPR data.

A 24-channel reflection/refraction seismograph (EG\&G ES-2401), with geophone cables of 2,5 , and $10 \mathrm{~m}$ geophone spacings, and various sound sources were used to determine depths and velocities beneath Beach Point. Geophones naving natural frequencies of $12 \mathrm{~Hz}$ were used for refraction profiles. Sound sources consisted of both a 16-lb sledgehammer and a trailermounted Bison elastic-wave generator (EWG). On-site analyses and quality control of the seismic data were conducted using SIPT refraction programs developed by Rimrock Software.

Common depth point (CDP) seismic reflection techniques were used to image the sedimentary units and crystalline basement underlying Beach Point Peninsula and to map the configuration of the Pleistocene P-K unconformity at the base of the surficial aquifer. The CDP method uses one shotpoint per receiver array. The entire array and shotpoint are moved with the use of a roll-along-switch after each shot. To calculate depths to reflectors, two-way times (TWTs) are converted to depths by using interval velocities determined from refraction profiling and from static corrections.

Eavesdropper reflection software produced by Interactive Concepts, Inc., was used for reflection data processing. On-site processing consisted of (1) trace-editing, (2) CDP sorting, and (3) velocity analysis. Trace-editing removes unwanted information, such as the air wave, and bad traces. CDP sorting groups the seismic data into blocks of information and assembles the resultant depths into a common horizontal location. Velocity analysis examines the velocities required to correct the seismic data for spatial distortions and gives a preliminary velocity-depth function for final corrections applied to the data.

Final processing steps include (1) editing to remove refracted first arrivals, surface waves, and air waves; (2) bandpass filtering; (3) CDP sorting; (4) velocity analysis; (5) normal-moveout (NMO) corrections; and (6) CDP stacking. Both refraction and reflection software packages are designed for use on an IBM-compatible personal computer.

The Bison EWG was used as the energy source to image deep reflectors, and the $16-1 \mathrm{~b}$ hammer was the source for shallow reflectors. Geophones having natural frequencies of $40 \mathrm{~Hz}$ were used for the reflection profiles. 


\section{Magnetic Surveys}

\subsection{Magnetic Gradiometer Scan}

The Schonstedt Gradiometer was used (1) to avoid shallow magnetic debris during emplacement of geophones or stakes and (2) at impact locations for seismic studies. The instrument does not record data or give a quantifiable reading, but simply emits a tone that represents differences in the magnetic field strength as measured by two sensors in the wand end of the instrument. The area was swept with the wand and anomalous locations were marked with spray paint. The gradiometer sweep was also used to indicate areas that required detailed coverage with the more quantitative geophysical equipment.

\subsection{Continuous Profiling Magnetometry}

Beach Point was divided into nine areas to facilitate processing and to permit a better view of isolated anomalies. Figures D.1 through D.11, Appendix D, show the area magnetic maps for the nine areas. Magnetic line acquisition parameters for the nine areas are described in Table 3. Data were acquired at a rate of 10 readings per second at a walking pace, resulting in less than $1 \mathrm{ft}$ spacing along traverses spaced $10 \mathrm{ft}$ apart. Two areas having anomalies that required more detailed scans were surveyed with profiles spaced $5 \mathrm{ft}$ apart; these are shown in Figures D.2 and D.5. The magnetic maps are used to identify ferrous metal objects, including pipes, drums, and buried tanks, which might be associated with point sources of contaminants.

TABLE 3 Magnetic Line Acquisition Parameters

\begin{tabular}{|c|c|c|c|c|}
\hline Area & $\begin{array}{c}\text { No. of } \\
\text { Stations }\end{array}$ & $\begin{array}{c}\text { No. of } \\
\text { Survey Lines }\end{array}$ & $\begin{array}{l}\text { Line } \\
\text { Length } \\
(\mathrm{ft})\end{array}$ & $\begin{array}{l}\text { Total Line } \\
\text { Footage }(\mathrm{ft})\end{array}$ \\
\hline 1 & 5,100 & 17 & 100 & 1,700 \\
\hline 2 & 12,000 & 20 & 200 & 4,000 \\
\hline 3 & 11,340 & 21 & 180 & 3,780 \\
\hline 4 & 5,280 & 11 & 160 & 1,760 \\
\hline 5 & 1,980 & 6 & 110 & 660 \\
\hline 6 & 1,620 & 6 & 90 & 540 \\
\hline 7 & 2,475 & 11 & 75 & 825 \\
\hline 8 & 1,080 & 6 & 60 & 360 \\
\hline 9 & 1,260 & 21 & 20 & 420 \\
\hline Totals & 42,135 & 119 & & 14,045 \\
\hline
\end{tabular}


Errors introduced into the magnetic data due to uncorrected diurnal variations, errors in location, or insufficient response speed to a changing signal are small in comparison with anomaly amplitudes. Therefore, the anomalies displayed on the magnetic maps are qualitatively significant. Some error, however, is introduced through inadvertent changes in instrument position or attitude relative to the ground surface. Moving around surface obstacles, changes in walking pace, or failure to trigger fiducial markers at the proper locition will also produce some positioning error. Marks were placed on , he data at 50-ft intervals and at the beginnings and ends of survey lines. Careful control of acc uisition and processing procedures kept errors to a minimum.

Magnetic anomalies can, in many cases, be explained by surface or near-surface ferrous objects; however, others remain unexplained. Anomalies are observed throughout the Edgewood area where iron-rich amphibolite was used as road fill. Twenty-two anomalies of unknown origin are listed in Table 4, with coordinates given at their centers. Anomalies associated with the roadway system on Beach Point, and with other obvious surface debris, are not listed.

The shoreline on the east side of the Beach Point Peninsula consists of concrete rubble and steel rebar, which causes large-amplitude, high-frequency anomalies. The rubble extends from approximately $200 \mathrm{~S}$ to the farthest southern point surveyed. The western half of the area consists of dense woods littered with metal debris that produces many small anomalies. All surficial metal objects in the area were noted as to location, size, and type. Two of eight concrete foundations present on Beach Point Peninsula contain rebar and also produce anomalies.

The eastern third of the site, beginning with survey Area 1 (Figures D.1 and D.2) at the southern end of the peninsula, is dominated by anomalies produced by road fill. Isolated anomalies west of the road are caused by surface debris, unless they are specifically identified in Table 4. An example of an unexplained anomaly is located at $1020 \mathrm{~S}-70 \mathrm{~W}$, although it is located near the road and may be associated with road debris. An area with profiles spaced $5 \mathrm{ft}$ apart was surveyed west of the rnad (Figure D.2) to examine the magnetic detail displayed on the Area 1 map. It is probable that all anomalies within $20 \mathrm{ft}$ of the road edge are associated with fill material.

Area 1 magnetics (Figure D.1). The southeastern two-thirds of the area, including anomalies along lines $70 \mathrm{~W}$ and $80 \mathrm{~W}$, is dominated by anomalies associated with road fill or by construction fill along the southeastern shore of Beach Point. The anomaly in the northwest quarter on line $130 \mathrm{~W}$ is produced by surficial debris. See Figure D. 2 for additional detail.

Area 2 magnetics (Figure D.3). Area 2 contains five unexplained anomalies observed along $\mathrm{N}-\mathrm{S}$ lines $100 \mathrm{~W}$ and $110 \mathrm{~W}$. The anomalies are observed only on one line and have widths ranging from 5 to $20 \mathrm{ft}$. The remainder of the anomalies to the east are associated with the University of Maryland bio-assay trailer, with the access road, or with slope-stability debris on the southeast shoreline. Anomalies in the western half of the area are caused by unknown, buried sources, as listed in Table 4. 
TABLE 4 Magnetic Anomalies with Nonsurface Source

\begin{tabular}{|c|c|c|c|c|}
\hline \multirow[b]{2}{*}{ Area } & \multirow{2}{*}{$\begin{array}{l}\text { Anomaly } \\
\text { No. }\end{array}$} & \multicolumn{2}{|c|}{ Coordinates } & \multirow[b]{2}{*}{ Anomaly Dimensions and Orientation } \\
\hline & & $x$ & Y & \\
\hline 1 & 1 & $70 W$ & $1020 S$ & Source unknown line $70 \mathrm{~W}, 8 \mathrm{ft}$ long \\
\hline \multirow[t]{5}{*}{2} & 2 & $110 \mathrm{~W}$ & $910 S$ & $\begin{array}{l}\text { Mound at surface (buried trench?) } \\
\text { seen only on line } 110 \mathrm{~W}, 12 \mathrm{ft} \text { long }\end{array}$ \\
\hline & 3 & $103 W$ & $867 S$ & $\begin{array}{l}\text { Source unknown line } 100 \mathrm{~W}, 20 \mathrm{ft} \\
\text { long }\end{array}$ \\
\hline & 4 & $110 \mathrm{~W}$ & $817 \mathrm{~S}$ & Source unknown $110 \mathrm{~W}, 15 \mathrm{ft}$ long \\
\hline & 5 & $111 \mathrm{~W}$ & $767 S$ & Source unknown $110 \mathrm{~W}, 10 \mathrm{ft}$ long \\
\hline & 6 & $110 \mathrm{~W}$ & $750 \mathrm{~S}$ & Source unknown $110 \mathrm{~W}, 5 \mathrm{ft}$ long \\
\hline \multirow[t]{10}{*}{3} & 7 & $75 W$ & $560 \mathrm{~S}$ & Possible buried tank next to slab \\
\hline & 8 & $60 \mathrm{~W}$ & $580 \mathrm{~S}$ & Possible buried tank next to slab \\
\hline & 9 & $130 W$ & $622 S$ & Anomalies (130W, 133W, and 145W) \\
\hline & 10 & $133 W$ & $5795\}$ & possibly associated \\
\hline & 11 & $145 \mathrm{~W}$ & $557 \mathrm{~S}$ & with a trench \\
\hline & 12 & $111 \mathrm{~W}$ & $720 S)$ & Series of \\
\hline & 13 & $114 \mathrm{~W}$ & $741 \mathrm{~S}$ & anomalies $(111 \mathrm{~W}, 114 \mathrm{~W}$ \\
\hline & 14 & $127 W$ & 7305 & $127 W, 144 W$, and $150 W$ ) \\
\hline & 15 & $144 W$ & $710 \mathrm{~S}$ & along E-W \\
\hline & 16 & $150 W$ & $690 S^{S}$ & linear trend \\
\hline \multirow[t]{4}{*}{4} & 17 & $130 \mathrm{~W}$ & $468 S$ & Gravel fill at surface on line $470 \mathrm{~S}$ \\
\hline & 18 & $37 W$ & $491 S$ & On two lines, $480 S$ and $490 S$ \\
\hline & 19 & $15 W$ & $530 S$ & Possible buried tank next to slab \\
\hline & 20 & $30 W$ & $530 \mathrm{~S}$ & Possible buried tank next to slab \\
\hline 6 & 21 & $65 W$ & $390 S$ & On line 390s, $5 \mathrm{ft}$ wide \\
\hline 7 & 22 & $18 \mathrm{~W}$ & $330 S$ & Source unknown \\
\hline
\end{tabular}


Area 3 magnetics (Figure D.4). Anomalies on the east are associated with road fill. Area 3 contains two clusters of unexplained anomalies, one in the northwest corner and one along an east-west linear trend between $710 \mathrm{~S}$ and $730 \mathrm{~S}$. Both features may be associated with burial trenches and should receive further examination. The large anomaly complex at $690 \mathrm{~S}-40 \mathrm{~W}$ is located at a surface disturbance. Anomalies in the northwest quarter are caused partially by surface debris. An anomaly centered at $560 \mathrm{~S}-75 \mathrm{~W}$ lies near the edge of a concrete slab and may represent a buried tank associated with a former mobile clothing impregnating plant (Jacobs Engineering Group, Inc. 1992). (The slab area is discussed further in the following paragraph on Area 4). See Figure D.5 for additional detail.

Area 4 magnetics (Figure D.6). Area 4 is surveyed over an area containing a large concrete slab extending from $10 \mathrm{~W}$ to $85 \mathrm{~W}$ and from $580 \mathrm{~S}$ to $525 \mathrm{~S}$. The slab served as the foundation for a mobile clothing impregnating plant (noted in the previous paragraph). The slab does not generate a significant anomaly, which indicates rebar was not used in its construction. Several magnetic anomalies are located peripherally to the slab and may indicate buried tanks, pipes, or trenches. See Figure D.5 for additional detail.

Area 5 magnetics (Figure D.7). All anomalies are associated with the access road fill.

Area 6 magnetics (Figure D.8). Anomalies are caused primarily by road fill. One small anomaly at $390 \mathrm{~S}-65 \mathrm{~W}$ remains unexplained.

Area 7 magnetics (Figure D.9). Anomalies are caused by road fill. The anomaly at $330 \mathrm{~S}-0 \mathrm{~W}$ is of unknown origin.

Area 8 magnetics (Figure D.10). Anomalies are caused by road fill.

Area 9 magnetics (Figure D.11). Anomalies are caused by road fill. 


\section{Electrical Surveys}

Electrical properties of the earth were measured at Beach Point Peninsula with a combination of horizontal profiling and vertical electrical sounding (VES) techniques. Electrical methods are dependent on potential fields induced through noncontact, electromagnetic (EM) induction or by fields induced through grounded electrodes. Data can be converted to either resistivity or conductivity for use in defining both the hydrogeologic framework and pore water chemistry. The chemistry of interstitial water plays the dominant role in electrical variations in the earth, and for this reason electrical methods are particularly suited for tracking contaminants. The characterization of three-dimensional electrical properties, in combination with other geophysical methods, is used to identify locations of point sources and to infer water movement from point sources to aquifers in natural groundwater flow systems.

Three instruments have been used to determine electrical properties at Beach Point Peninsula: two EM systems, the EM31 and EM34; and one resistivity instrument, the ABEM Terrameter. Figure 9 shows a comparison of the electrical response of the EM31 and the ABEM/Octapod in a horizontal profile along the Base Line.

Resistivity data (Figure 9) recorcied with the ABEM/Octapod represent apparent resistivity values averaged over the upper $6 \mathrm{ft}$. Because of the extremely high amplitude of nearsurface resistivity, the anomaly amplitudes were truncated at $100 \Omega \cdot \mathrm{m}$.

Two resistivity curves, calculated from the EM31, are also displayed in Figure 9: one with the EM transmitter-receiver pair oriented longitudinal (parallel) to the direction of the Base Line, and a second with the pair orthogonal (at a right angle) to the Base Line. In both orientations, EM data represent mean values averaged over 0 to $20 \mathrm{ft}$ depth. Conductivities are measured along orthogonal azimutis in order to evaluate the electrical anisotropy of the subsurface, such as might be associated with linear pipes, trenches, or plumes. Conductivities are converted to resistivity using the equation:

$$
\text { resistivity }(\Omega \cdot \mathrm{m})=\frac{1000}{\text { conductivity }}(\mathrm{mS} / \mathrm{m})
$$

Inspection of the three resistivity curves leads to the following observations:

1. The ABEM/Octapod apparent resistivity values are generally much higher than EM resistivities. This indicates that mean resistivities of the upper $6 \mathrm{ft}$ are much higher than mean resistivities of the upper $20 \mathrm{ft}$. In other words, resistivities decrease with depth. 


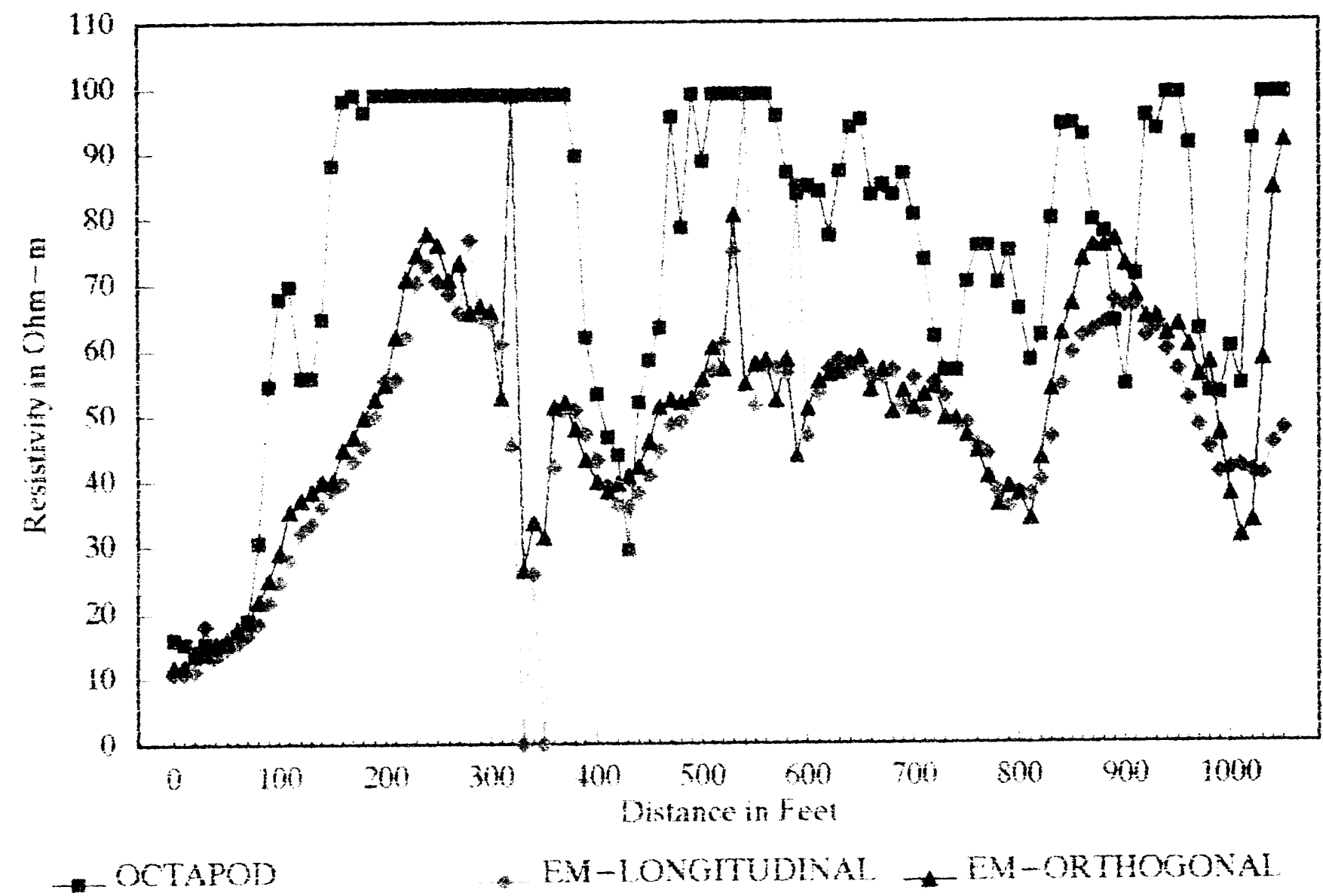

FIGURE 9 Beach Point Base Line Resistivity Profiles from ABEM/Octapod Resistivity and EM31 Data (EM31 data were acquired with the transmitter receiver boom longitudinal [parallel] and orthogonal [at right angles] to the line axis.) 
2. EM resistivities for the longitudinal orientation and the orthogonal orientation are nearly identical, except for minor excursions on the south end of the Base Line (i.e., anisotropy is not a factor in the upper $20 \mathrm{ft}$ ).

3. Resistivities determined with the EM 31 and the ABEM/Octapod are nearly identical in the northern $80 \mathrm{ft}$ of the Base Line (i.e., the low-resistivity buried layer present along the central and southern Base Line rises to the surface in the northern $80 \mathrm{ft}$ ).

Resistivity differences between the ABEM/Octapod and the EM31 measurements are explained by the fact that soil saturation and water chemistry change with depth. Increased saturation and chloride content cause apparent resistivities to be less than those of the same sediments when dry or partially saturated. The similarity of resistivity values calculated using two orientations of the EM31 boom indicates that lateral anisotropy of surficial materials is essentially absent along the Base Line in the upper $20 \mathrm{ft}$. Finally, where the land surface approaches sea level at the northern end of the Base Line, the ABEM and EM31 provide nearly identical resistivities. This observation suggests that resistivity change is due to increased saturation or to chloride content (or both), since GPR data suggest that the subsurface is homogeneous to depths greater than $30 \mathrm{ft}$ at the northern end of the line. Figure 9 provides quality control through a cross-check of electrical methods.

\subsection{Horizontal Conductivity Profiling - EM31}

EM31 data were collected in nine data sets along east-west profiles, spaced $10 \mathrm{ft}$ apart, with profile lengths decreasing to the north, from $180 \mathrm{ft}$ in length in the south to about $50 \mathrm{ft}$ in the north. The nine areas coincide with magnetic areas shown in Figures D.1 through D.11. The Base Line serves as a tie line to link the nine data areas. Line locations and the configuration of EM31 conductivities are shown on Figure 10. Data were acquired on a digital data logger at a 0.5 -s sampling rate, resulting in a mean station spacing of $1.5 \mathrm{ft}$. Electromagnetic data acquisition parameters are shown in Table 5.

The configuration of the EM31 surface is marked by high-amplitude, short-wavelength anomalies of anthropogenic origin and by low-amplitude, longer-wavelength anomalies characteristic of natural changes in subsurface soils. The large-amplitude anomalies are easily explained by surficial features, such as the University of Maryland bio-assay trailer, the access road, metal debris strewn about the site, and two concrete slabs north of $650 \mathrm{~S}$.

Conductivities, ranging from 10 to $40 \mathrm{mS} / \mathrm{m}$, are largely explained by natural variations in electrical properties of the subsurface at Beach Point Peninsula. Conductive areas to the east 


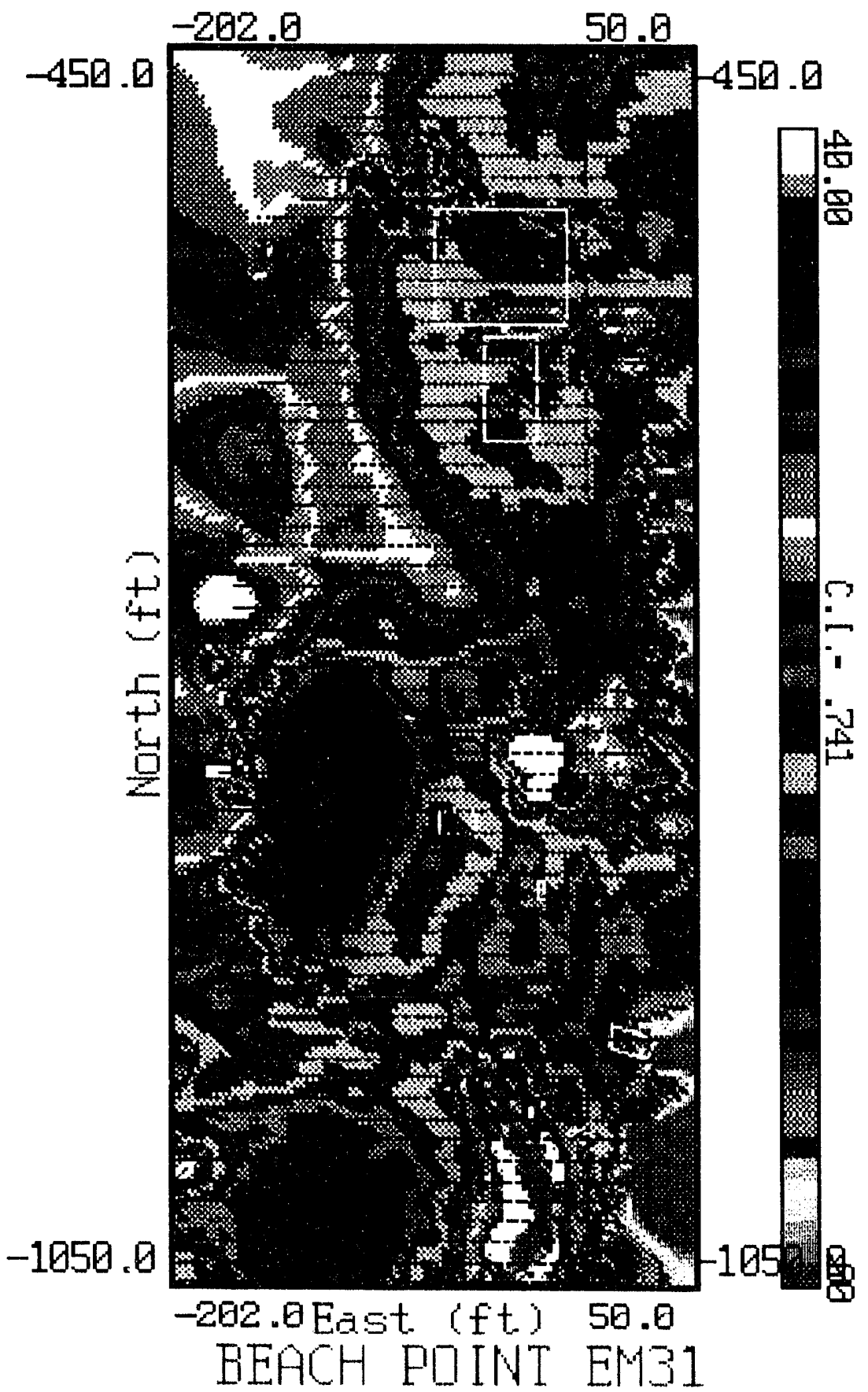

FIGURE 10 Beach Point EM31 Anomalies (Conductive areas to the east are produced by surficial objects, including road fill and a trailer. Conductive areas to the west are associated with highly saturated clays and organic soils in the wooded portion of beach point. Less conductive anomalies in the central areas may be in response to a deeper water table. High-intensity, lowconductivity anomalies centrally located north of 7305 may be related to activities associated with a former building on the concrete slab in that area. Intense minima, particularly along Lines 520 S and 530S, may signify gravel pits and trenches into which contaminants were dumped.) 
TABLE 5 EM31 Line Acquisition Parameters

\begin{tabular}{|c|c|c|c|c|}
\hline Area & $\begin{array}{c}\text { No. of } \\
\text { Stations }\end{array}$ & $\begin{array}{l}\text { No. of } \\
\text { Lines }\end{array}$ & $\begin{array}{c}\text { Line } \\
\text { Length ( } \mathrm{ft} \text { ) }\end{array}$ & $\begin{array}{c}\text { Total Line } \\
\text { Footage } \\
\text { (ft) }\end{array}$ \\
\hline $\begin{array}{c}1 \\
2 \\
3 \\
4 \\
5 \& 6 \\
7 \& 8 \\
9 \\
\text { Base Line }\end{array}$ & $\begin{array}{r}1,332 \\
2,560 \\
2,350 \\
974 \\
721 \\
832 \\
465 \\
444\end{array}$ & $\begin{array}{r}11 \\
21 \\
21 \\
11 \\
11 \\
16 \\
3 \\
1\end{array}$ & $\begin{array}{r}180 \mathrm{E}-W \\
180 \mathrm{E}-W \\
170 \mathrm{E}-W \\
150 \mathrm{E}-W \\
100 \mathrm{E}-W \\
60 \mathrm{E}-W \\
200 \mathrm{E}-W \\
1,050 \mathrm{~N}-\mathrm{S}\end{array}$ & $\begin{array}{r}1,980 \\
3,780 \\
3,570 \\
1,650 \\
1,100 \\
960 \\
600 \\
1,050\end{array}$ \\
\hline Totals & 9,677 & 95 & & 14,690 \\
\hline
\end{tabular}

are produced by surficial objects, including road fill and a trailer. Conductive areas to the west are associated with highly saturated clays and organic soils in the wooded portion of Beach Point Peninsula. The axis of the peninsula, except for small circular or elliptical positive anomalies, is associated with a sinuous trend of low conductivities. An anomaly in this trend, centered at $810 \mathrm{~S}-125 \mathrm{~W}$, cannot be explained by surface topography or anthropogenic surface features. A possible cause of this anomaly is observed on a GPR profile discussed in Section 4.1.

Two concrete slabs lying between $520 \mathrm{~S}$ and $640 \mathrm{~S}$ are associated with a broad negative in the central negative trend. A positive anomaly at $580 \mathrm{~S}$ to $590 \mathrm{~S}-25 \mathrm{~W}$ and an unusually negative anomaly at $527 \mathrm{~S}-85 \mathrm{~W}$ are probably of anthropogenic origin. The positive anomaly is located near the southeast corner of the larger slab. The cause of the positive anomaly is uncertain; the negative anomaly, however, may indicate the presence of a burial pit or trench.

An area extending from approximately $480 \mathrm{~S}$ to $780 \mathrm{~S}$ in the western wooded area, near the northern tip, is relatively more conductive than the axial region. The more conductive areas to the west reach $30 \mathrm{mS} / \mathrm{m}$, whereas the axial area is associated with conductivities of less than $15 \mathrm{mS} / \mathrm{m}$. High-intensity, low-conductivity anomalies centrally located north of $730 \mathrm{~S}$ may be related to activities associated with the former building on the concrete slab discussed in the preceding paragraph. Intense minima, particularly along lines 520S and 530S, may signify gravel pits and trenches into which contaminants were dumped. Less conductive anomalies in the central areas may be in response to a deeper water table.

The access road is associated with a triplicate, parallel, linear anomaly in the southern area of study, with a negative anomaly being flanked by two positive anomalies (Figure 10). The 


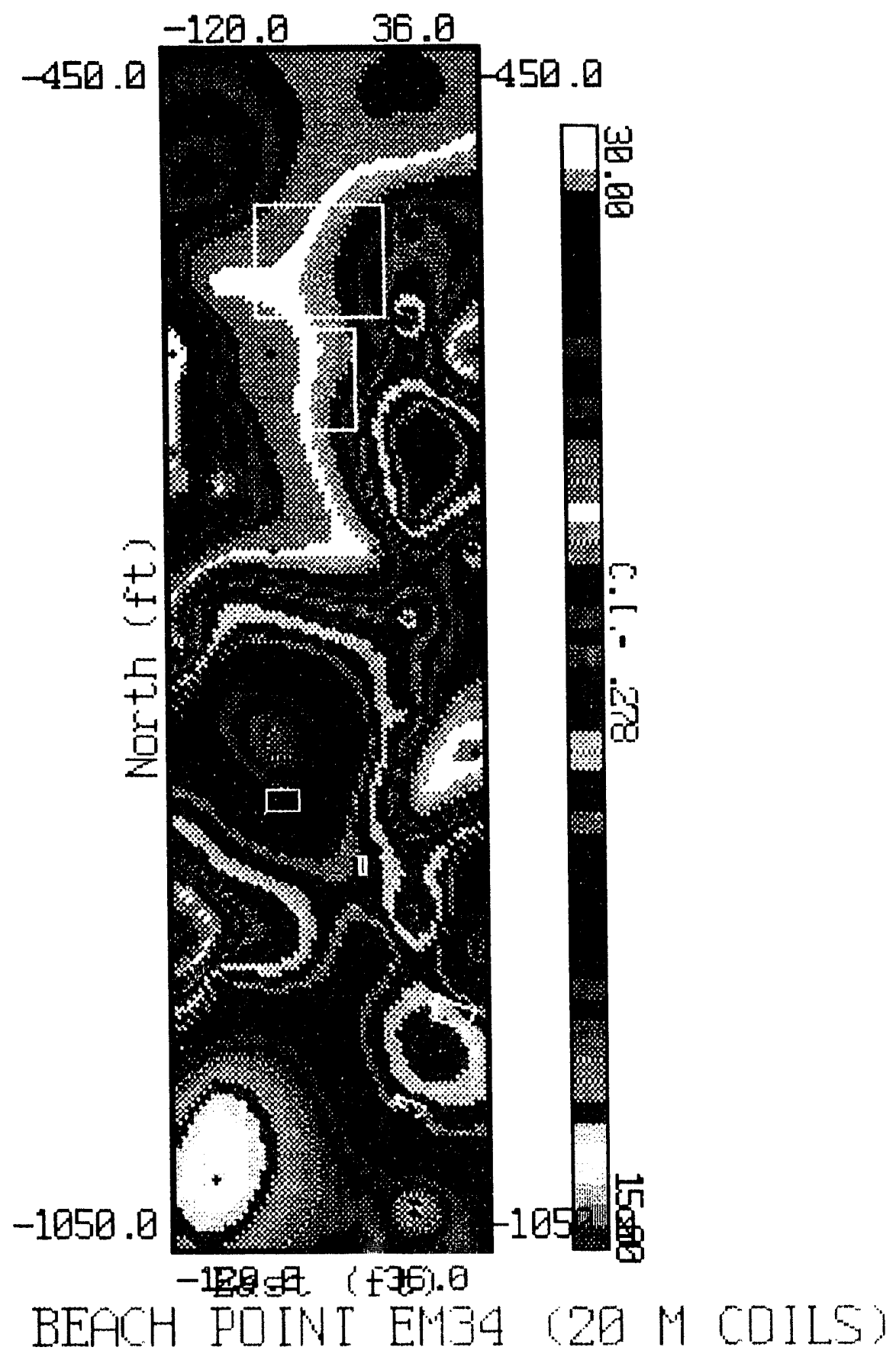

FIGURE 11 Beach Point EM34 Anomalies with 20-Meter Coil Spacings (The conductivities are the result of mean electrical properties of sediment and interstitial pore fluids between the surface and a depth of approximately $50 \mathrm{ft}$.) 
triplicate signature is a common trait of EM mapping where the instrument crosses a long, narrow conductor, such as that caused by road fill. The central minimum is simply an artifact of antenna/receiver geometry.

\subsection{Horizontal Conductivity Profilling - EM34}

EM34 data were collected in the horizontal dipole mode with coil spacings at $32.8,65.6$, and $131.2 \mathrm{ft}$, providing mean conductivities over depth ranges of 24.6, 49.2, and $98.4 \mathrm{ft}$, respectively. Data were acquired along the north-south Base Line for all three coil separations. Additional data were recorded at the $65.6-\mathrm{ft}(20-\mathrm{m})$ coil spacing at locations shown on the EM34 map (Figure 11). The EM34 data were acquired in order to develop a better understanding of the distribution of electrical conductivities at greater depths than could be provided with the EM31.

The configuration of mean conductivities over a depth range of 0 to $49.2 \mathrm{ft}$ (Figure 11) is similar to the map of EM31 data shown in Figure 10. However, the centrally located, sinuous trend of low conductivities observed on the EM31 map is shifted to the east $40-50 \mathrm{ft}$ on the EM34 map. The relationship between the mean conductivities is shown on Figure 12, where EM34 data are overlaid on EM31 data. The association of low conductivities with the concrete slabs noted in the previous section for EM31 data is no longer observed on the EM34 map. EM34 conductivity trends are more closely associated with facies and pore water chemistry variations in the deeper parts of the surficial aquifer than in the near-surface clays.

\subsection{Horizontal Resistivity Profiling - Octapod}

A map of horizontal resistivity values based on 194 stations is shown in Figure 13. The map mimics, in a general way, the map of EM31 data (Figure 10), although the access road across the site is represented by a much more prominent resistivity anomaly, reflecting its shallower sensing range. The low-resistivity, sinuous lineament, oriented N-S, is produced by road fill. The most prominent resistivity feature, other than the road anomaly, is a large, lowamplitude minimum, centered at approximately $650 \mathrm{~S}-100 \mathrm{~W}$. It is probable that this anomaly is produced by natural differences in near-surface resistivity, such as increasing saturation and thickening of near-surface clay.

The high-resistivity linear trend in the central and north-central parts of the map may be a result of natural change due to less saturated conditions in the central peninsula; however, this area is located in an area of waste-liquid disposal pits. If waste liquids were associated with high resistivities, the waste could also contribute to the anomaly. High-resistivity areas, over $150 \Omega \cdot \mathrm{m}$ in the north, coincide with low-conductivity features associated with the former building site. 


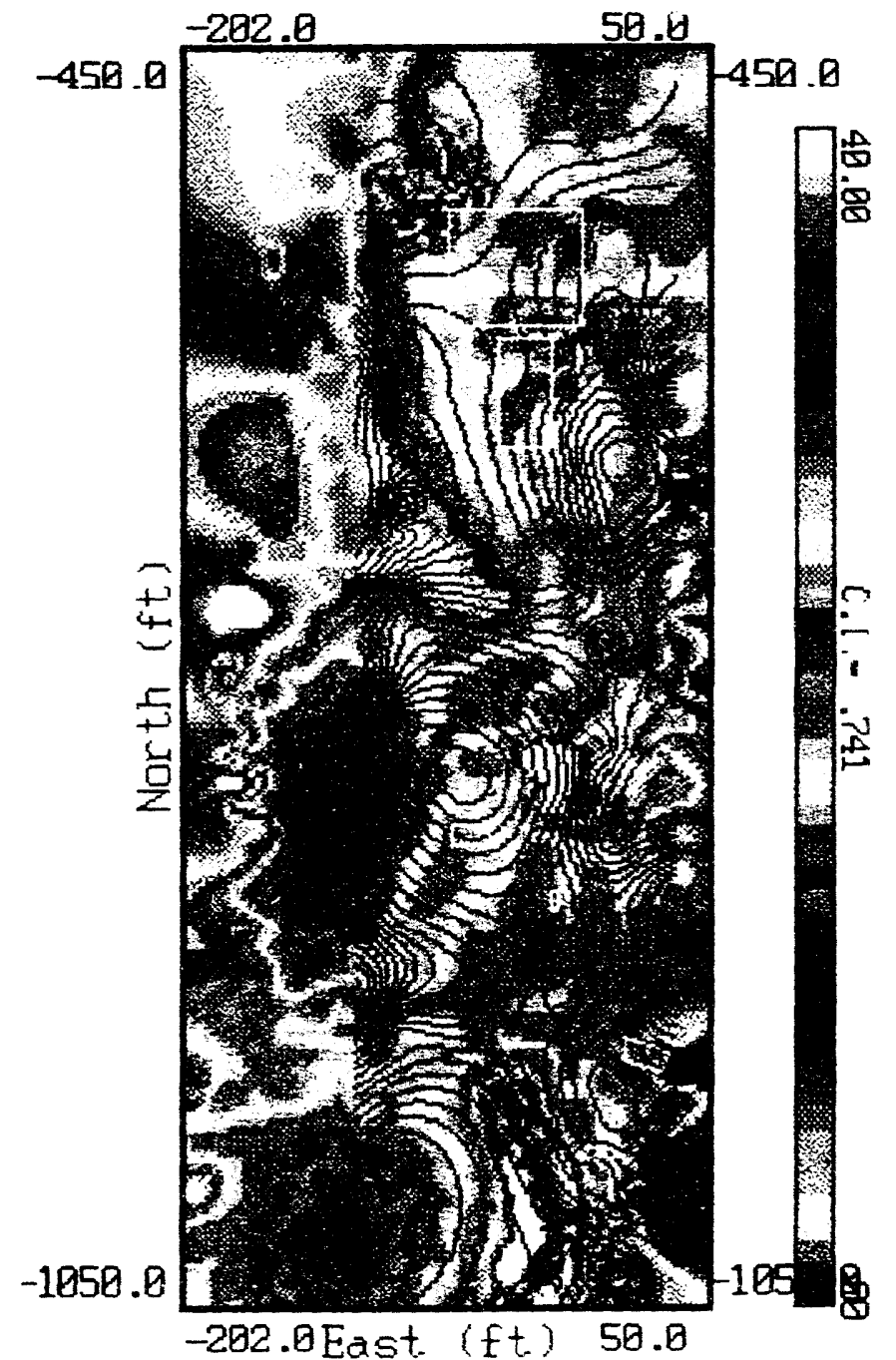

FIGURE 12 Overlay Map of EM31 and EM34 Data Showing the Shift of Anomaly Minima to the East with Increasing Depth

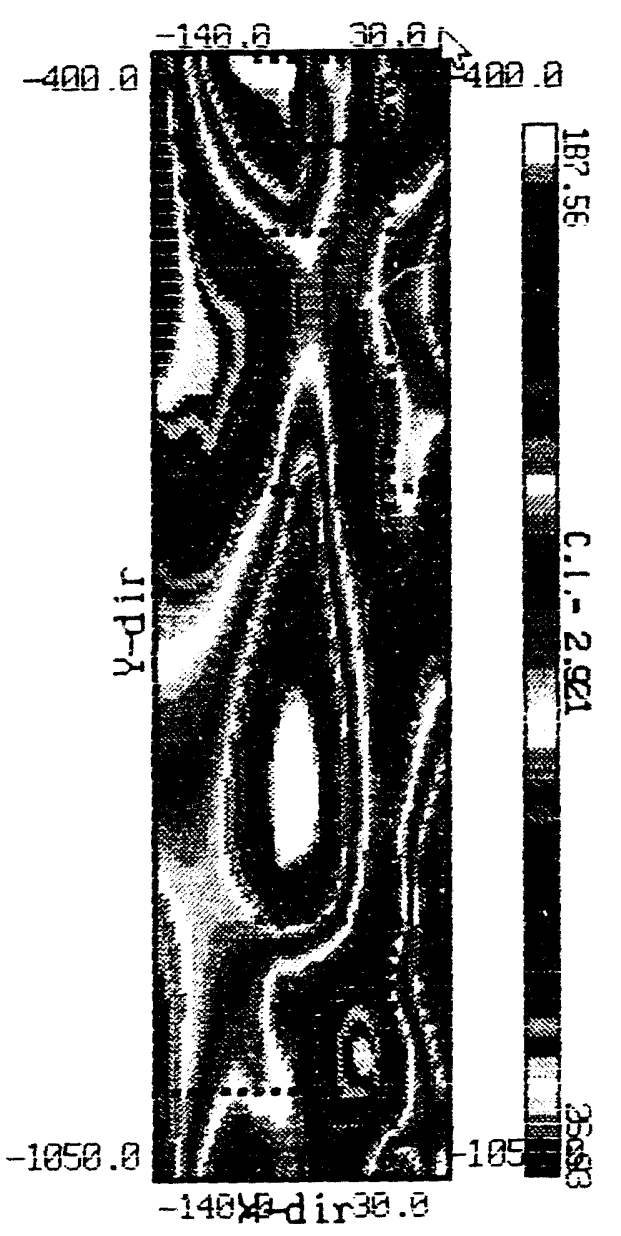

FIGURE 13 Regional Resistivity Map Constructed from Horizontal Resistivity Data Collected with the Octapod (A lowresistivity sinuous lineament, oriented $\mathrm{N}-\mathrm{S}$, is produced by road fill. Highresistivity areas, over $150 \Omega \cdot m$ in the north, coincide with low-conductivity features associated with the former building site.) 


\subsection{Vertical Resistivity Sounding}

Vertical electrical soundings (VES) at Beach Point Peninsula were centered at 15 sites, located as listed in Table 6 . Resistivity data were determined within the depth range extending from the surface to approximately $200 \mathrm{ft}$. Resistivity-depth curves and their inversions are shown in Appendix A.

Analyses of VES curves provide resistivities and depths, which in combination with EM and horizontal resistivity data are used to construct a resistivity cross section beneath the Base Line, as shown in Figure 14. Resistivities are obtained from converted EM31 and EM34 data, ABEM/Octapod profiling, and VES. Mean resistivity at the total sensing depths of the EM31, EM34, and ABEM/Octapod are used.

A thin skin of high surficial resistivities in Figure 14 defines the electrical characteristics of the vadose zone above the water table. An abrupt drop in resistivities at the water table and below is defined by data derived from the deeper EM sounding measurements. Below depths of $100 \mathrm{ft}$, the cross-section characteristics are controlled by data obtained from VES.

An electrical anomaly, reaching approximately $60 \Omega \cdot \mathrm{m}$, in a background of values less than $40 \Omega \cdot \mathrm{m}$, is located between $700 \mathrm{~S}$ and 550S. The anomaly is observed on EM31, EM34, and VES stations located along the Base Line. The field curves of resistivity versus electrode separation at stations located between $650 \mathrm{~S}$ and $750 \mathrm{~S}$ are characterized by rapidly rising apparent resistivities at maximum electrode spacings (see Appendix A). Because of the inherent ambiguity in the interpretation of electrical depth sounding curves, due to possible horizontal resistivity changes, a single depth sounding interpretation would not conclusively define the deep anomaly. However, the anomaly is also observed with EM34, at 30-m and 40-m coil spacings, for three independent measurements. The shape of the anomaly, its lack of conformity with flat-lying stratigraphy, and its depth suggest the presence of a high-resistivity zone contained in the surficial aquifer. The high resistivities may be associated with a plume that originated at sources outlined by low-conductivity anomalies described earlier in the discussion on the EM31 survey, Sectior 3.1, Horizontal Conductivity Profiling. Lower resistivities in the surficial aquifer are probably caused by high chloride content due to saltwater intrusion from tidal action in Bush River.

Composition of the contaminants contained in pore liquids producing the electrical anomaly is uncertain; however, concentrations up to 20 parts per million (ppm) volatile organics, consisting of tetrachloroethane and trichloroethene, among others, have been reported in Beach Point groundwater (Burton 1993). Since volatile organics have high resistivities, it is possible that the resistivity anomaly does correspond with a dense, nonaqueous-phase liquid (DNAPL) plume. Further study is needed to investigate the level of electrical response and chemical interactions at low concentration levels (a few ppm) and with different types of clay minerals. 
TABLE 6 Vertical Electrical

Soundings at Beach Point

Site

Sounding No. Location of Center

\begin{tabular}{|c|c|}
\hline 1 & $650 S-10 W$ \\
\hline 2 & $1050 S-5 W$ \\
\hline 3 & 950S - OW \\
\hline 4 & 850S - OW \\
\hline 5 & 750 S - OW \\
\hline 6 & 550S - OW \\
\hline 7 & 450 S - OW \\
\hline 8 & 350 S - OW \\
\hline 9 & 250 - OW \\
\hline 10 & $150 S$ - OW \\
\hline 11 & $450 S-50 W$ \\
\hline 12 & $850 S-50 W$ \\
\hline 13 & $750 S-50 W$ \\
\hline 14 & $650 S-50 W$ \\
\hline 15 & $1400 S-0 W$ \\
\hline
\end{tabular}




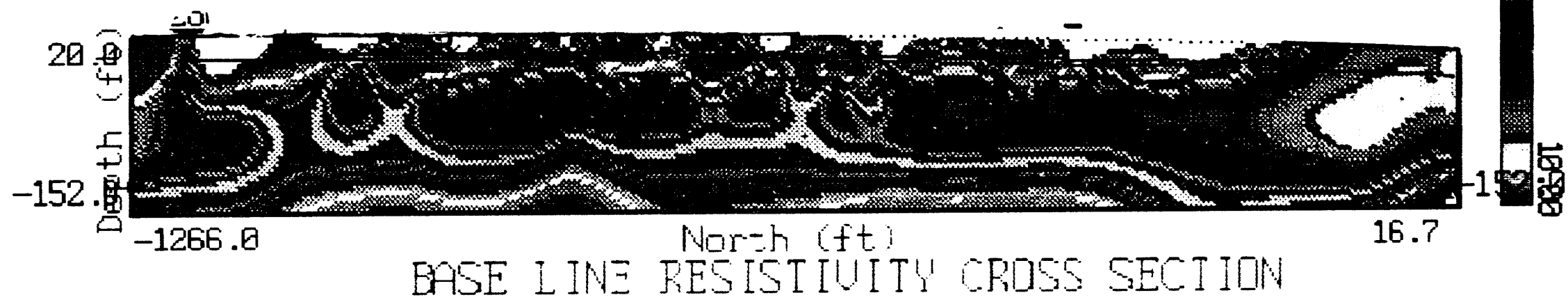

FIGURE 14 Resistivity Cross Section beneath the Beach Point Base Line (Resistivities are obtained from converted EM data, Octapod profiling, and electrical depth soundings. The surficial aquifer is a relatively low-resistivity lens pierced by high-resistivity "plumes" that may indicate descending dense, nonaqueous-phase liquids.) 


\section{Ground Penetrating Radar Surveys}

\subsection{Monostatic Ground Penetrating Radar}

Depth of penetration using monostatic ground penetrating radar at Beach Point Peninsula ranged from 5 to $15 \mathrm{ft}$, with surface conditions playing a major role. In general, the best penetration was achieved in undisturbed wooded areas on the west side of the Peninsula. A range setting of 150 nanosecnnds (ns) was used for the regional survey at a scan rate of 32 scans per second. The transceiver was pulled by hand at approximately $2 \mathrm{ft} / \mathrm{s}$.

Prior to running the production lines for the survey, replicate runs were made over the same line to determine whether a $100-$ or $300-\mathrm{MHz}$ antenna would provide the greater penetration. A secondary consideration was the resolution of thin beds. Following several scans, it was decided that the $100-\mathrm{MHz}$ transceiver would provide optimal results for studying regional geologic structure. The $100-\mathrm{MHz}$ antenna has a virtual resolution (VR) of $4 \mathrm{ft}$, where VR is the minimum thickness of a layer that is resolvable. The $300-\mathrm{MHz}$ antenna was used around and over selected areas in order to better locate anomalies of anthropogenic origin. Wave-velocity characteristics of the subsurface soils were determined by running profiles over a buried waterline in southeastern Beach Point Peninsula. The pipe, buried $3.5 \mathrm{ft}$ below the ground surface, indicated that wave velocities must be $7-9 \mathrm{~ns} / \mathrm{ft}$ for the fill material overlying the pipe. (Velocities over the pipe may not be representative of native soils underlying Beach Point.)

GPR profiles were collected along east-west lines spaced $50 \mathrm{ft}$ apart. South-to-north profiles, spaced $10 \mathrm{ft}$ apart, were acquired where unusual anomalies were observed. A more detailed survey was performed around and over the large concrete pad centrally located on Beach Point Peninsula. Several areas along the western portion of Beach Point Peninsula were inaccessible due to dense vegetation. A total of 19,415 linear feet was surveyed along 132 profiles.

Inspection of GPR data reveals a wavy reflector underlying a strong horizontal reflector in the western portion of the survey in the area of $800 \mathrm{~S}$, running from $190 \mathrm{~W}$ to $30 \mathrm{E}$ (Figure 15). A valley or trough, approximately $10 \mathrm{ft}$ deep, underlies the horizontal reflector at the western end of the profile. The horizontal reflector is probably the result of a sharp contrast in soil type or soil chemistry. The wavy reflector may correlate with the contact between a surficial clay and a lower sand unit observed in outcrops along the shoreline. Its high reflectivity may also be due to higher concentrations of iron in the sand, which were also observed in some of the outcrops.

The GPR data may also indicate a trench or pit centered at grid coordinates $925 \mathrm{~S}-140 \mathrm{~W}$, near a small berm, which may be the material dug from the trench. This trench was seen only in one south-north profile along $140 \mathrm{~W}$, running from $980 \mathrm{~S}$ to $900 \mathrm{~S}$ (Figure 16). 


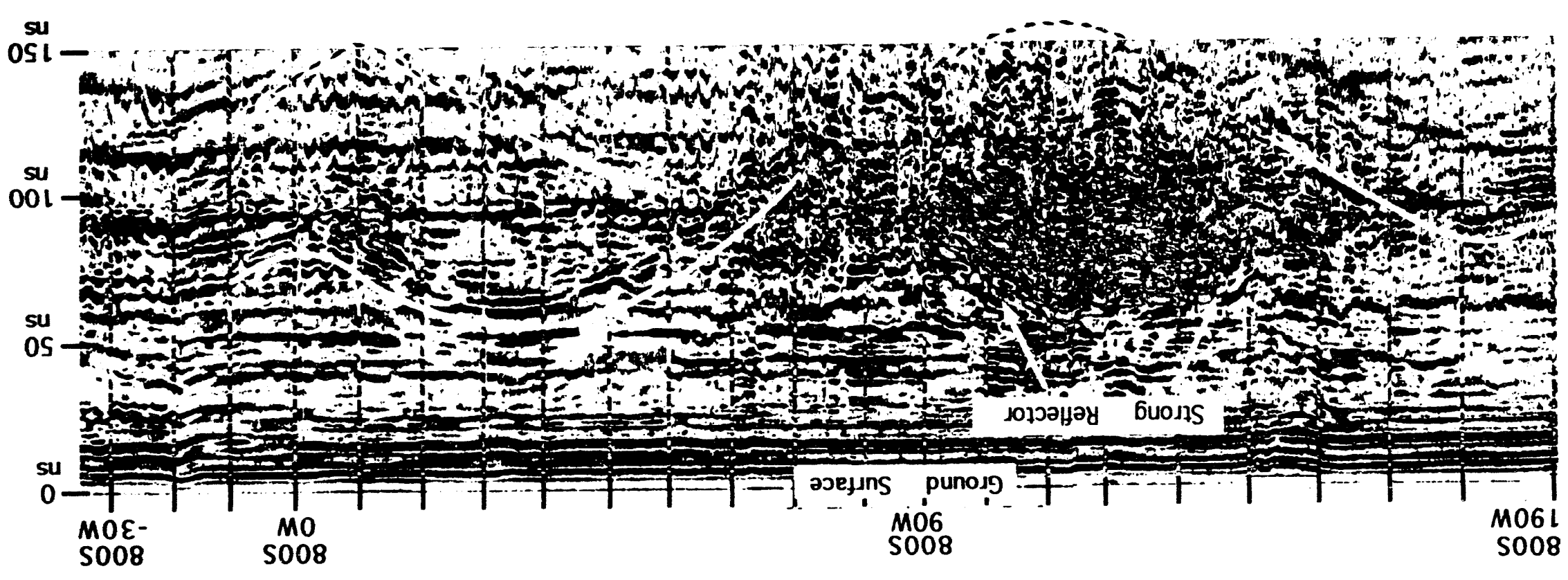




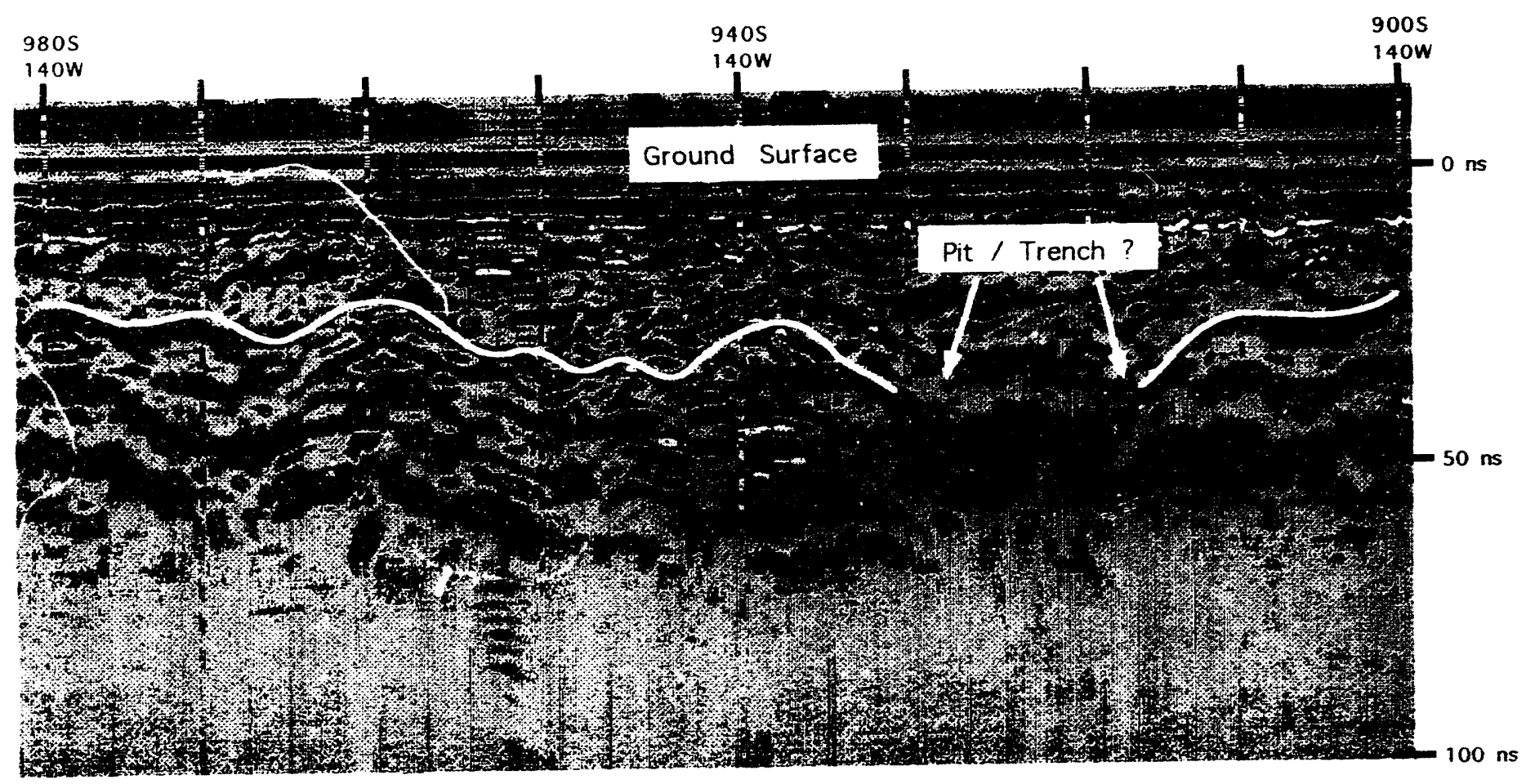

FIGURE 16 GPR Profile over a Possible Buried Pit or Trench 
Many GPR anomalies of anthropogenic origin were detected. Most of them are single, one-point anomalies, but a few were detected in more than one profile. In the northern portion of the survey area, possible pipes were seen. These pipes trend from east to west and appear to end at the western shureline. Several GPR profiles collected around the large concrete pad revealed a possible underground storage tank (UST) located just east of the northeast corner of the large concrete slab (Figure 4). The suspected UST is roughly centered at grid coordinates $540 \mathrm{~S}, 8 \mathrm{~W}$ and is approximately $12.5 \mathrm{ft}$ long, oriented northsouth. Figure 17 shows the GPR anomaly over the suspected UST. This profile was collected east-to-west along 537.5S.

\subsection{Bistatic Ground Penetrating Radar}

A majority of the GPR profiles were collected with the $100-\mathrm{MHz}$ antenna in the monostatic mode; however, selected profiles were also collected in the bistatic mode, using both the $100-$ and $300-\mathrm{MHz}$ antennas. In the bistatic mode, the transmitter and receiver were separated by a fixed distance of $4.5 \mathrm{ft}$. The bistatic configuration was used to establish the hydrostratigraphic framework to depths of $30 \mathrm{ft}$. Range settings of 150 and $300 \mathrm{~ns}$ were used. A total of 4,750 linear feet was surveyed along 17 profiles in the bistatic mode. A list of GPR profiles collected in the bistatic mode is provided in Appendix B.

Bistatic GPR data are used to illustrate stratigraphic detail to $30-\mathrm{ft}$ depths along the Base Line from $0 \mathrm{~N}$ to $1,000 \mathrm{~S}$ (Figures 18 to 21 ). This profile has been enhanced by computer processing, which included deconvolution and Kirchoff migration. The deconvolution helped eliminate flat-lying, ringing multiples in the shallower part of the section; the Kirchoff migration removed some of the diffraction and bowtie patterns originating in the troughs of dune-shaped reflectors.

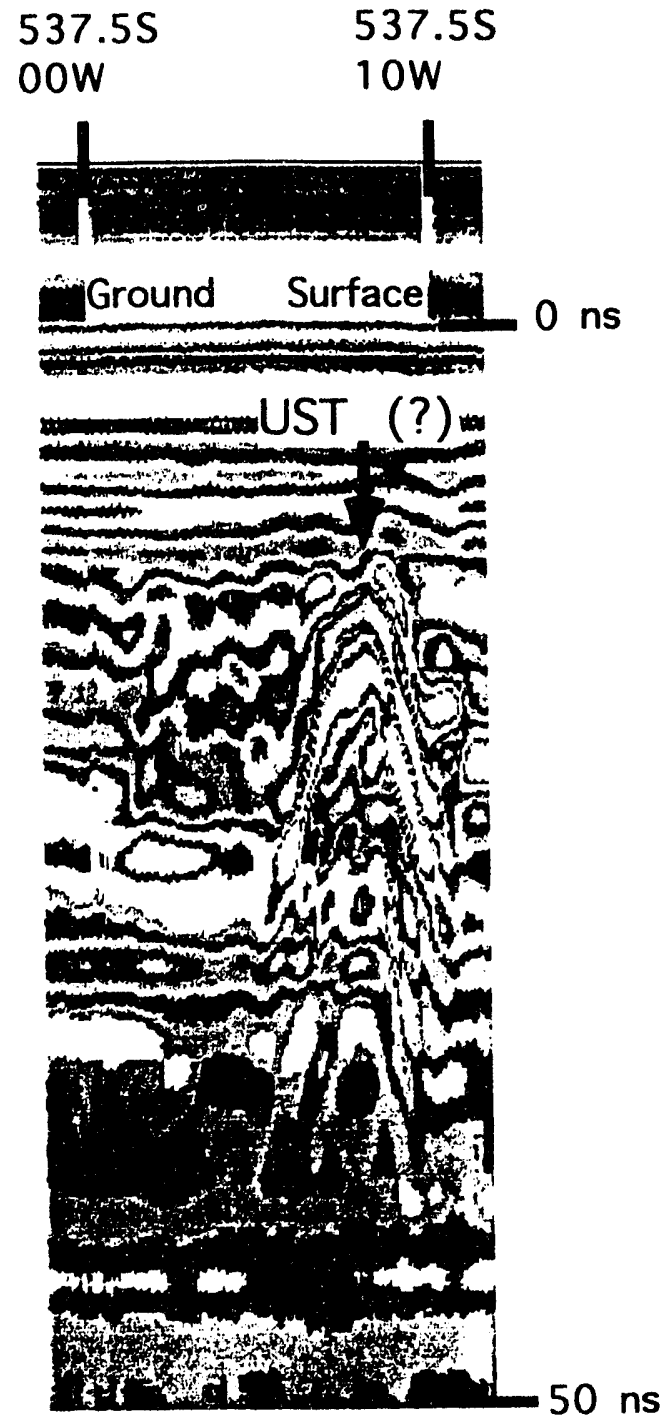

FIGURE 17 GPR Anomaly Produced by a Buried Tank East of the Concrete Slab 


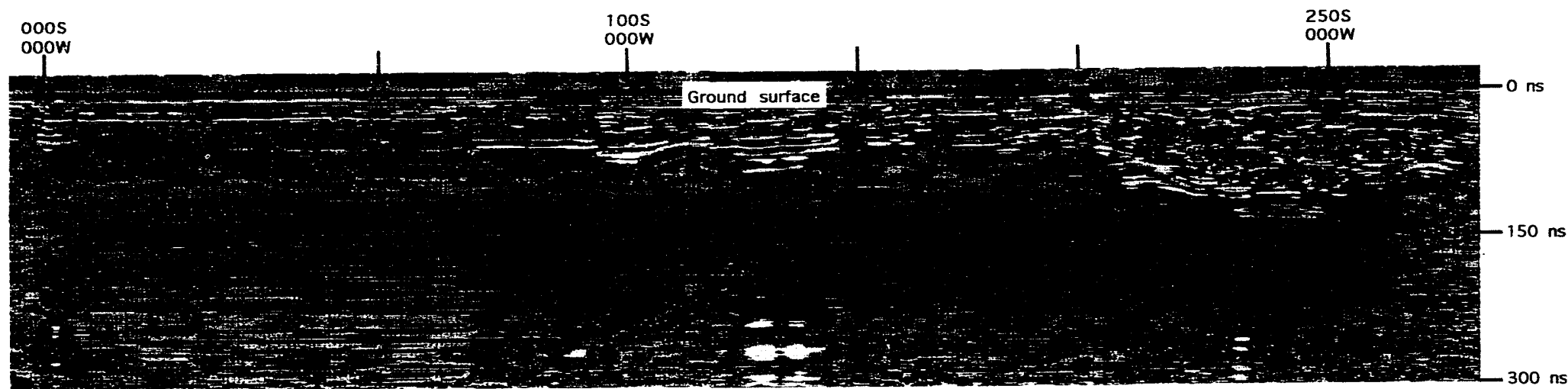

FIGURE 18 GPR Profile at the North End of the Base Line (The wavy reflector descends rapidly to the north.)

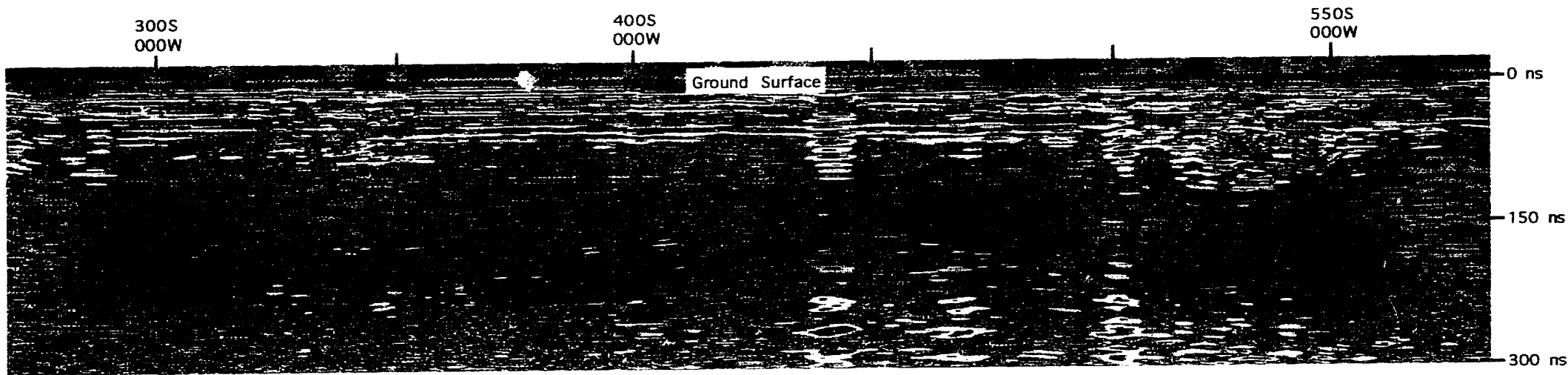

FIGURE 19 GPR Profile between 250 S and 600S along the Base Line 
A series of shallow lenses in the upper 10 to $12 \mathrm{ft}$ of the Base Line cross section were seen in the monostatic mode. The top of a deeper undulating reflector, however, was seen only in the bistatic configuration. This reflector is characteristic of topography observed in a dune terrain near shorelines. The dune-shaped reflectors rest on a gently-dipping reflector, with a northeast apparent dip at depths greater than $20 \mathrm{ft}$.

Figure 22 shows the relationship between the dune-shaped reflector and EM31 anomalies. EM data have been converted to resistivities to be consistent with resistivities shown in the cross section in Figure 14. A direct correlation between the reflector and resistivity is observed on the north end of the profile, where the reflector approaches the surface. To the south, where surface elevations increase, the relationship disappears. Since the EM31 has a maximum sensing depth of $20 \mathrm{ft}$, it is probable that the reflector is beyond the detection depth of the EM31 to the south. Since the correlation is strong to the north, where the reflector is only $10 \mathrm{ft}$ deep, it is probable that the lithology below the reflector is a sand. 


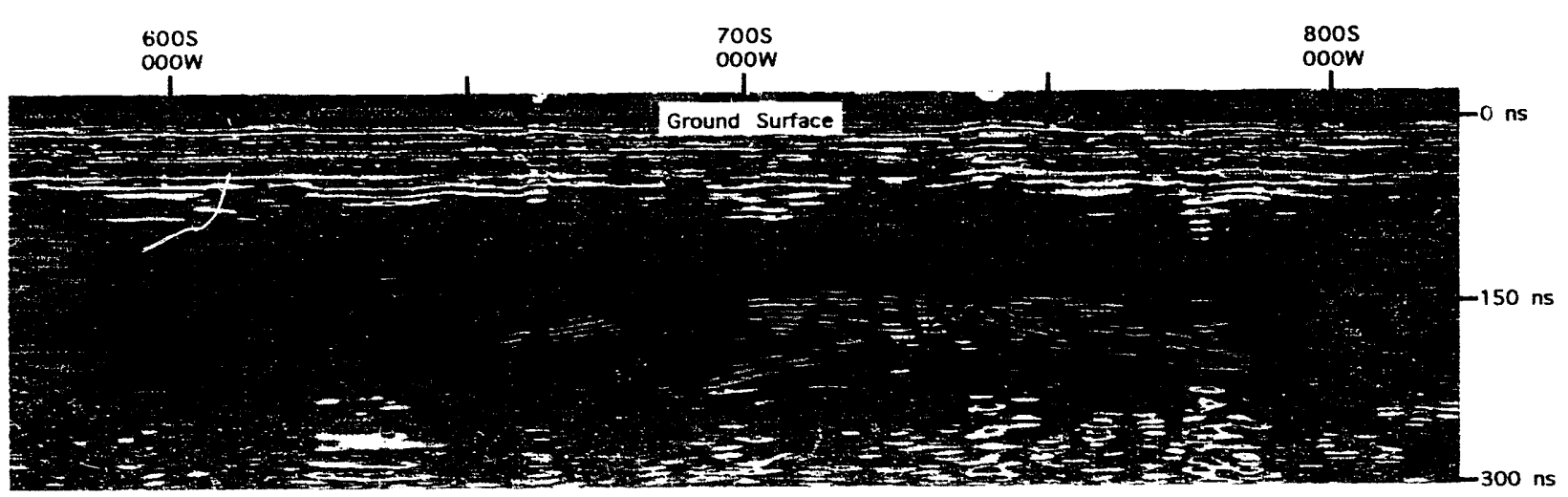

FIGURE 20 GPR Profile between 600 S and 800 S along the Base Line

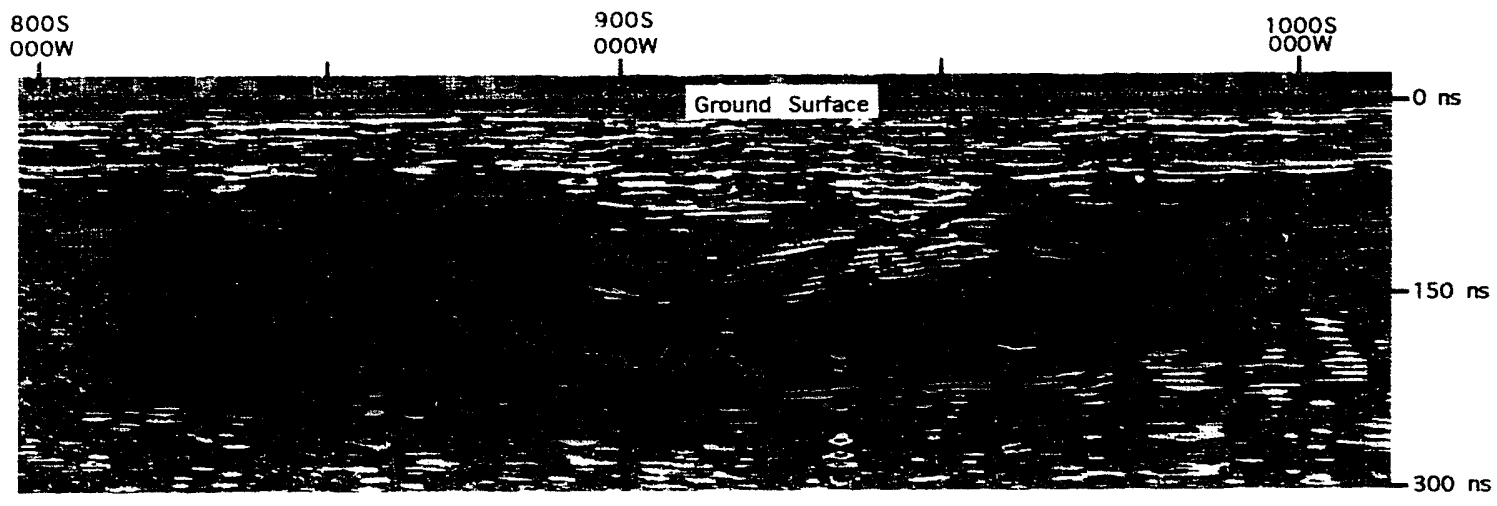

FIGURE 21 GPR Profile between 800 S and 1050 S along the Base Line 
(A)

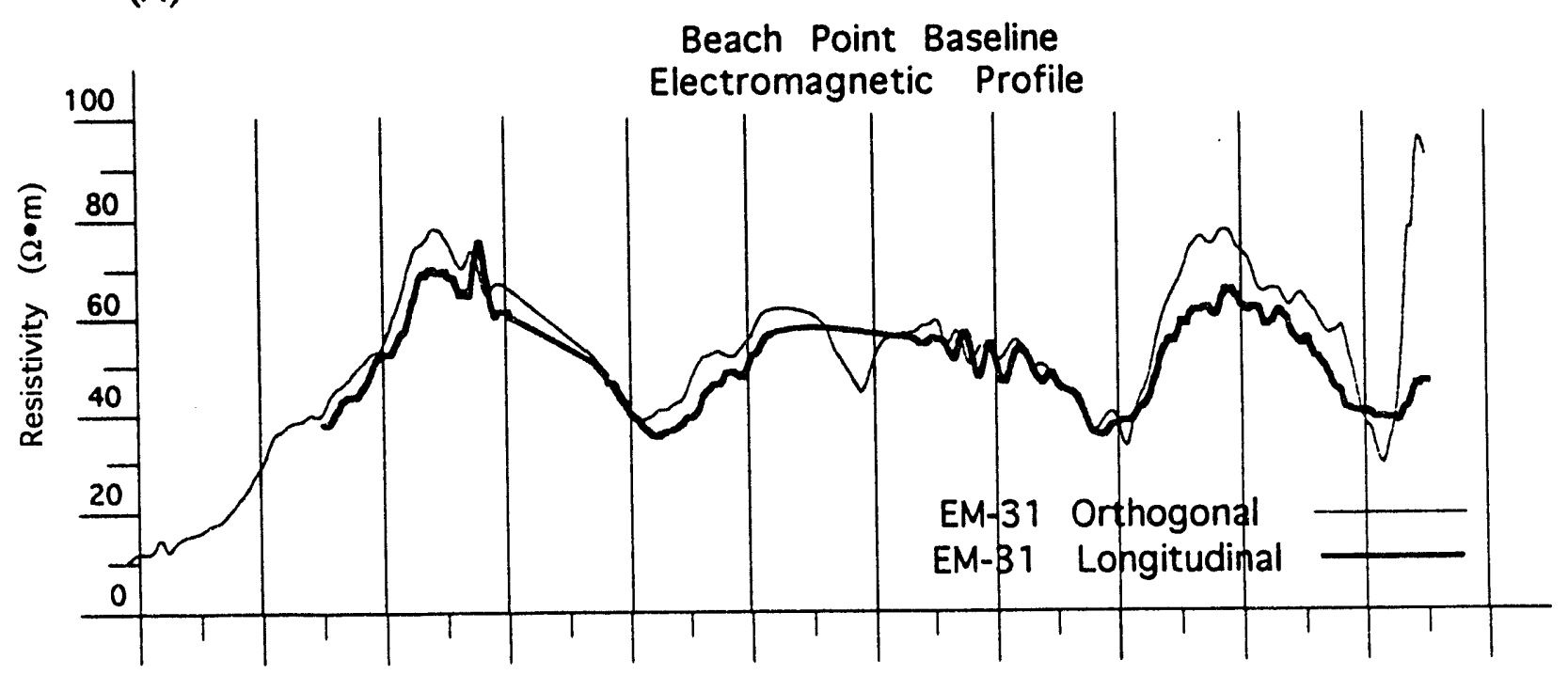

(B)

Beach Point Baseline

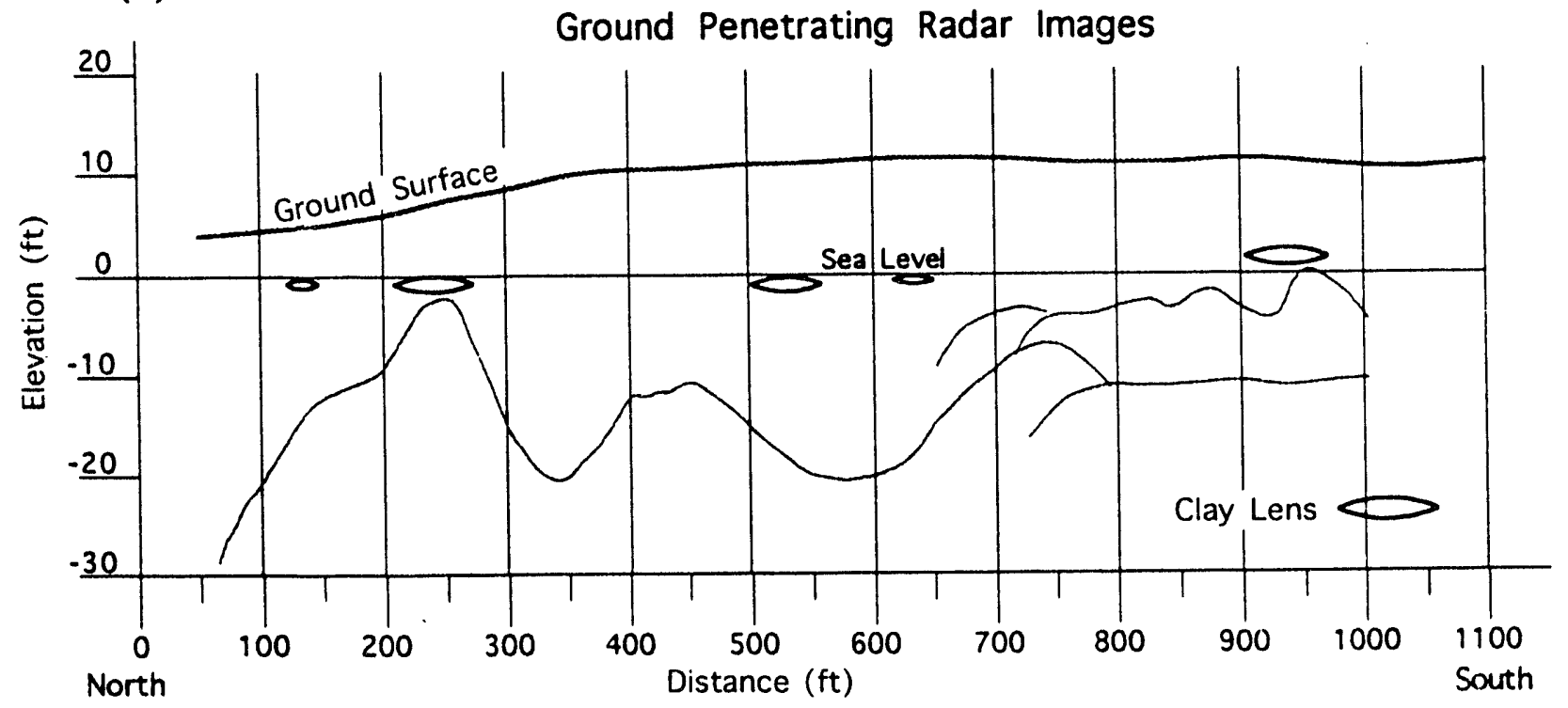

FIGURE 22 Relationship between EM31 Anomalies and GPR Reflectors 


\section{High-Resolution Seismic Surveys}

An integral part of the seismic programs at Beach Point is the determination of the stratigraphy and structure of the Atlantic Coastal Plain sediments down to the Precambrian crystalline basement. Seismic refraction and reflection surveys provide the most precise geophysical information on depths to lithologic units comprising the hydrogeologic framework below a depth of $30 \mathrm{ft}$. The following section provides a description of the subsurface based on seismic surveys. Locations of all seismic lines are shown on Figure 23.

\subsection{Seismic Refraction Profiling}

Refraction profiles provide velocity and depth information to about $300 \mathrm{ft}$ depth. The longest shot-detector distance of 1,624 ft was not adequate to obtain a refracted arrival from the crystalline basement. Velocity data calculated from the refraction profiles were used to constrain velocities used in reflection profiling.

Four 24-channel seismic refraction profiles were recorded in the Beach Point Peninsula area at two sites (Table 7). Two profiles (BCHNS-5M and BCHNS-10M) are aligned N-S on the peninsula Base Line with five meter and 10 meter take-out separations, respectively. Two additional profiles (BCHEW-5M and BCHEW-10M) are aligned E-W on the Beach Point Road (see Figure 23). Table 7 indicates shot and receiver geometries and field recording parameters for the refraction profiles.

Figure 24 shows the velocity-depth distribution determined from refraction profiles on Beach Point Road. Maximum shot-detector distance was 1,624 ft. Average velocities between major refractors are 2,015 ft/s for the vadose zone, $5,480 \mathrm{ft} / \mathrm{s}$ for saturated Pleistocene sediments of the surficial aquifer below the water table, and $6,025 \mathrm{ft} / \mathrm{s}$ for the top of the Cretaceous immediately beneath the P-K unconformity. The water table refractor descends in elevation to the east, from $10 \mathrm{ft}$ below land surface on the west to $20 \mathrm{ft}$ on the east, where it is approximately at sea level. The P-K unconformity also has an apparent slope downward to the east.

Seismic refraction soundings along the Base Line also provide data for construction of a velocity-depth profile beneath Beach Point Peninsula (Figure 25). A velocity increase from $1,245 \mathrm{ft} / \mathrm{s}$ for the vadose zone to $5,395 \mathrm{ft} / \mathrm{s}$ for the surficial aquifer has been determined. Water table depth remains a constant $13 \mathrm{ft}$ beneath the profile. The apparent rise of the water table to the north is an artifact caused by a drop in surface elevation. Depth to crystalline basement shown in Figure 26 is based upon reflection data. 


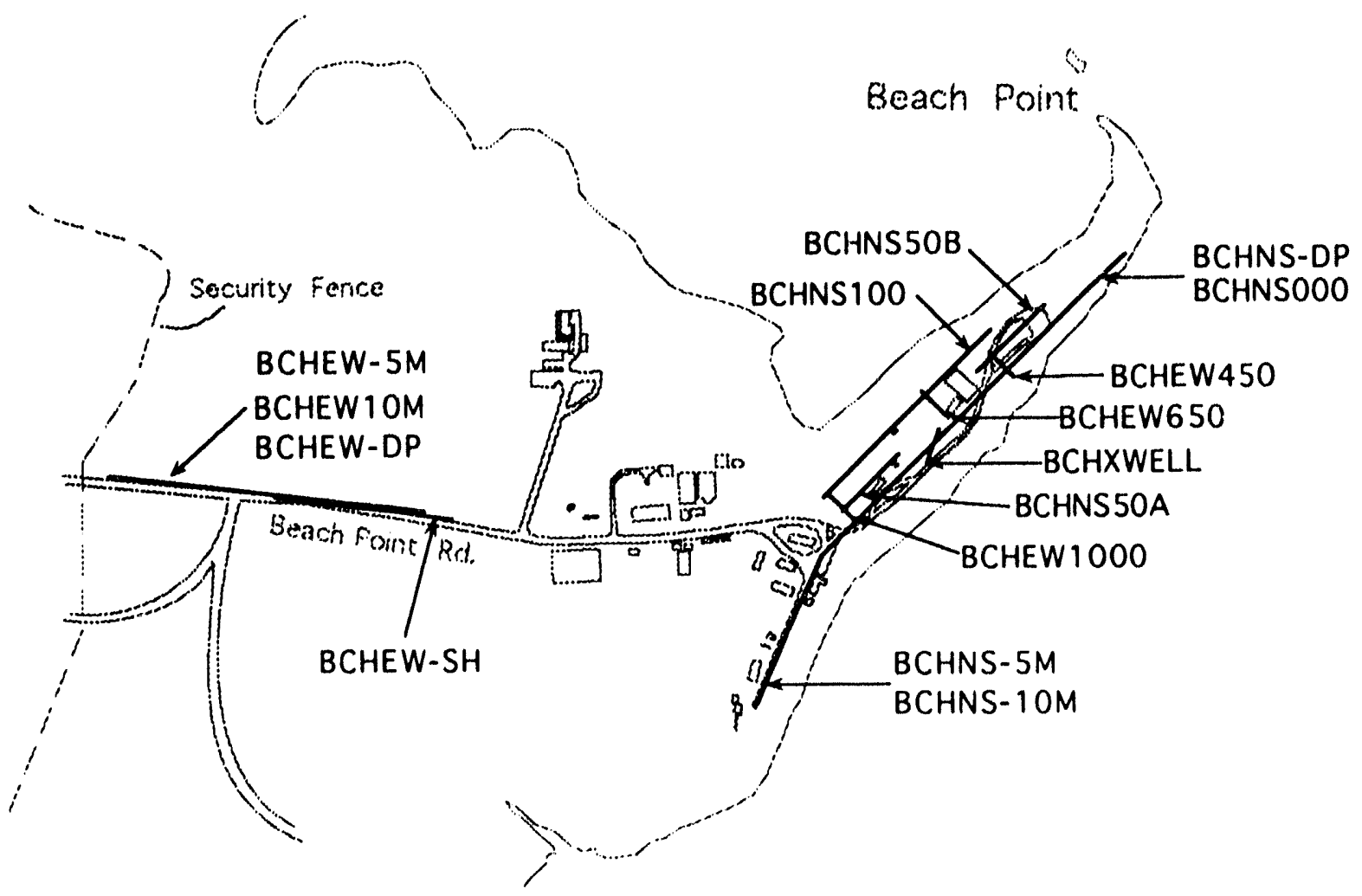

Explanation
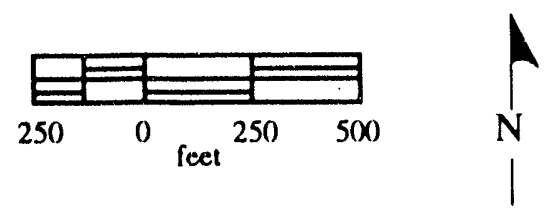

FIGURE 23 Location of Seismic Survey Lines at Beach Point

TABLE 7 Refraction Profiles at Beach Point

\begin{tabular}{lrcccc}
\hline \multicolumn{1}{c}{ Line ID } & $\begin{array}{c}\text { Geophone } \\
\text { Interval }(\mathrm{m})\end{array}$ & $\begin{array}{c}\text { No. of } \\
\text { Spreads }\end{array}$ & $\begin{array}{c}\text { Total Spread } \\
\text { Length }(\mathrm{m})\end{array}$ & $\begin{array}{c}\text { Longest Shot- } \\
\text { Receiver Dist. }\end{array}$ & No. of Shots \\
\hline BCHNS-5M & 5 & 4 & 295 & 145 & 13 \\
BCHNS-10M & 10 & 2 & 350 & 450 & 12 \\
BCHEW-5M & 5 & 3 & 235 & 120 & 12 \\
BCHEW-10M & 10 & 1 & 230 & 495 & 7 \\
\hline
\end{tabular}

a Multiple spreads overlap by 12 geophones. A single spread consists of 24 geophones. 


\section{BCHEW-10M}

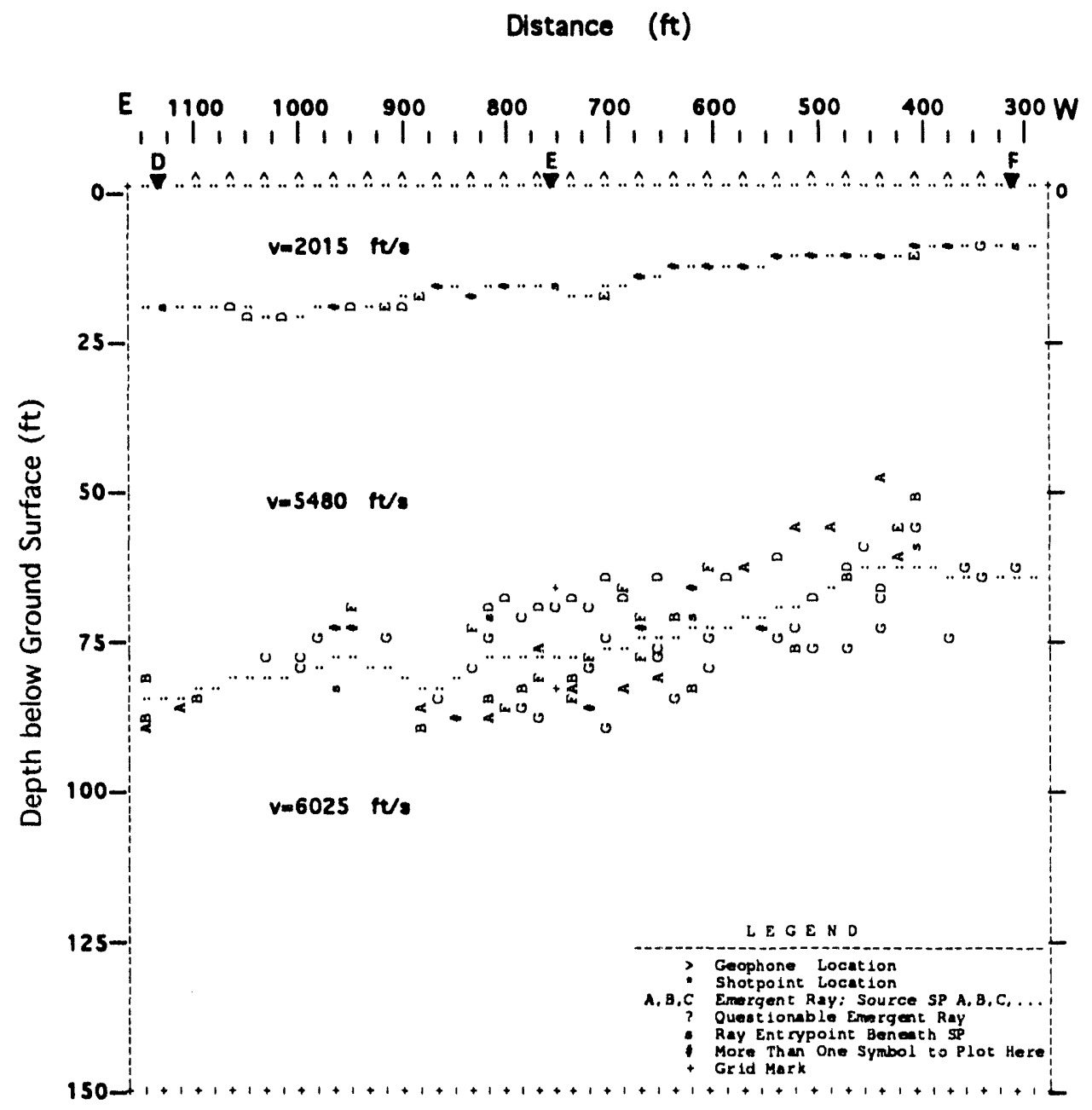

FIGURE 24 Seismic Refraction Interpretation along the Access Road to Beach Point 


\section{BCHNS-5M}

\section{Distance ( $f t)$}

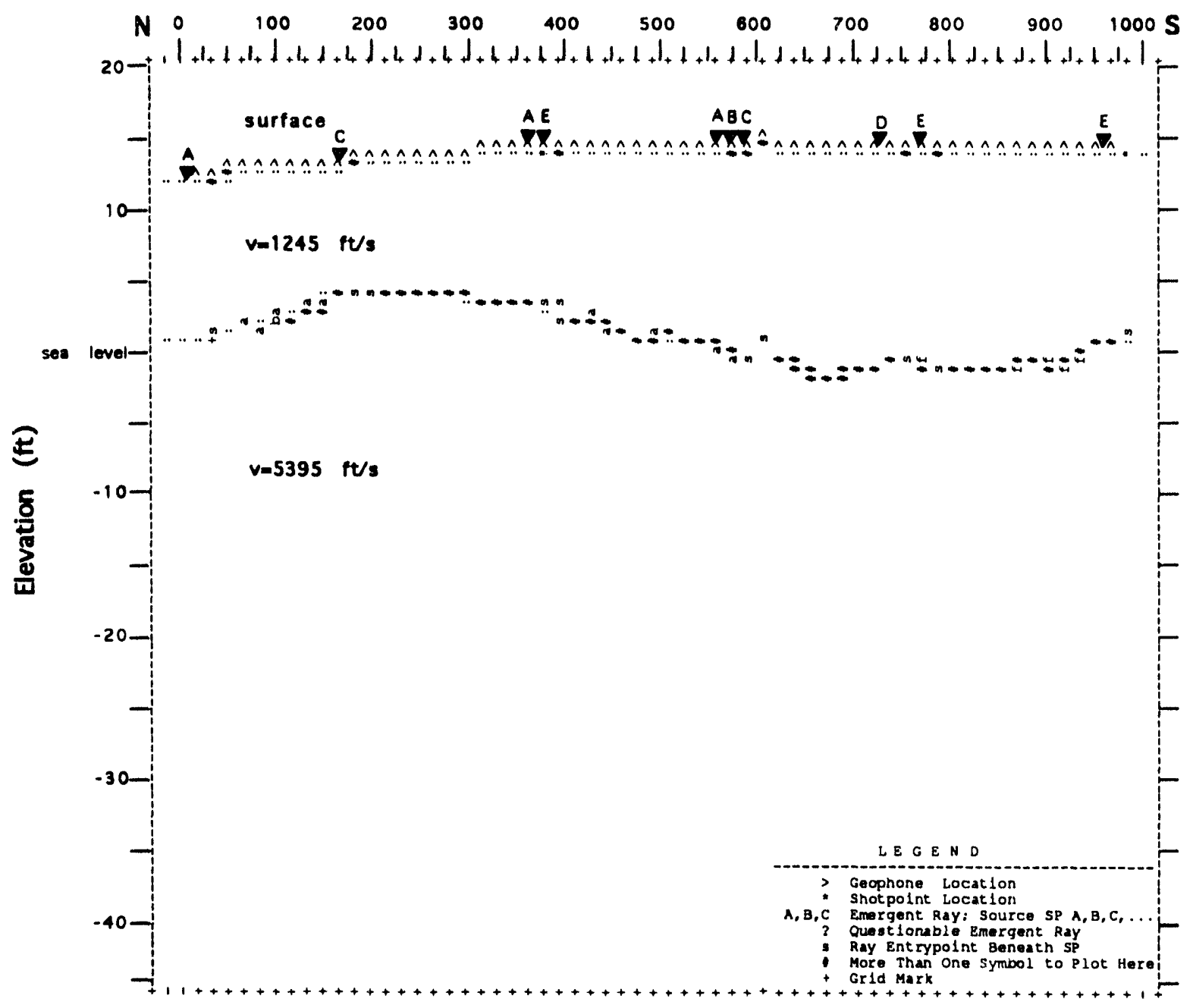

FIGURE 25 Seismic Refraction Interpretation along the Beach Point Base Line 


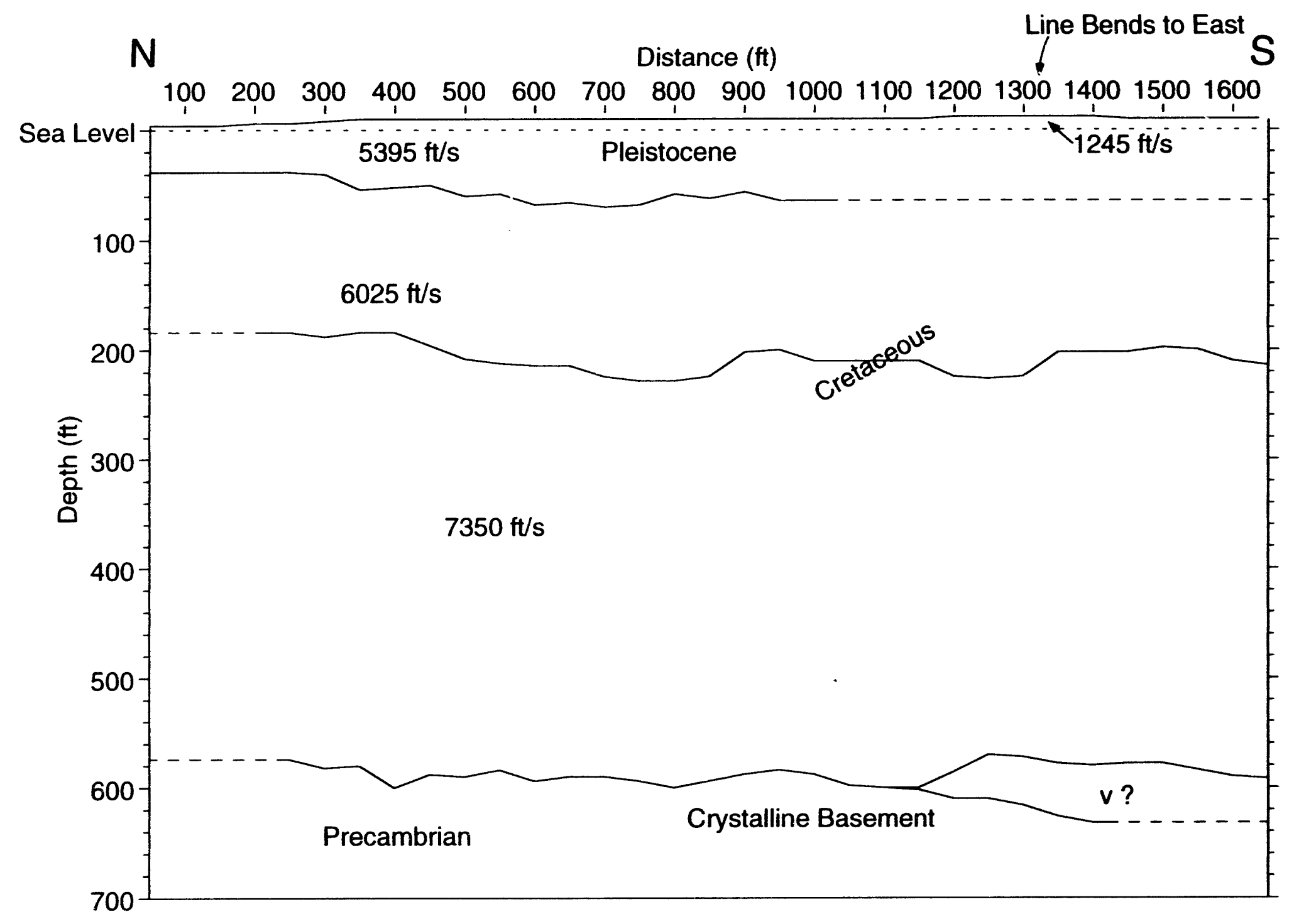

FIGURE 26 Facies below Beach Point Peninsula on the Basis of Seismic Data 


\subsection{Seismic Reflection Profiling}

A total of 11 seismic reflection profiles, two deep and nine shallow ones comprising 5,340 linear feet, were recorded at Beach Point Peninsula and along the access road to Beach Point. Reflection profiles are divided into two data sets on the basis of depth of interest. Shallow profiles map the sedimentary section from the water table down to the P-K unconformity at the base of the surficial aquifer. Deep reflection profiles image sediments from the P-K unconformity to the Precambrian crystalline basement.

Eight shallow reflection profiles were recorded on Beach Point Peninsula and one on Beach Point Road (see Figure 23). One NW-SE profile was located between wells CC-33 and CC-34. Background noise within a 100-ft radius of a pump in well CC-33 had an adverse effect on seismic data quality, although it was possible to map reflectors and to correlate reflectors with subsurface information from the lithologic and gamma-ray logs.

One deep profile was oriented N-S along the axis of the peninsula on the Base Line. A second deep profile was shot along Beach Point Road. The deep reflection profiles used a group interval of $2 \mathrm{~m}$ and had the shot point of fset $30 \mathrm{~m}$ from the end of the geophone array. The distance from shot to furthest detector was $249 \mathrm{ft}$. Table 8 shows reflection profiles at Beach Point and lists the shot-point geometries. (Note that some profiles were shot in feet and some in meters.) Stacked seismic sections of all reflection lines are included in Appendix C.

TABLE 8 Reflection Profiles at Beach Point

\begin{tabular}{llrlrr}
\hline & Type and & $\begin{array}{c}\text { Shot Point } \\
\text { and } \\
\text { Line ID } \\
\text { Orientation } \\
\text { Interval }\end{array}$ & Offset & No. of Shots & $\begin{array}{r}\text { CDP Line } \\
\text { Length (ft) }\end{array}$ \\
\hline BCHNS-DP & Deep NS & $30 \mathrm{~m}$ & $2 \mathrm{~m}$ & 240 & 1,605 \\
BCHEW-DP & Deep EW & $30 \mathrm{~m}$ & $2 \mathrm{~m}$ & 113 & 797 \\
BCHNSO00 & Shallow NS & $40 \mathrm{ft}$ & $3 \mathrm{ft}$ & 312 & 954 \\
BCHNS50A & Shallow NS & $10 \mathrm{~m}$ & $1 \mathrm{~m}$ & 72 & 252 \\
BCHNS50B & Shallow NS & $8 \mathrm{~m}$ & $1 \mathrm{~m}$ & 70 & 249 \\
BCHNS100 & Shallow NS & $5 \mathrm{~m}$ & $1 \mathrm{~m}$ & 190 & 644 \\
BCHEW1000 & Shallow EW & $42 \mathrm{ft}$ & $3 \mathrm{ft}$ & 31 & 98 \\
BCHEW650 & Shallow EW & $48 \mathrm{ft}$ & $3 \mathrm{ft}$ & 25 & 96 \\
BCHEW450 & Shallow EW & $34 \mathrm{ft}$ & $2 \mathrm{ft}$ & 42 & 100 \\
BCHEW-SH & Shallow EW & $10 \mathrm{~m}$ & $1 \mathrm{~m}$ & 132 & 453 \\
BCHXWELL & Shallow & $10 \mathrm{ft}$ & $1 \mathrm{ft}$ & 84 & 92 \\
\hline
\end{tabular}

a Line runs $\mathrm{N}$ from Borehole CC-34 to Borehole CC-33. 
The longest reflection lines provide coherent reflections down to the Precambrian crystalline basement ai $500-600 \mathrm{ft}$ depth. Shorter lines, such as the line between wells CC-33 and CC-34 (BCHXWELL seismic line), produced coherent reflections as shallow as $10 \mathrm{ft}$ but predominantly in the $40-70 \mathrm{ft}$ range.

\subsubsection{Shallow Roflection Analysis}

Stacked seismic profiles for shallow reflection lines are processed from variable-fold (6-12 fold) data (Appendix C). Prior to stacking, each section was bandpass-filtered (generally 100-300 Hz); edited to remove early refracted arrivals, surface waves, and air waves; CDPsorted; and corrected for normal moveout. Normal moveout velocities used for correcting the data were obtained from average velocities (calculated from refracted arrivals) and from normal moveout analysis of the CDP-sorted but unstacked reflection data. Depth estimates, as labeled along the right vertical axis for each section, were obtained from normal moveout velocities and refraction data and were averaged to a one-dimensional velocity-depth model for Beach Point. Note that in Figures C. 1 to C.6 (Appendix C) the depth scale is nonlinear because of increasing velocities with depth. A discussion of profile reflection detail is contained in Appendix C.

Reflectors are correlated with gamma-ray logs in wells CC-33 and CC-34 (see Figure 7). A continuous reflector at about $30-40 \mathrm{~ms}$ is observed on all sections, corresponding to a depth of about 40-70 ft. An interpretation of reflection data on the Base Line is shown in Figure 26. Depths to reflectors approximate those expected down to the base of the surficial aquifer at the P-K unconformity. A map of the unconformity constructed from reflection times is shown in Figure 27. The configuration of the surface does not appear to be associated with sediments dipping uniformly to the southeast, but rather to an erosional surface more representative of an unconformity. This interpretation suggests an early Pleistocene age for this reflector. The reflector deepens to at least $70 \mathrm{ft}$ below sea level along the baseline between about $600 \mathrm{~S}-850 \mathrm{~S}$.

\subsubsection{Deop Roflection Analysis}

Deep reflection profile BCHEW-DP was recorded west-to-east along Beach Point Road and is shown in Appendix $C$ (Figure C.2). The profile includes nearly the entire line occupied by shallow profile BCHEW-SH (Figure C.3, Appendix C). The location of the shallow line is indicated by the arrows on the top of Figure C.2. The shallowest reflectors imaged by this seismic section range in two-way travel time from 40 to $50 \mathrm{~ms}$, which is approximately $82-107 \mathrm{ft}$ in depth. Continuous reflection events are observable to at least $180 \mathrm{~ms}$ for two-way travel time, corresponding to depths of $500 \mathrm{ft}$ (see Figure 28).

The depth scale for the deep lines is obtained from average velocities calculated for velocities of refracted arrivals and from normal moveout analysis of the CDP-sorted but 


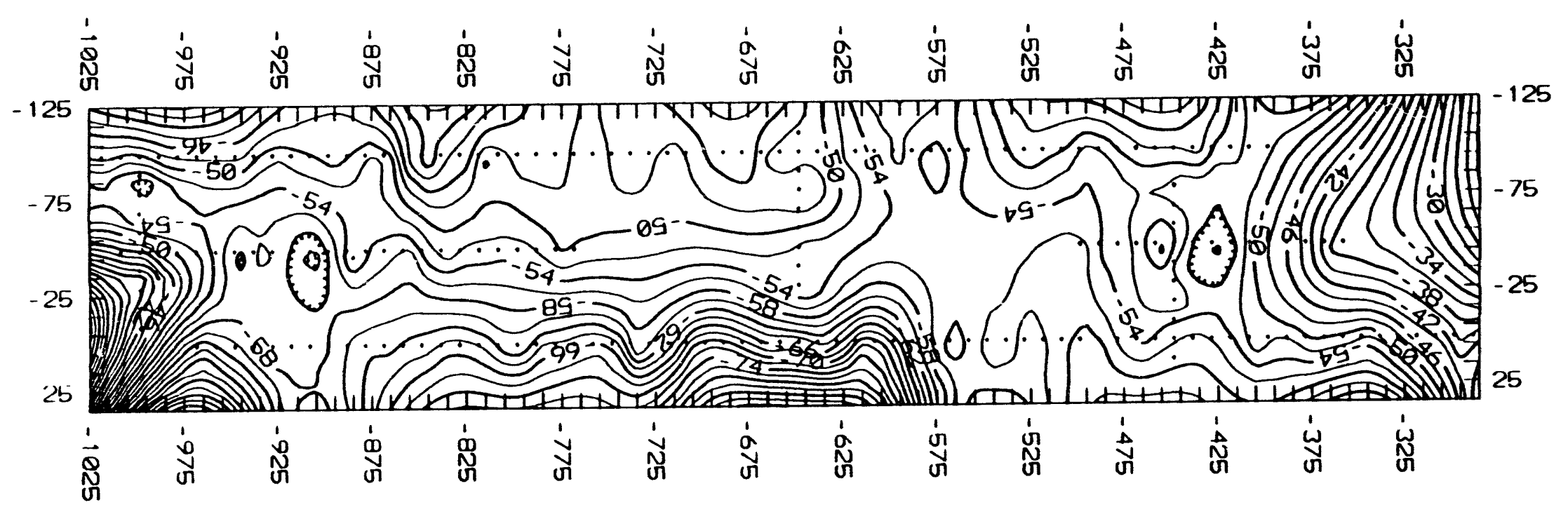

Elevation of P-K Unconformity ( $f t$ ) (Cnst Stk V $=4210 \mathrm{ft} / \mathrm{s}$ )

FIGURE 27 Configuration of the Pleistocene-Age Unconformity Developed on Cretaceous Coastal Plain Sediments on the Basis of High-Resolution Seismic Reflection Data 


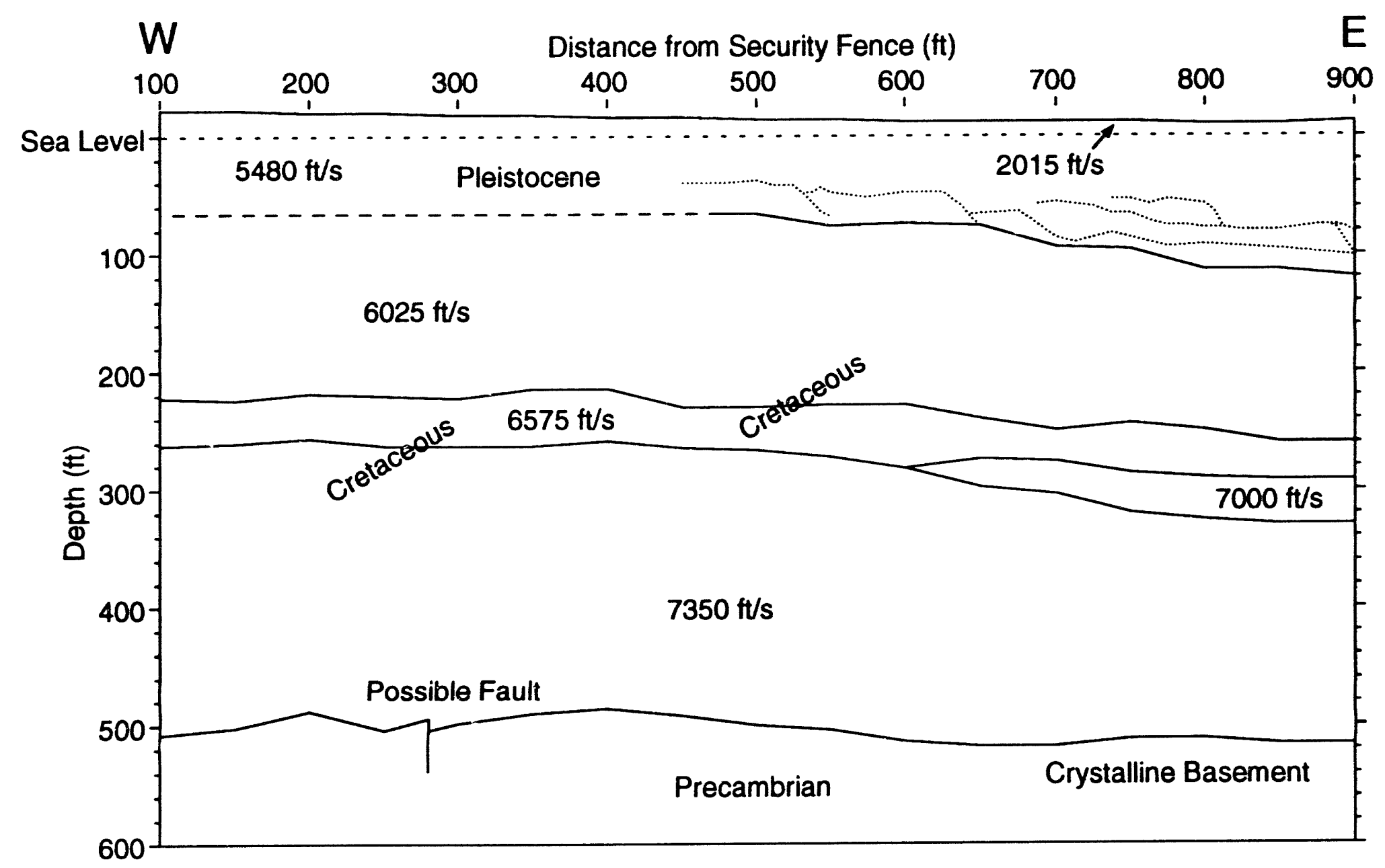

FIGURE 28 Facies below Beach Point Road on the Basis of Seismic Data 
unstacked reflection data. However, depth estimates below approximately $150 \mathrm{ft}$ are poorly constrained because of the uncertainty of interval and stacking velocities. Therefore, the depth estimates listed for relatively deep features should be regarded with caution.

Preliminary interpretation suggests at least two distinct seismic facies on profile BCHEW-DP. The shallowest seismic facies is characterized by high-amplitude reflection events that are horizontally continuous for $165 \mathrm{ft}$ or more. The base of this facies is at a 105-ms twoway travel time at CDP 500, shallows to 95-ms two-way travel time at CDP 400 , and becomes obscured by poorer-quality data on the western part of the profile. The second seismic facies underlies the previous unit and is marked by lower-amplitude reflection events that are also horizontally continuous. These facies probably represent Cretaceous strata.

The general character of the deep reflectors reveals some relief. A down-shift of about $18 \mathrm{~ms}$ in the deep reflector at a horizontal distance of about $295 \mathrm{ft}$ in the W-E section (Figure C.2, Appendix C) suggests the presence of a fault with a drop of about 50-80 ft in the Cretaceous rocks. An up-shift of about the same amount at a hcrizontal distance of about $1,300 \mathrm{ft}$ in the N-S section (Figure C.1, Appendix C) may also be a fault. However, lower data coherency and the presence of a bend in the line at a horizontal distance of about $1,348 \mathrm{ft}$ make the cause of the shift in the N-S line less certain. A deep, semicontinuous reflector is visible in both sections in the two-way travel-time range of $170-210 \mathrm{~ms}$. The most continuous of these reflectors is believed to correspond to the second unconformity, separating Atlantic Coastal Plain sediments and the Precambrian crystalline basement. 


\section{Discussion}

\subsection{Hydrogeologic Framework}

Well logs and outcrops provide the basic subsurface geologic control for this study. Geophysical applications, including ground penetrating radar, EM31, EM34, electrical resistivity, seismic refraction, and seismic reflection, complement the basic geologic studies and define the hydrogeological and hydrogeochemical framework.

GPR imaging provides a detailed display of reflectors to a depth of $30 \mathrm{ft}$. The reflectors represent a depositional contact separating surface clays from underlying sands and a thin gravel lens seen in outcrops. Where a prominent reflector rises close to the surface, resistivity increases (Figure 22), indicating that the lithologic unit below the reflector is a sand. A good correlation between GPR imaging and electrical response is noted at $800 \mathrm{~S}-150 \mathrm{~W}$, where a strong reflector approaches the surface in an area of low conductivity values, suggesting a thinning clay overburden. The good correlation indicates that EM31 data can be used as a first approximation to locations where the surficial clays are thin. This observation is important where contaminants have been introduced as surface spills, in trenches, or in unlined pits.

Seismic imaging gives detail on the facies beneath the area, as shown in Figures 26 and 28. Seismic imaging on Beach Point Road provides excellent detail on the geological development of the surficial aquifer. A succession of fluvial terraces, declining in elevation toward the east, are representative of episodic and constructive channel filling of alluvium during Pleistocene-age sea level rise (Figure 28). The terraces rest upon a surface ranging in elevation from 60 to $120 \mathrm{ft}$ below sea level. The surface is probably an erosional unconformity of Pleistocene age that formed during low sea level stands. Channels cut into the surface have local relief of 20 to $30 \mathrm{ft}$, with thalwegs sloping to the southeast toward Bush River (Figure 27).

Easterly dipping reflectors, below the P-K unconformity (Figure 28), mark undifferentiated depositional sequences of Cretaceous-age, Atlantic Coastal Plain strata. The sequences of easterly dipping reflectors contain wedges of strata thickening to the south and east. On the basis of reflection data alone, and given the lack of deep borehole control, a positive identification of the Canal Creek aquifer cannot be made. The dipping Cretaceous strata rest on a faulted crystalline basement ranging in depth from $500 \mathrm{ft}$ on the Beach Point Road reflection profile (Figure 28) to $600 \mathrm{ft}$ on the south end of the Beach Point Peninsula profile (Figure 26).

\subsection{Possible Point Sources of Contaminants}

Evidence of the disturbances of near-surface strata is clearly displayed by magnetic and electrical conductivity maps of Beach Point Peninsula (Figures 29 and 30). Although the access 


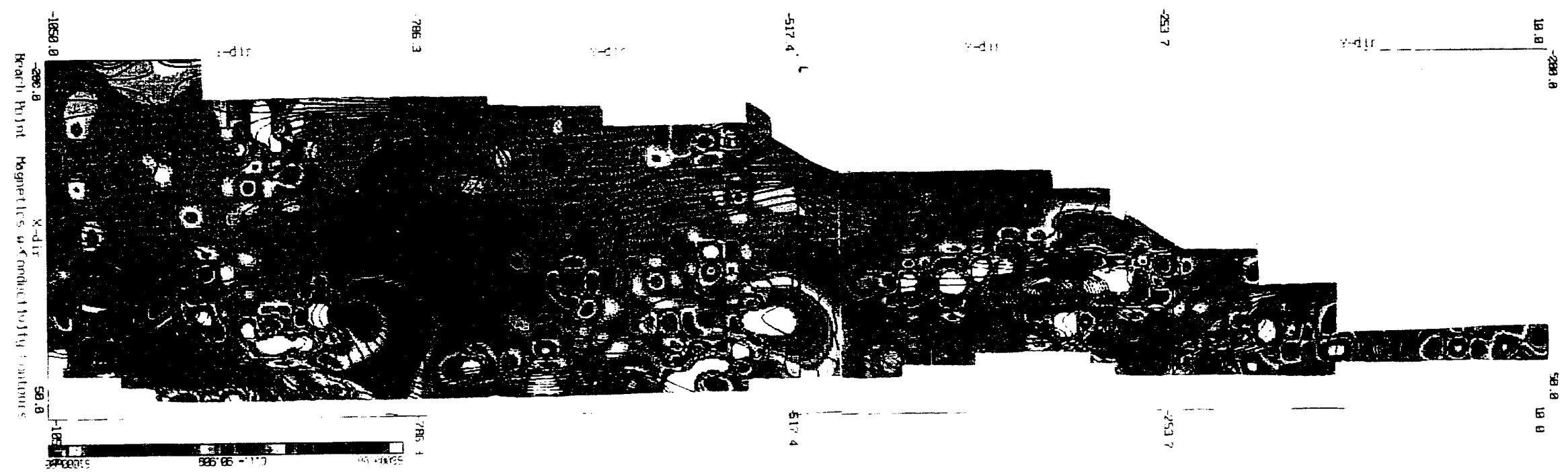

FIGURE 29 Magnetic Map of Beach Point with Conductivity Overlay

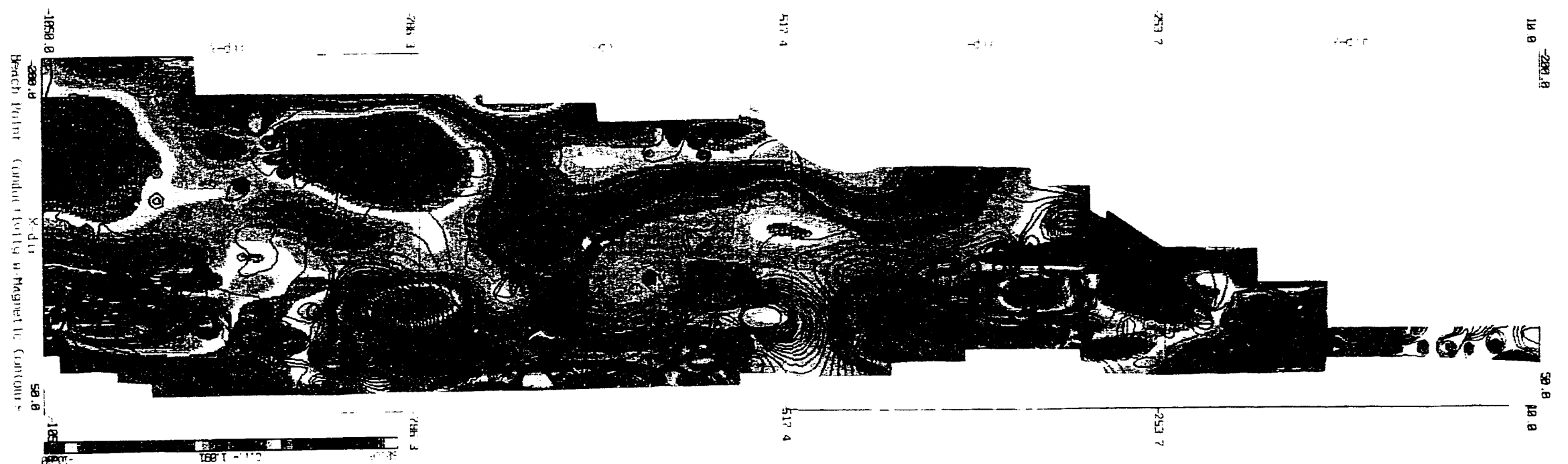

FIGURE 30 Conductivity Map of Beach Point with Magnetic Overlay 
road to Beach Point is the dominant geophysical feature, additional point sources of magnetic, conductive, and resistive areas appear as subcircular or elliptical images. Unidentified anomalies that should receive further investigation because they could be interpreted as being caused by buried tanks, pipes, pits, or trenches are listed in Table 4 (Section 2.2) and in the discussion of conductivities (Section 3.1).

The area most likely containing point sources of contaminants is in proximity to the concrete slabs located between the coordinates $600 \mathrm{~S}$ to $520 \mathrm{~S}$ and $10 \mathrm{~W}$ to $100 \mathrm{~W}$.

Specific coordinates of magnetic anomaly centers are:

$530 S-15 \mathrm{~W}$
$530 \mathrm{~S}-30 \mathrm{~W}$
$560 \mathrm{~S}-75 \mathrm{~W}$
$580 \mathrm{~S}-60 \mathrm{~W}$

Coordinates for conductivity anomaly centers are:

580 s to $590 \mathrm{~S}-25 \mathrm{~W}$ (good conductor)

$520 \mathrm{~S}$ to $540 \mathrm{~S}-85 \mathrm{~W}$ (circular poor conductor)

The positive magnetic anomalies and highly conductive areas may indicate metal tanks or pipes, whereas the poorly conductive areas may indicate a burial pit or trench. (It should also be pointed out that trenching and mounds were observed on the surface at $910 \mathrm{~S}-110 \mathrm{~W}, 420 \mathrm{~S}$ to $500 \mathrm{~S}-90 \mathrm{~W}$.) A circular poor conductor is located at the southern extension of the trenching observed at the surface northwest of the concrete slab. The high resistivities may indicate the surficial point sources for possible contaminants imaged in electrical depth sounding. (This is discussed in the next section).

\subsection{Possible Contaminant Plume}

A distance-vs.-depth cross section, displaying electrical resistivity along the Base Line, is illustrated in Figure 14. Conversion of all electrical data, including conductivity and resistivity, into one resistivity data set indicates that the surficial aquifer is a relatively low-resistivity lens sandwiched between higher resistivities above and below. The low-resistivity lens is noncontinuous where higher resistivities extend through the lens at approximately $650 \mathrm{~S}$.

The unusual appearance of the anomaly, its lack of continuity in the flat-lying surficial aquifer, and the absence of structure, as observed on the Base Line seismic profile, suggest the presence of saltwater intrusion from tidal action in Bush River. A dense, nonaqueous-phase liquid, such as 1,1,2,2-tetrachloroethane $\left(\mathrm{C}_{2} \mathrm{H}_{2} \mathrm{Cl}_{4}\right)$ observed in well CC-33 at Beach Point, 
could produce the noncontinuous effect. It has been found that traces of contaminant can drastically alter electrical current flow through saturated media. Introduction of a contaminant into the subsurface may have been through point-source locations outlined by nonconducting areas 527S-85W and 520S and 530S, described in Section 3.1. 


\section{Summary and Conclusions}

Buildings located at the Beach Point test site were used for small-scale chemical agent storage ( $G$ agents), laboratories, storehouses, offices, and machine shops. Several of these structures were built with sewer systems that discharged directly to Kings Creek and Bush River. A few of the buildings were constructed with septic systems, which allowed effluent to percolate into the subsurface (Jacobs Engineering Group, Inc., 1992).

A series of geophysical surveys, supported by drilling and outcrop mapping, has defined the hydrogeologic framework, possible point sources of contaminants, and a possible contaminant plume beneath Beach Point Peninsula. Some of the point sources are believed to be associated with activities in and adjacent to the building that rested on the large concrete slab centered at 550S-50W. The slab served as the foundation for a mobile clothing impregnation plant. Wastes were discharged into unlined pits and were allowed to percolate into the subsurface. Some of the wastes generated from rocket fuel fire suppression tests were discharged directly on the ground surface and either ran off into the streams or percolated into the subsurface. Areas where discharge occurred and where pits were dug resulted in anomalous zones on resistivity and conductivity maps.

Specific conclusions are as follows:

1. The general hydrogeologic framework in the Chesapeake Bay area beneath Beach Point has been described. Fine sands, silts, and clays, 40 to $80 \mathrm{ft}$ thick, rest on the $\mathrm{P}-\mathrm{K}$ unconformity incised onto sediments of Cretaceous age.

2. Cretaceous sediment thicknesses ranging up to $500 \mathrm{ft}$ thick are observed from seismic reflection profiling. Gentle southeast dips are observed and conform to published descriptions of Cretaceous structure.

3. The Precambrian crystalline basement lies at a depth of 500 to $600 \mathrm{ft}$ beneath the Beach Point Peninsula.

4. Possible point sources of contaminants are outlined by high-intensity, negative-conductivity anomalies. Some of the anomalies are located around a concrete slab that served as the foundation for a former clothing impregnation plant. Other anomalies are observed throughout the site. Interactions between some volatile organic compounds and clays are known to increase the electrical resistivity of clays.

5. Contaminant pathways from point, surficial sources to the base of the surficial aquifer may be outlined by a high-resistivity anomaly that penetrates the surficial aquifer. The contaminants may be DNAPLs, consisting of volatile organic compounds, resting on the Pleistocene-age unconformity defined by the reflection profile (see Conclusion 1). DNAPLs could migrate along the topographic gradient of the erosional contact. 


\section{References}

Barker, R.D., 1981, "The Offset System of Electrical Resistivity Sounding and its Use with a Multicore Cable," Geophysical Prospecting 29:128-143.

Bennett, R.R., and R.R. Meyer, 1952, "Geology and Ground-Water Resources of the Baltimore Area," Maryland Department of Geology, Mines and Water Resources, Bulletin 4.

Burton, D.T., 1993, "Biotoxicity Assessment of Groundwater, Chemistry of Beach Point Groundwater, Well 33B," personal communication.

Cline, J.J., W.J. Delfine, and D.K. Cooper, 1986; "Hydrolysis of 1,1,1-Trichloroethene: Formation of 1,1-Dichloroethene," in Proceedings of Petroleum Hydrocarbons and Organic Chemicals in Ground Water: Prevention, Detection and Restoration, National Water Well Association.

Dingmen, R.J., H.F. Ferguson, and R.O. Martin, 1956, "The Water Resources of Baltimore and Harford Counties," Maryland Department of Geology, Mines and Water Resources, Bulletin 17.

EAI Corporation, 1989, "Historical Records Search and Site Survey of Edgewood Area Buildings: EAI Corporation, Abingdon, Maryland," prepared for U.S. Army Chemical Research, Development, and Engineering Center, Contract No. DAAA15-87-D-0021, Task 021.

Hughes, W.B., 1993, "Hydrogeology and Soil-Gas Analyses at J-Field, Aberdeen Proving Ground, Maryland," U.S. Geological Survey, Water Resources Investigations Report, prepared in cooperation with the U.S. Army, Aberdeen Proving Ground Support Activity, Environmental Management Division, Towson, Md.

Hughes, W.B., 1991, "Application of Marine Seismic Profiling to a Groundwater Contamination Study," Aberdeen Proving Ground, Md., Ground Water Monitoring Review 11(1):97-102.

Jacobs Engineering Group, Inc., 1992, "Focused Feasibility Study Draft Field Sampling Plan; Beach Point Test Site Aberdeen Proving Ground-Edgewood Area, Maryland," Washington Operations.

Lorah, M.M., and Clark, J.S., in preparation, Contamination of Ground Water, Surface Water, and Soil and Evaluation of Selected Pumpage Scenarios in the Canal Creek Area of Aberdeen Proving Ground, Maryland, U.S. Geological Survey Open-File report 92. 
Lorah, M.M., and D.A. Vroblesky, 1989, Inorganic and Organic Ground-Water Chemistry in the Canal Creek Area of Aberdeen Proving Ground, Maryland, U.S. Geological Survey WaterResources Investigations report 89-4022.

McGinnis, L.D., et al., 1992a, Interim Progress Report - Geophysics: Building E5440 Decommissioning, Aberdeen Proving Ground, Argonne National Laboratory report ANL/ESD/TM-42.

McGinnis, L.D., et al., 1992b, Geophysical Study of the Building 103 Dump, Aberdeen Proving Ground, Argonne National Laboratory report ANL/ESD/TM-51.

McGinnis, M.G., et al., 1992a, Interim Progress Report - Geophysics: Building E5375 Decommissioning, Aberdeen Proving Ground, Argonne National Laboratory report ANL/ESD/TM-37.

McGinnis, M.G., et al., 1992b, Interim Progress Report - Geophysics: Decommissioning of Buildings E5974 and E5978, Aberdeen Proving Ground, Argonne National Laboratory report ANL/ESD/TM-47.

Miller, S.F., et al., 1992a, Interim Progress Report - Geophysics: Building E5476 Decommissioning, Aberdeen Proving Ground, Argonne National Laboratory report ANL/ESD/TM-43.

Miller, S.F., et al., 1992b, Interim Progress Report - Geophysics: Building E5190 Decommissioning, Aberdeen Proving Ground, Argonne National Laboratory report ANL/ESD/TM-33.

Nemeth, G., J.M. Murphy, and J.H. Zarzycki, 1983, Environmental Survey of the Edgewood Area of Aberdeen Proving Ground, Maryland, U.S. Army Toxic and Hazardous Materials Agency report DRXTH-AS-FR-82185.

Oliveros, J.P., and P. Gernhardt, 1989, Hydrogeologic Data for the Canal Creek Area, Aberdeen Proving Ground, Maryland, April 1986-March 1988, U.S. Geological Survey, Open-File report 89-387.

Oliveros, J.P., and D.A. Vroblesky, 1989, Hydrogeology of the Canal Creek Area, Aberdeen Proving Ground, Maryland, U.S. Geological Survey Water-Resources Investigations report 89-4021.

Southwick, D.L., J.P. Owens, and J. Edwards, Jr., 1969, The Geology of Harford County, Maryland, Maryland Geological Survey. 
Thompson, M.D., et al., 1992a, Interim Progress Report - Geophysics: Building E5282 Decommissioning, Aberdeen Proving Ground, Argonne National Laboratory report ANL/ESD/TM-36.

Thompson, M.D., et al., 1992b, Interim Progress Report - Geophysics: Building E5481 Decommissioning, Aberdeen Proving Ground, Argonne National Laboratory report ANL/ESD/TM-44. 
Appendix A:

Resistivity Depth Sounding Curves 
R150S; OW

\begin{tabular}{cccccc}
\hline$L \#$ & $\begin{array}{c}\text { Resistivity } \\
(\Omega \cdot m)\end{array}$ & $\begin{array}{c}\text { Thickness } \\
(\mathrm{m})\end{array}$ & $\begin{array}{c}\text { Elevation } \\
(\mathrm{m})\end{array}$ & $\begin{array}{c}\text { Long. Cond. } \\
(\mathrm{S})\end{array}$ & $\begin{array}{c}\text { Trans. Res. } \\
\left(\Omega \cdot \mathrm{m}^{2}\right)\end{array}$ \\
\hline & & & 4.00 & & \\
1 & 122.7 & 1.32 & 2.67 & 0.0107 & 162.3 \\
2 & 56.99 & 3.00 & -0.326 & 0.0526 & 171.1 \\
3 & 23.35 & 35.63 & -35.95 & 1.52 & 832.0 \\
4 & 8.99 & & & & \\
\hline
\end{tabular}

R450S; OW

\begin{tabular}{cccccc}
\hline$L \#$ & $\begin{array}{c}\text { Resistivity } \\
(\Omega \cdot m)\end{array}$ & $\begin{array}{c}\text { Thickness } \\
(\mathrm{m})\end{array}$ & $\begin{array}{c}\text { Elevation } \\
(\mathrm{m})\end{array}$ & $\begin{array}{c}\text { Long. Cond. } \\
(\mathrm{S})\end{array}$ & $\begin{array}{c}\text { Trans. Res. } \\
\left(\Omega \cdot \mathrm{m}^{2}\right)\end{array}$ \\
\hline & & & & & \\
1 & 111.2 & 0.433 & 3.00 & & \\
2 & 36.09 & 0.922 & 2.64 & 0.0255 & 38.24 \\
3 & 97.75 & 2.07 & 0.567 & 0.0212 & 202.9 \\
4 & 36.38 & 47.07 & -46.51 & 1.29 & $1,712.9$ \\
5 & 72.61 & & & & \\
\hline
\end{tabular}

R550S; OW

\begin{tabular}{lccccc}
\hline$L \#$ & $\begin{array}{c}\text { Resistivity } \\
(\Omega \cdot m)\end{array}$ & $\begin{array}{c}\text { Thickness } \\
(\mathrm{m})\end{array}$ & $\begin{array}{c}\text { Elevation } \\
(\mathrm{m})\end{array}$ & $\begin{array}{c}\text { Long. Cond. } \\
(\mathrm{S})\end{array}$ & $\begin{array}{c}\text { Trans. Res. } \\
\left(\Omega \cdot \mathrm{m}^{2}\right)\end{array}$ \\
\hline & & & & & \\
1 & 95.59 & 1.61 & 2.38 & 0.0169 & 154.8 \\
2 & 588.2 & 1.48 & 0.895 & 0.00252 & 873.6 \\
3 & 27.94 & 16.41 & -15.51 & 0.587 & 458.6 \\
4 & 55.08 & & & & \\
\hline
\end{tabular}



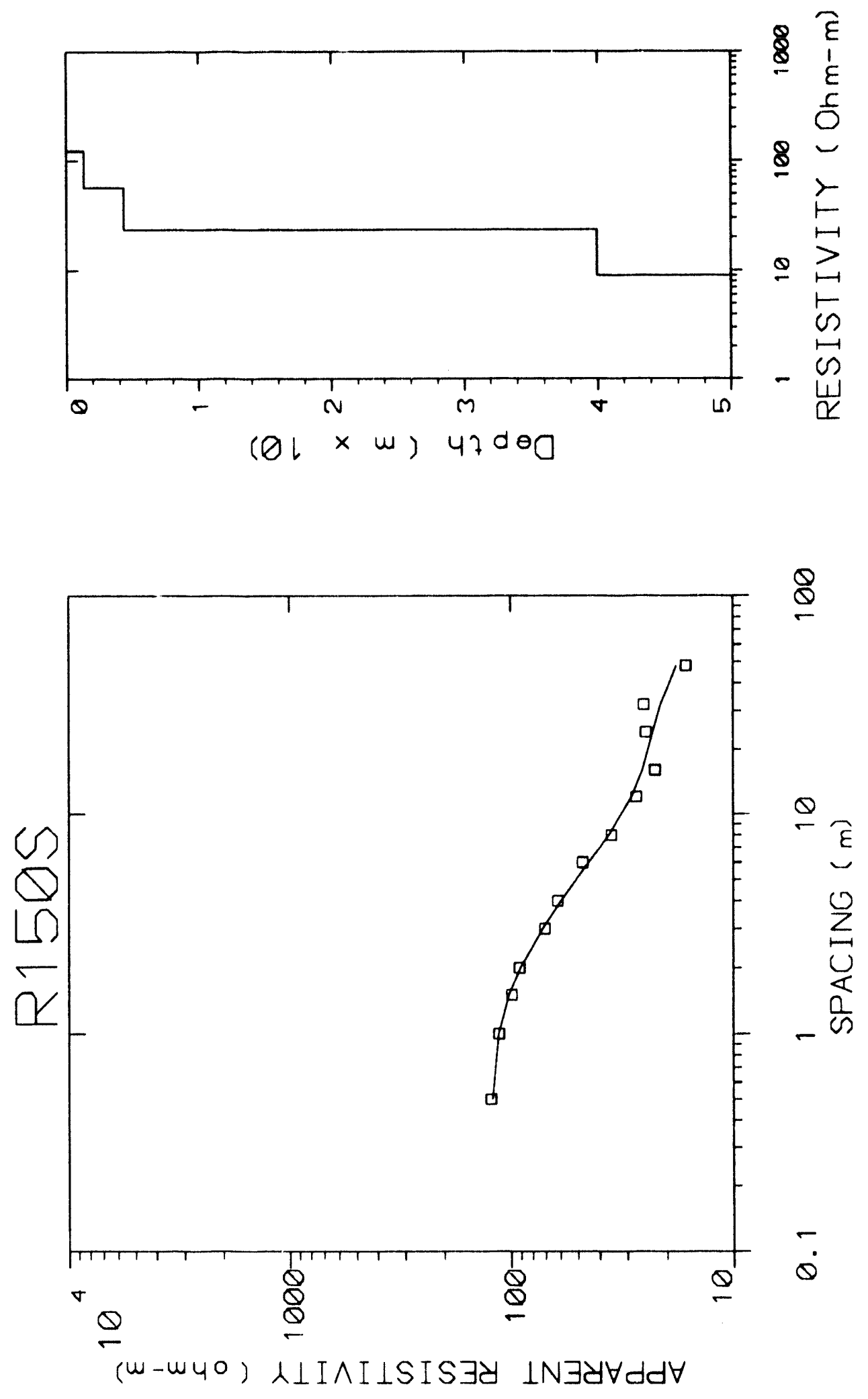

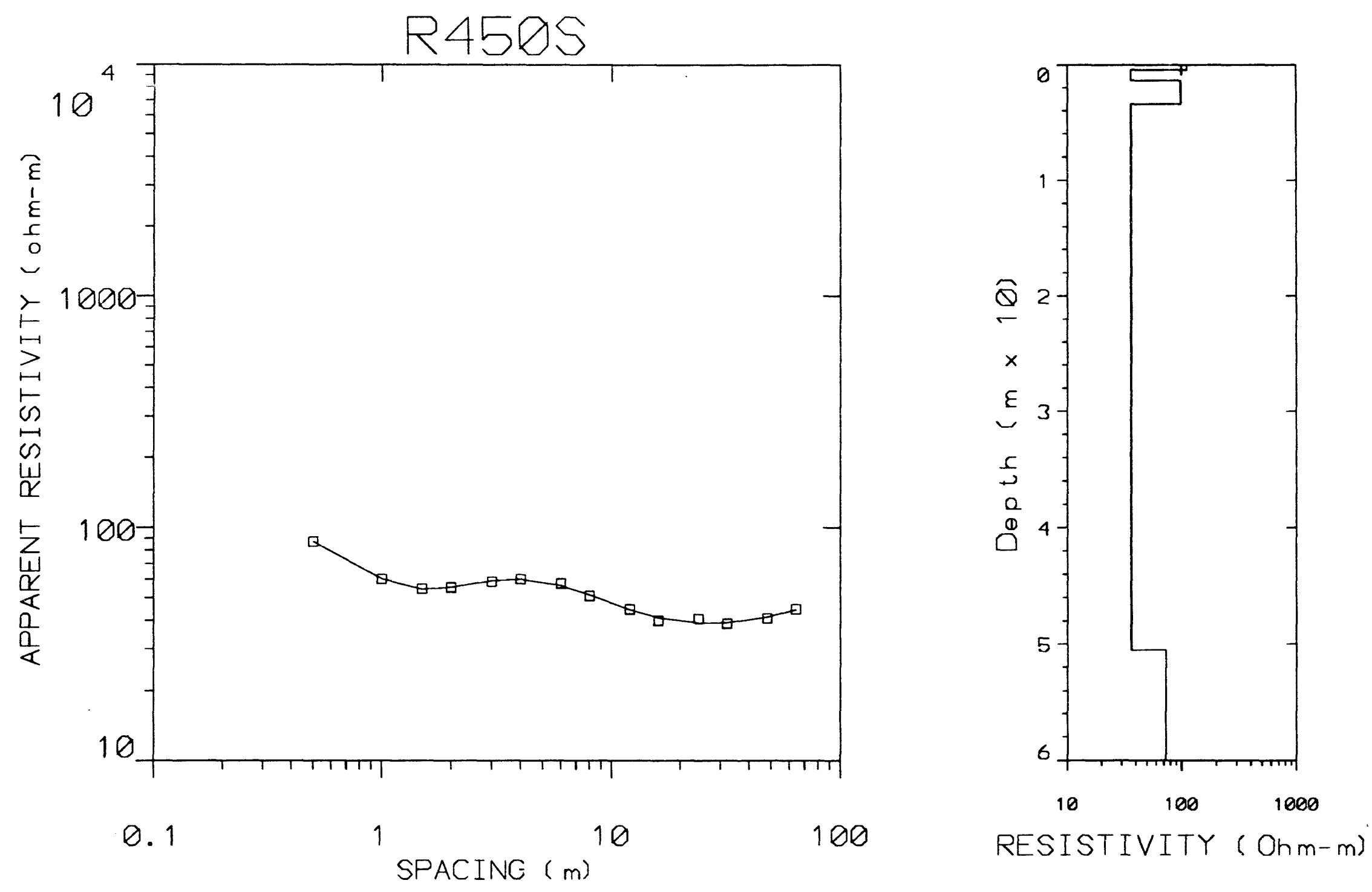

2 

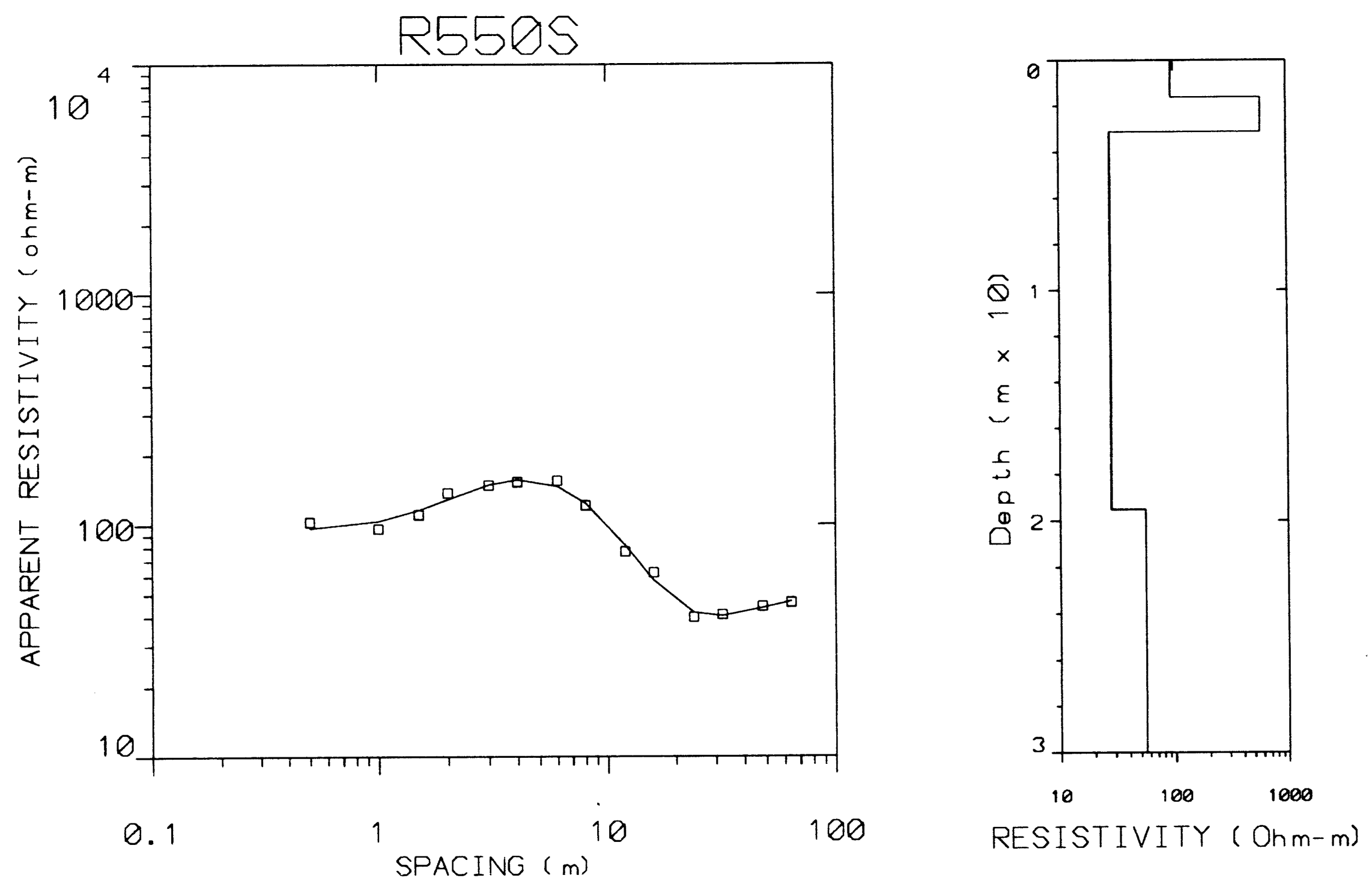

న 
R650S; OW

\begin{tabular}{cccccc}
\hline$L \#$ & $\begin{array}{c}\text { Resistivity } \\
(\Omega \cdot m)\end{array}$ & $\begin{array}{c}\text { Thickness } \\
(\mathrm{m})\end{array}$ & $\begin{array}{c}\text { Elevation } \\
(\mathrm{m})\end{array}$ & $\begin{array}{c}\text { Long. Cond. } \\
(\mathrm{S})\end{array}$ & $\begin{array}{c}\text { Trans. Res. } \\
\left(\Omega \cdot \mathrm{m}^{2}\right)\end{array}$ \\
\hline & & & & & \\
1 & 147.6 & 0.509 & 3.49 & 0.00345 & 75.25 \\
2 & 46.03 & 0.900 & 2.58 & 0.0195 & 41.45 \\
3 & 160.3 & 8.35 & -5.76 & 0.0521 & $1,340.0$ \\
4 & 19.33 & 30.36 & -36.13 & 1.57 & 587.2 \\
5 & 895.3 & & & & \\
\hline
\end{tabular}

R750S; OW

\begin{tabular}{cccccc}
\hline$L \#$ & $\begin{array}{c}\text { Resistivity } \\
(\Omega \cdot m)\end{array}$ & $\begin{array}{c}\text { Thickness } \\
(\mathrm{m})\end{array}$ & $\begin{array}{c}\text { Elevation } \\
(\mathrm{m})\end{array}$ & $\begin{array}{c}\text { Long. Cond. } \\
(\mathrm{S})\end{array}$ & $\begin{array}{c}\text { Trans. Res. } \\
\left(\Omega \cdot \mathrm{m}^{2}\right)\end{array}$ \\
\hline & & & & & \\
1 & 314.1 & 0.500 & 3.49 & 0.00159 & 157.1 \\
2 & 35.88 & 0.982 & 2.51 & 0.0273 & 35.26 \\
3 & 201.4 & 4.16 & -1.64 & 0.0206 & 839.3 \\
4 & 22.16 & 24.04 & -25.69 & 1.08 & 532.9 \\
5 & $3,056.4$ & & & & \\
\hline
\end{tabular}

R850S; OW

\begin{tabular}{lccccc}
\hline$L \#$ & $\begin{array}{c}\text { Resistivity } \\
(\Omega \cdot m)\end{array}$ & $\begin{array}{c}\text { Thickness } \\
(\mathrm{m})\end{array}$ & $\begin{array}{c}\text { Elevation } \\
(\mathrm{m})\end{array}$ & $\begin{array}{c}\text { Long. Cond. } \\
(\mathrm{S})\end{array}$ & $\begin{array}{c}\text { Trans. Res. } \\
\left(\Omega \cdot \mathrm{m}^{2}\right)\end{array}$ \\
\hline & & & & & \\
1 & 252.1 & 0.303 & 3.69 & 0.00120 & 76.55 \\
2 & 45.93 & 0.841 & 2.85 & 0.0183 & 38.66 \\
3 & 350.1 & 1.85 & 0.999 & 0.00530 & 649.8 \\
4 & 54.80 & & & & \\
\hline
\end{tabular}



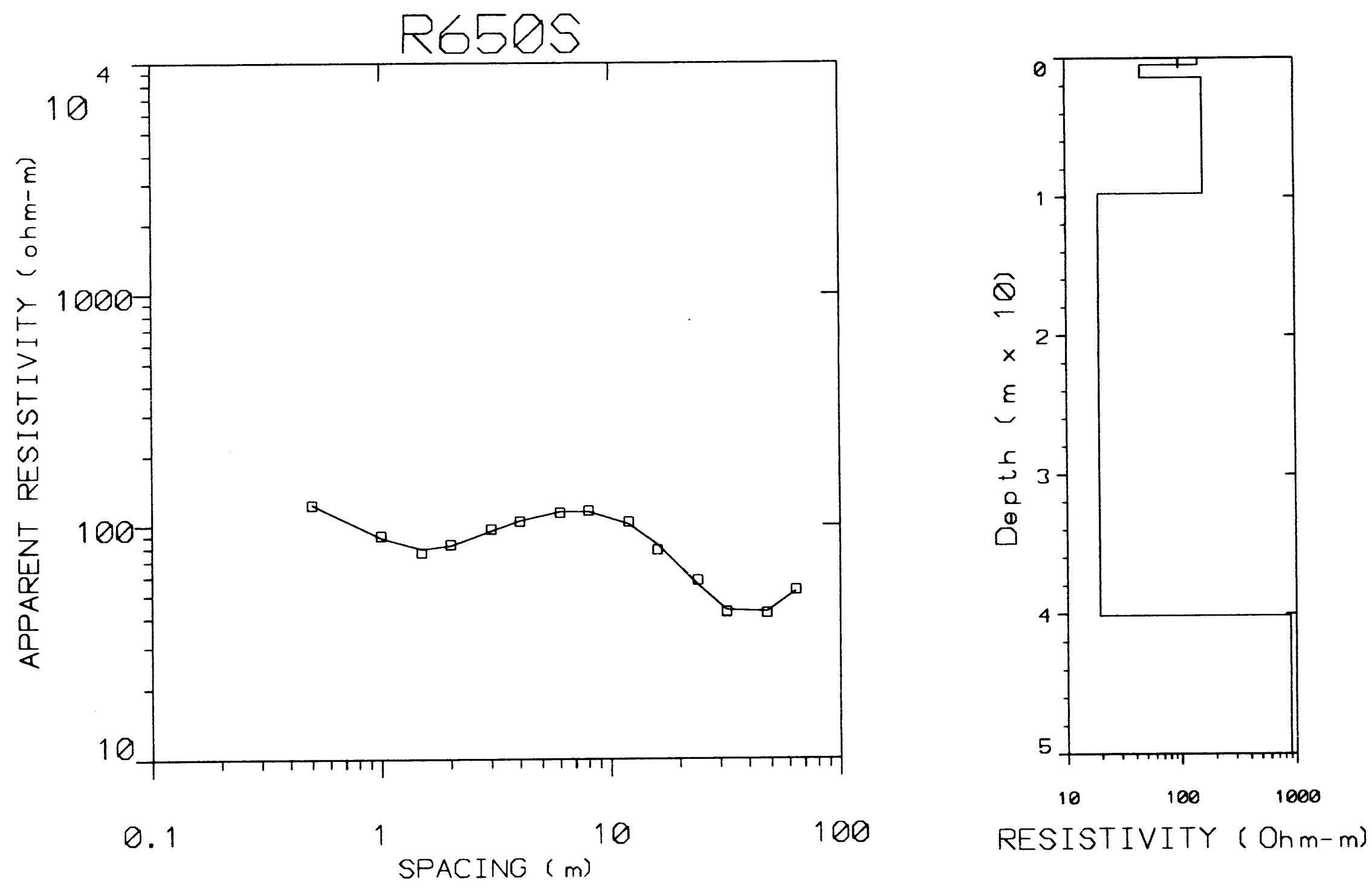

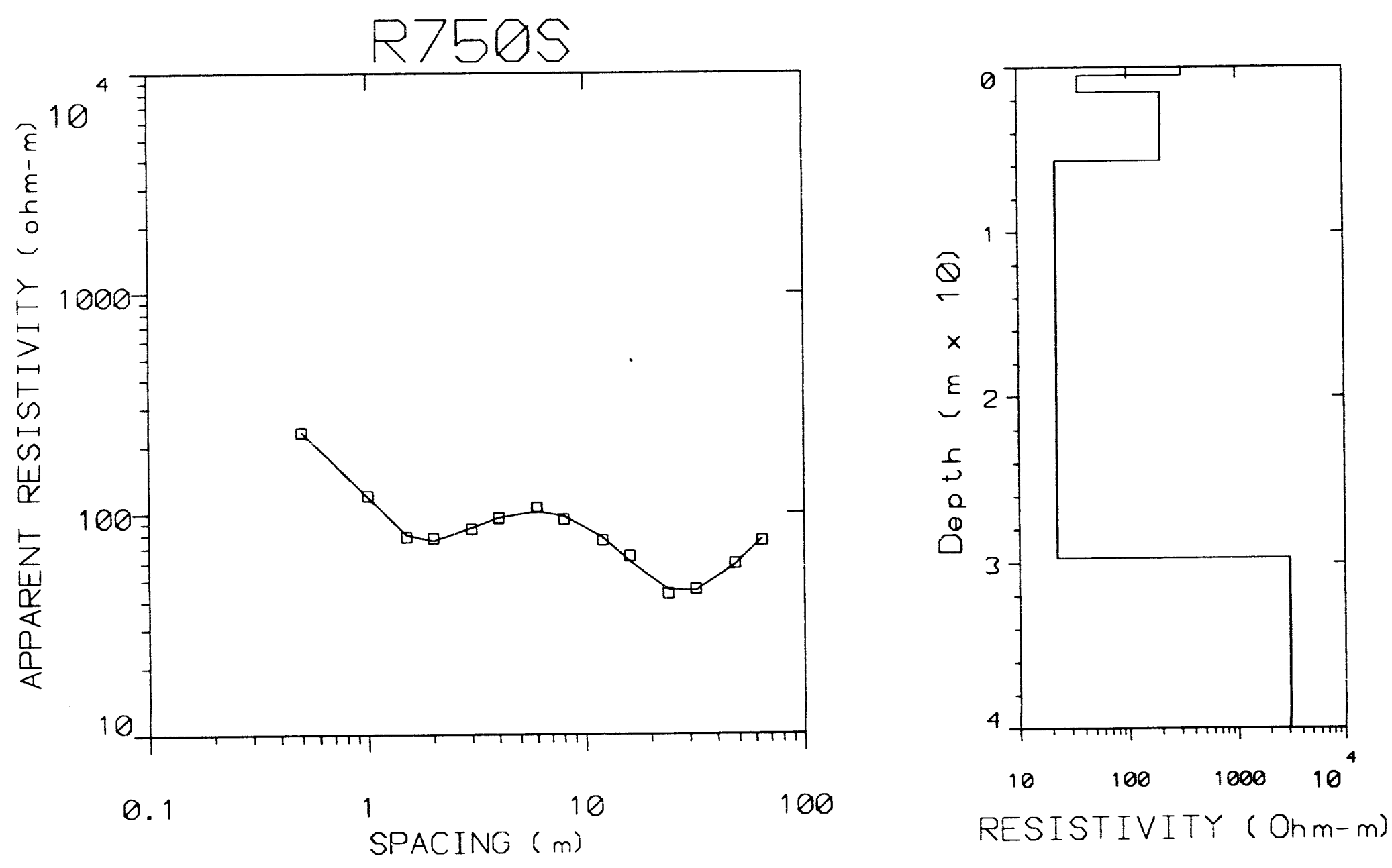

gn 

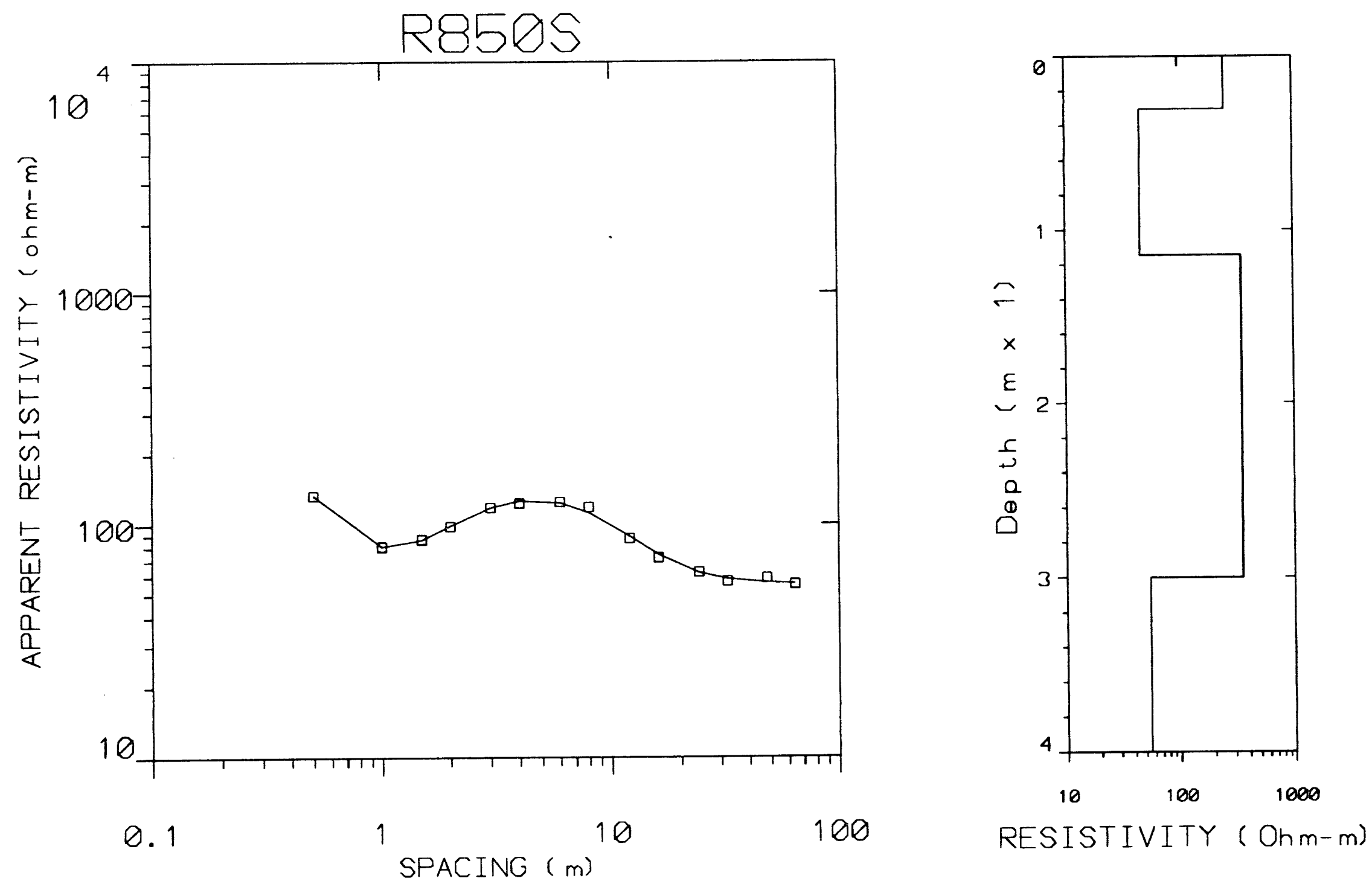

8 
R950S; OW

\begin{tabular}{cccccc}
\hline$L \#$ & $\begin{array}{c}\text { Resistivity } \\
(\Omega \cdot m)\end{array}$ & $\begin{array}{c}\text { Thickness } \\
(\mathrm{m})\end{array}$ & $\begin{array}{c}\text { Elevation } \\
(\mathrm{m})\end{array}$ & $\begin{array}{c}\text { Long. Cond. } \\
(\mathrm{S})\end{array}$ & $\begin{array}{c}\text { Trans. Res. } \\
\left(\Omega \cdot \mathrm{m}^{2}\right)\end{array}$ \\
\hline & & & & & \\
1 & 294.0 & 0.625 & 3.37 & 0.00213 & 183.9 \\
2 & 78.73 & 1.42 & 1.95 & 0.0180 & 111.9 \\
3 & 156.3 & 5.28 & -3.33 & 0.0338 & 826.5 \\
4 & 50.86 & 37.96 & -41.29 & 0.746 & $1,931.1$ \\
5 & 95.98 & & & & \\
\hline
\end{tabular}

R1050S; OW

\begin{tabular}{cccccc}
\hline$L \#$ & $\begin{array}{c}\text { Resistivity } \\
(\Omega \cdot m)\end{array}$ & $\begin{array}{c}\text { Thickness } \\
(\mathrm{m})\end{array}$ & $\begin{array}{c}\text { Elevation } \\
(\mathrm{m})\end{array}$ & $\begin{array}{c}\text { Long. Cond. } \\
(\mathrm{S})\end{array}$ & $\begin{array}{c}\text { Trans. Res. } \\
\left(\Omega \cdot \mathrm{m}^{2}\right)\end{array}$ \\
\hline & & & & & \\
1 & 302.6 & 0.814 & 3.18 & 0.00269 & 246.6 \\
2 & 112.0 & 8.66 & -5.48 & 0.0773 & 970.7 \\
3 & 30.06 & 12.00 & -17.48 & 0.399 & 361.0 \\
4 & 103.6 & & & & \\
\hline
\end{tabular}

R1400S; OW

\begin{tabular}{cccccc}
\hline$L \#$ & $\begin{array}{c}\text { Resistivity } \\
(\Omega \cdot m)\end{array}$ & $\begin{array}{c}\text { Thickness } \\
(\mathrm{m})\end{array}$ & $\begin{array}{c}\text { Elevation } \\
(\mathrm{m})\end{array}$ & $\begin{array}{c}\text { Long. Cond. } \\
(\mathrm{S})\end{array}$ & $\begin{array}{c}\text { Trans. Res. } \\
\left(\Omega \cdot \mathrm{m}^{2}\right)\end{array}$ \\
\hline & & & & & \\
1 & 47.61 & 0.785 & 3.21 & 0.0164 & 37.38 \\
2 & 37.80 & 1.98 & 1.23 & 0.0524 & 74.97 \\
3 & 0.771 & 1.86 & -0.635 & 2.41 & 1.44 \\
4 & $14,759.8$ & 83.23 & -83.86 & 0.00564 & $1.228 \mathrm{E}+06$ \\
5 & 177.2 & & & & \\
\hline
\end{tabular}



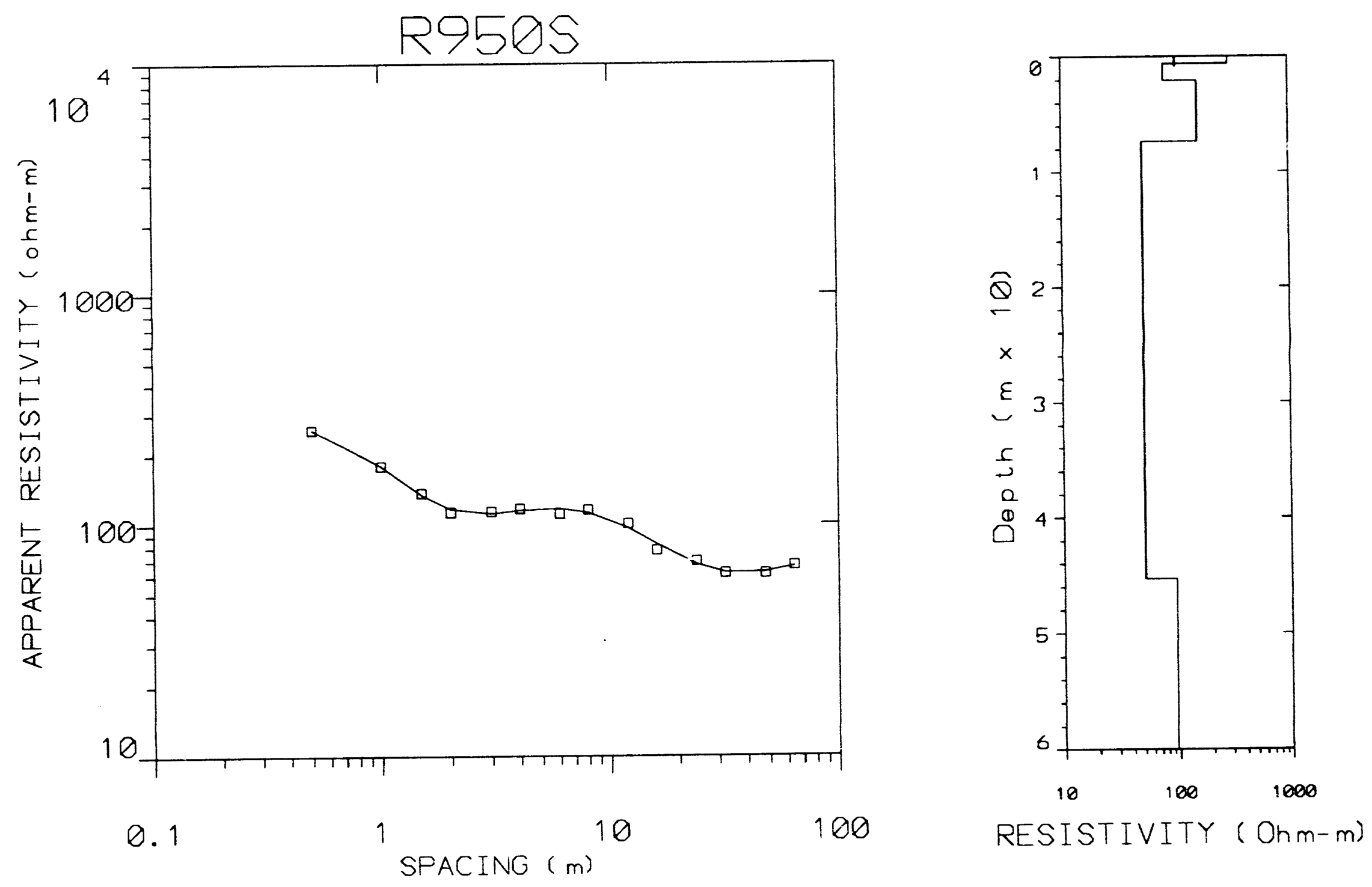

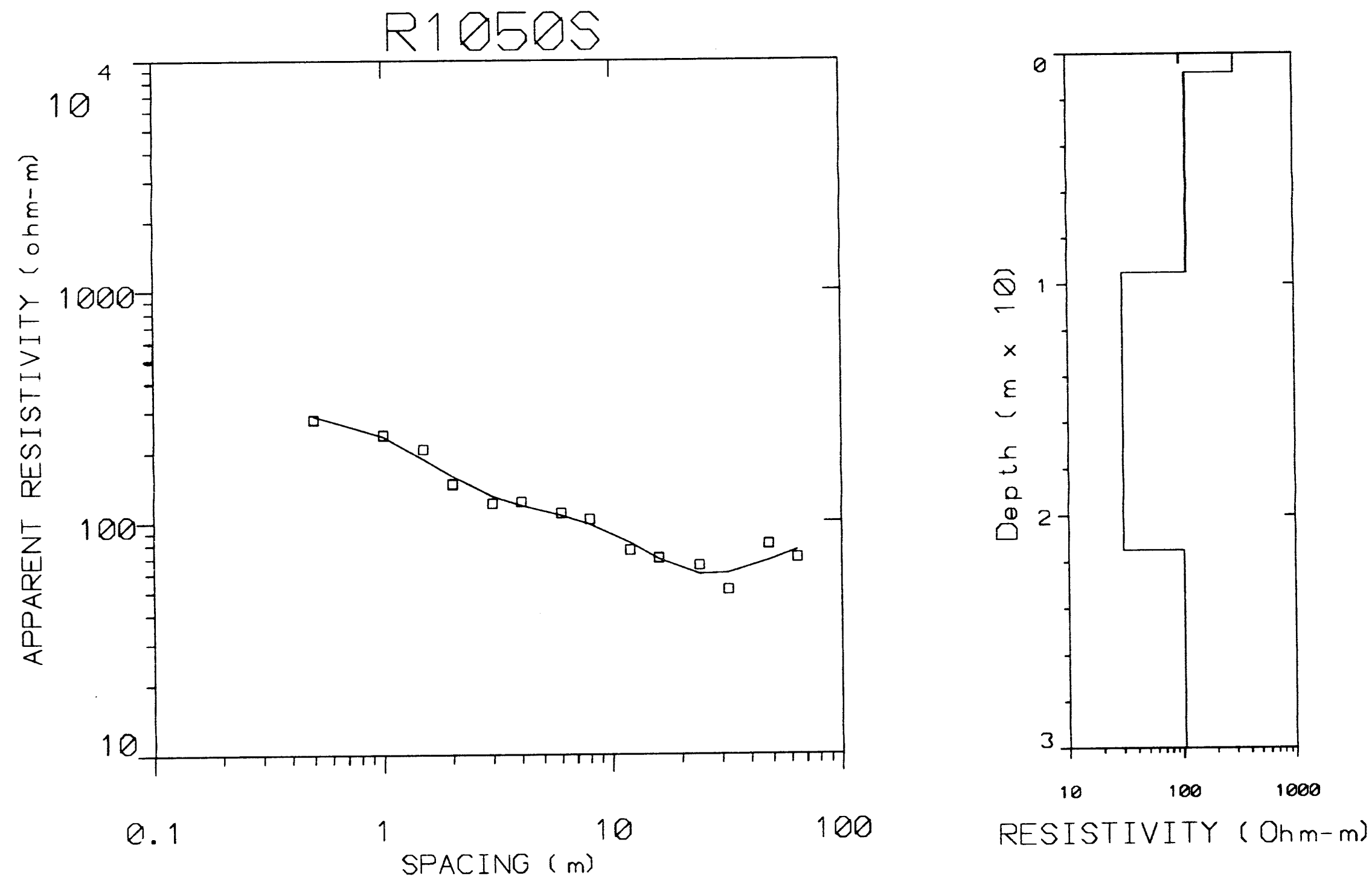


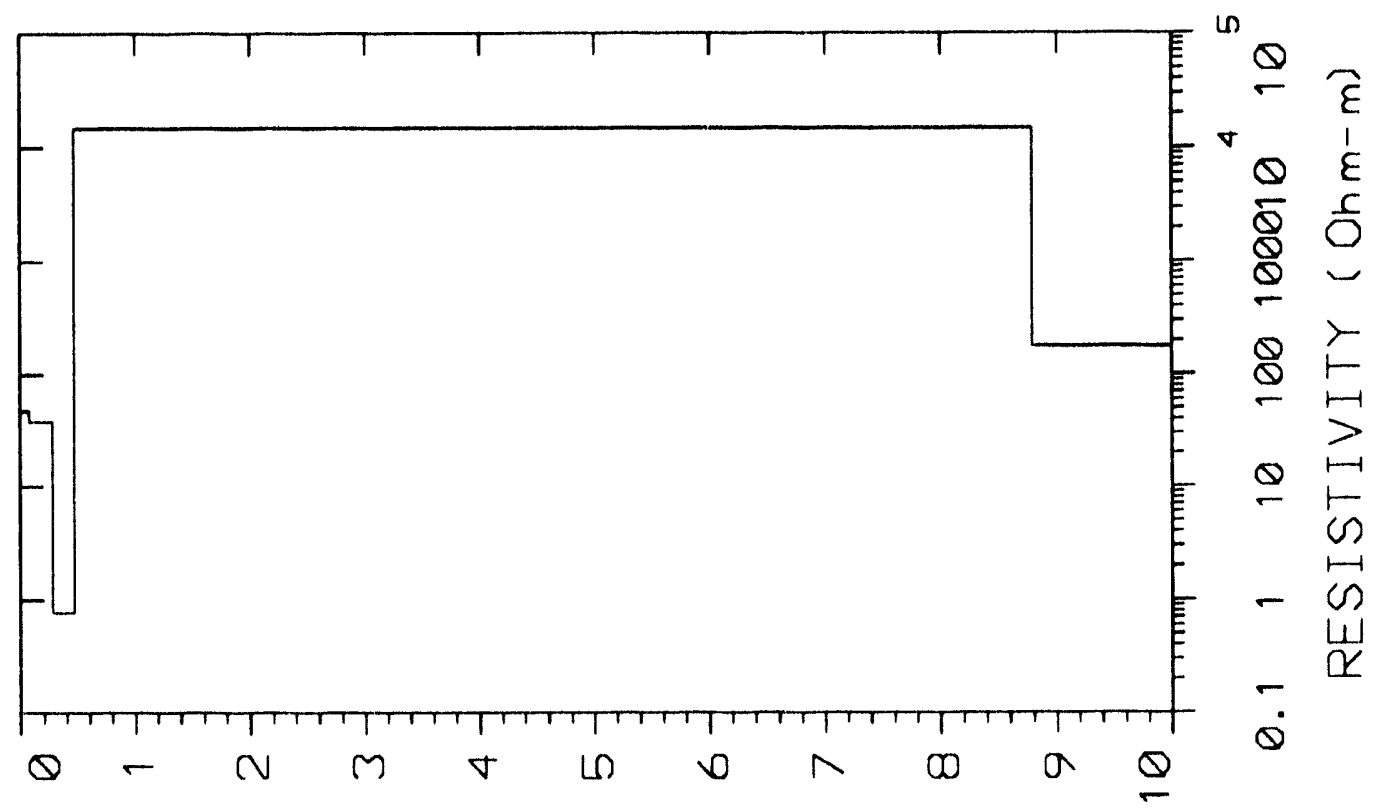

$(\theta l \times m) 47 d \theta 0$

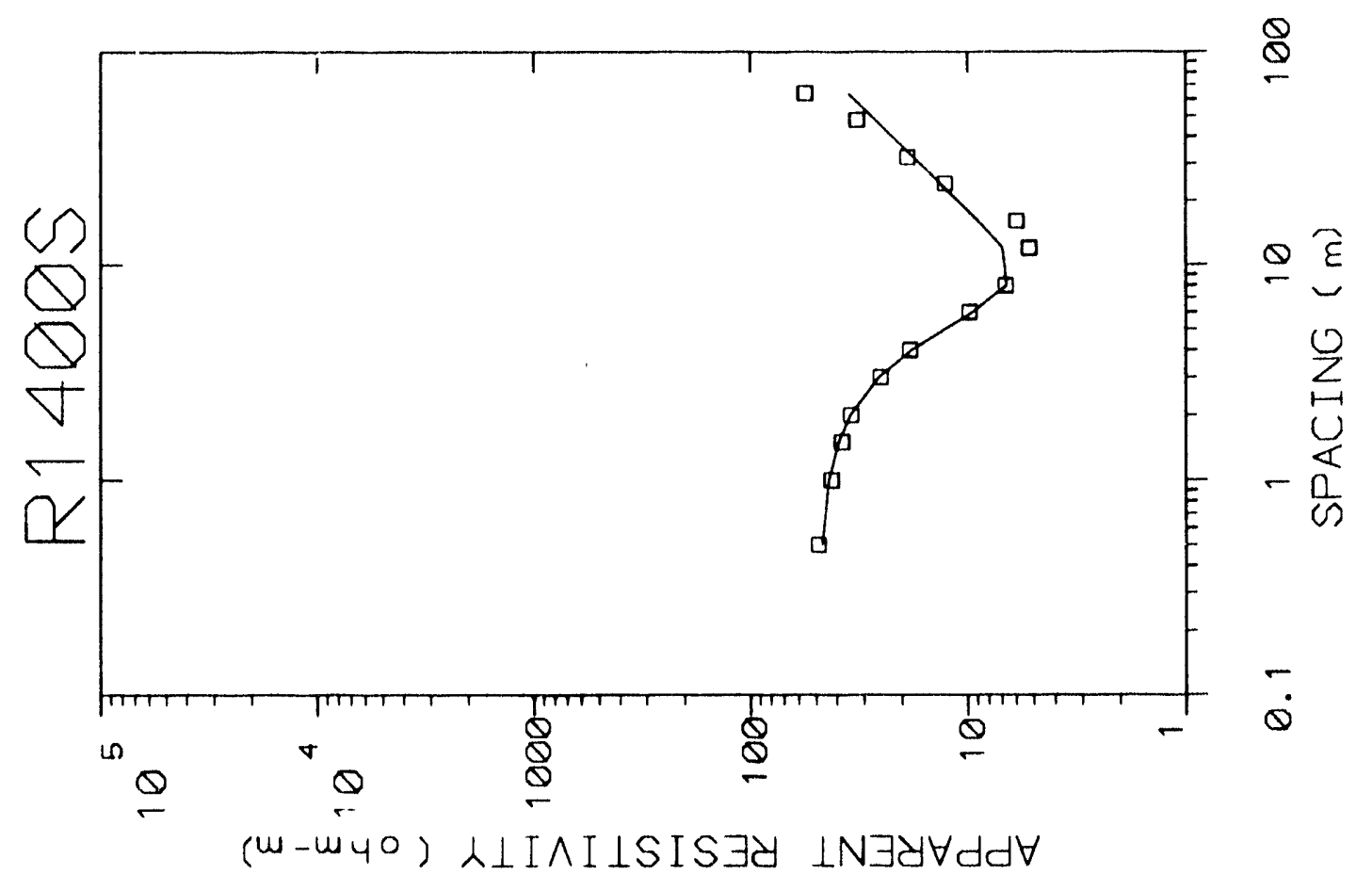


R450S; 50W

\begin{tabular}{cccccc}
\hline L\# & $\begin{array}{c}\text { Resistivity } \\
(\Omega \cdot m)\end{array}$ & $\begin{array}{c}\text { Thickness } \\
(\mathrm{m})\end{array}$ & $\begin{array}{c}\text { Elevation } \\
(\mathrm{m})\end{array}$ & $\begin{array}{c}\text { Long. Cond. } \\
(\mathrm{S})\end{array}$ & $\begin{array}{c}\text { Trans. Res. } \\
\left(\Omega \cdot \mathrm{m}^{2}\right)\end{array}$ \\
\hline & & & & & \\
1 & 333.9 & 0.480 & 3.51 & 0.00144 & 160.3 \\
2 & 152.1 & 0.581 & 2.93 & 0.00382 & 88.49 \\
3 & 121.7 & 8.37 & -5.43 & 0.0688 & $1,019.9$ \\
4 & 18.07 & & & & \\
\hline
\end{tabular}

R650S; 50W

\begin{tabular}{cccccc}
\hline$L \#$ & $\begin{array}{c}\text { Resistivity } \\
(\Omega \cdot m)\end{array}$ & $\begin{array}{c}\text { Thickness } \\
(\mathrm{m})\end{array}$ & $\begin{array}{c}\text { Elevation } \\
(\mathrm{m})\end{array}$ & $\begin{array}{c}\text { Long. Cond. } \\
(\mathrm{S})\end{array}$ & $\begin{array}{c}\text { Trans. Res. } \\
\left(\Omega \cdot \mathrm{m}^{2}\right)\end{array}$ \\
\hline & & & & & \\
1 & 535.2 & 0.479 & 3.52 & $8.951 \mathrm{E}-04$ & 256.4 \\
2 & 98.38 & 1.39 & 2.12 & 0.0142 & 137.5 \\
3 & 181.3 & 6.13 & -4.01 & 0.0338 & $1,113.2$ \\
4 & 45.83 & & & & \\
\hline
\end{tabular}

R700S; OW

\begin{tabular}{cccccc}
\hline$L \#$ & $\begin{array}{c}\text { Resistivity } \\
(\Omega \cdot m)\end{array}$ & $\begin{array}{c}\text { Thickness } \\
(m)\end{array}$ & $\begin{array}{c}\text { Elevation } \\
(\mathrm{m})\end{array}$ & $\begin{array}{c}\text { Long. Cond. } \\
(\mathrm{S})\end{array}$ & $\begin{array}{c}\text { Trans. Res. } \\
\left(\Omega \cdot \mathrm{m}^{2}\right)\end{array}$ \\
\hline & & & & & \\
1 & 83.49 & 0.893 & 3.10 & 0.0107 & 74.64 \\
2 & 39.00 & 2.67 & 0.427 & 0.0686 & 104.4 \\
3 & 206.6 & 4.43 & -4.01 & 0.0214 & 917.3 \\
4 & 25.59 & 18.86 & -22.87 & 0.737 & 482.8 \\
5 & 107.8 & & & & \\
\hline
\end{tabular}



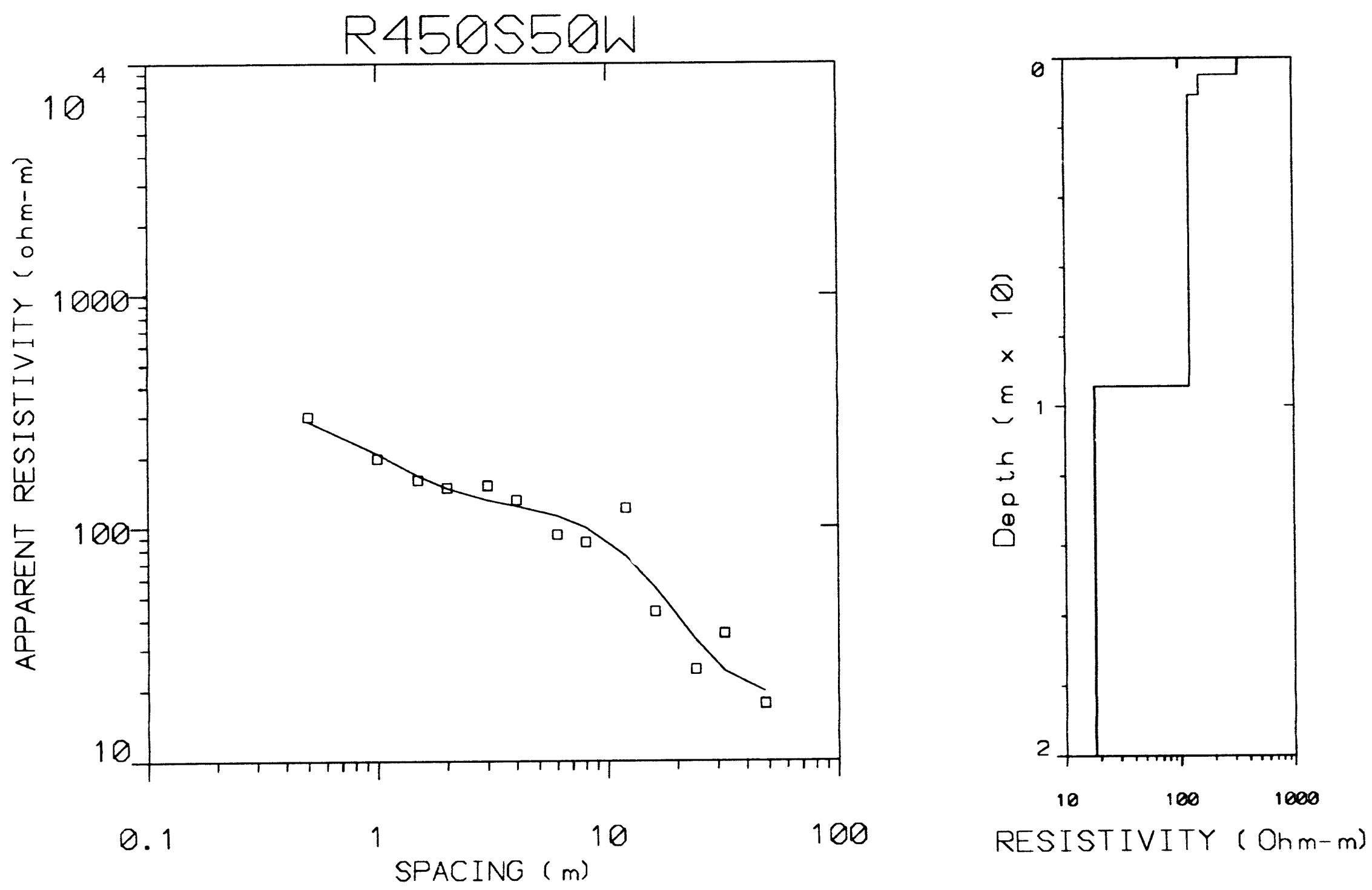

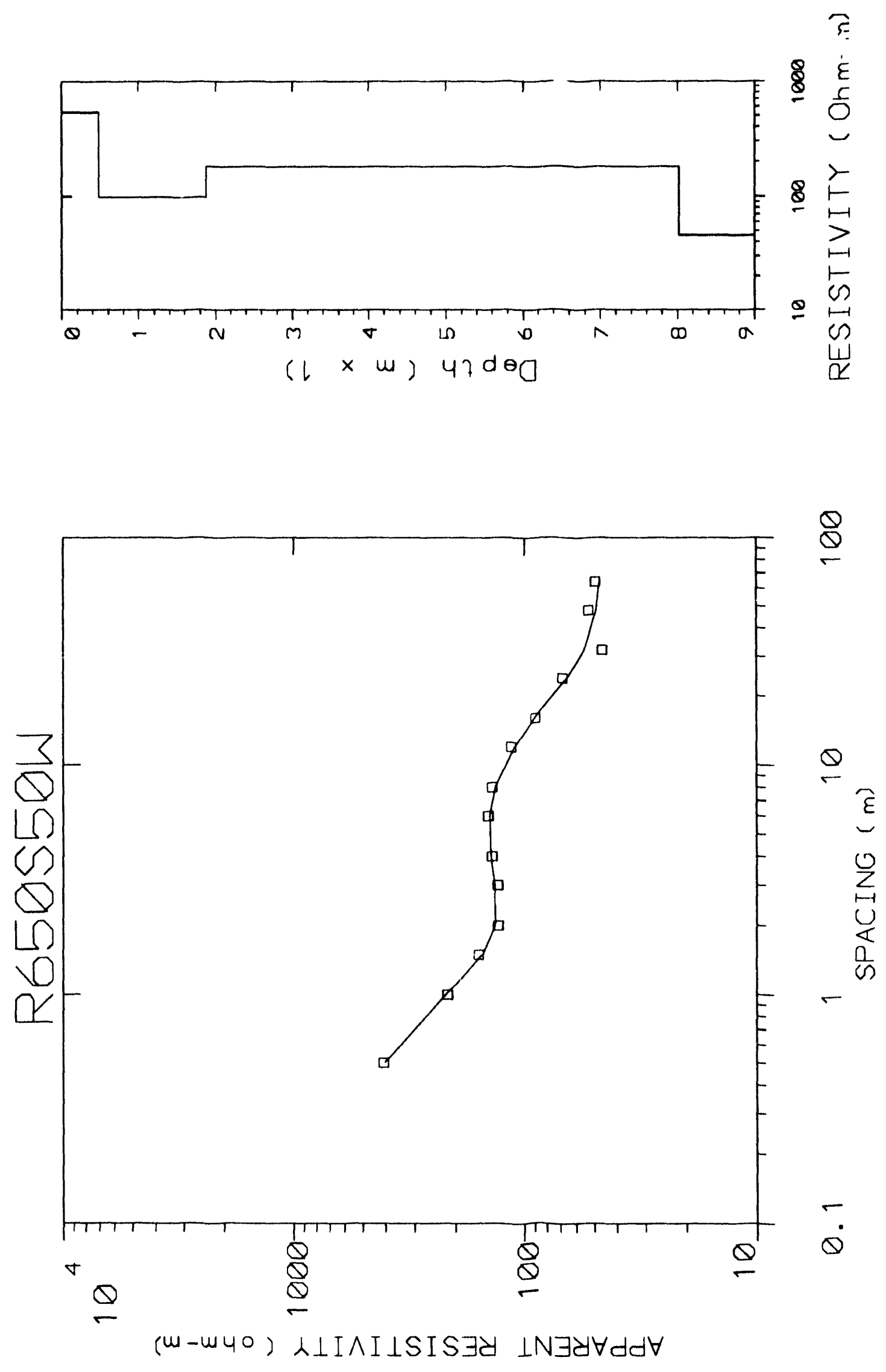

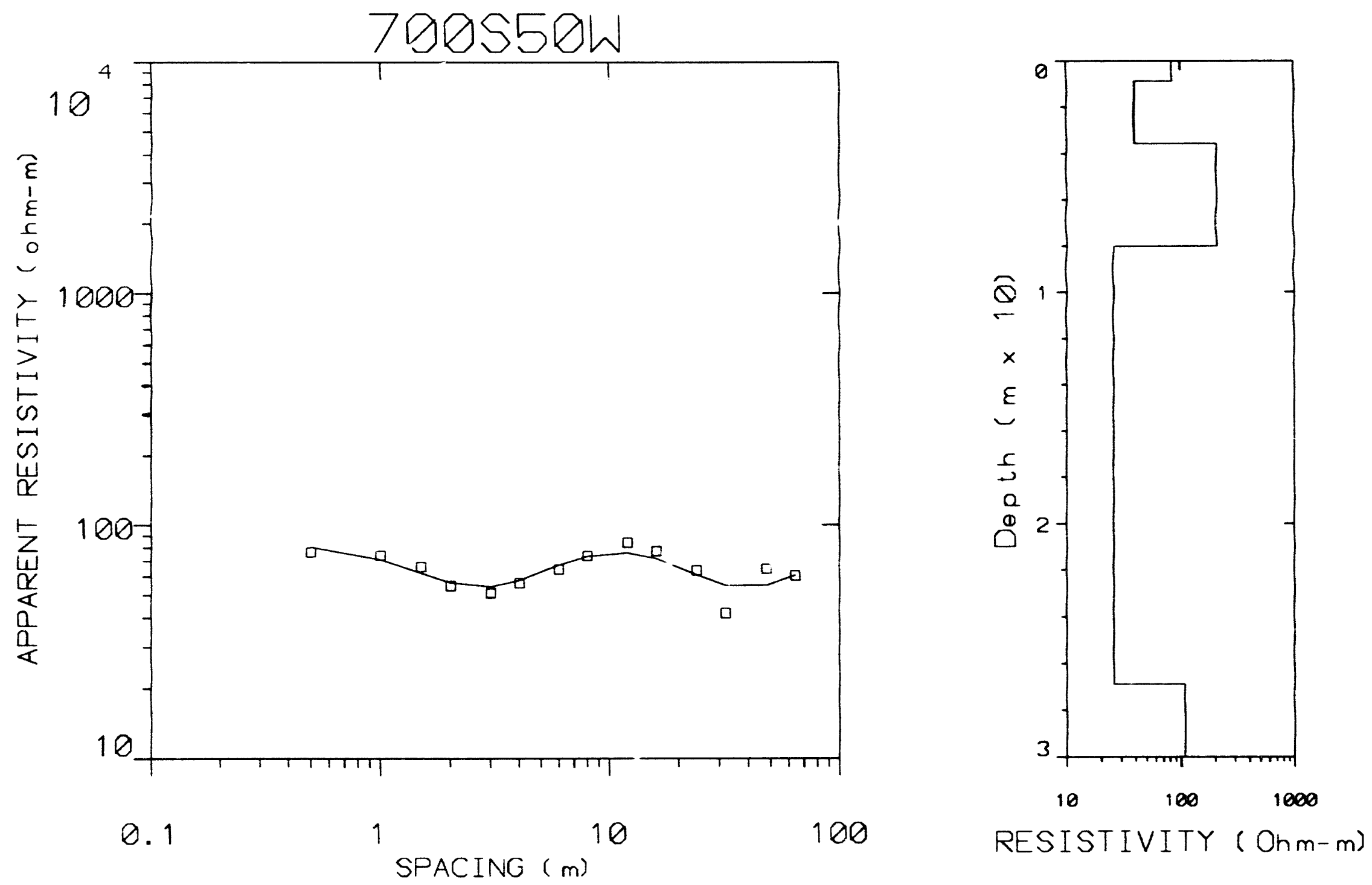
R750S; 50W

\begin{tabular}{lccccc}
\hline$L \#$ & $\begin{array}{c}\text { Resistivity } \\
(\Omega \cdot m)\end{array}$ & $\begin{array}{c}\text { Thickness } \\
(\mathrm{m})\end{array}$ & $\begin{array}{c}\text { Elevation } \\
(\mathrm{m})\end{array}$ & $\begin{array}{c}\text { Long. Cond. } \\
(\mathrm{S})\end{array}$ & $\begin{array}{c}\text { Trans. Res. } \\
\left(\Omega \cdot \mathrm{m}^{2}\right)\end{array}$ \\
\hline & & & & & \\
1 & 544.8 & 0.543 & 3.45 & $9.979 \mathrm{E}-04$ & 296.2 \\
2 & 122.9 & 6.62 & -3.16 & 0.0538 & 813.8 \\
3 & 43.82 & 58.27 & -61.44 & 1.32 & $2,554.2$ \\
4 & 658.4 & & & & \\
\hline
\end{tabular}

R850S; 50W

\begin{tabular}{lccccc}
\hline & $\begin{array}{c}\text { Resistivity } \\
(\Omega \cdot m)\end{array}$ & $\begin{array}{c}\text { Thickness } \\
(\mathrm{m})\end{array}$ & $\begin{array}{c}\text { Elevation } \\
(\mathrm{m})\end{array}$ & $\begin{array}{c}\text { Long. Cond. } \\
(\mathrm{S})\end{array}$ & $\begin{array}{c}\text { Trans. Res. } \\
\left(\Omega \cdot \mathrm{m}^{2}\right)\end{array}$ \\
\hline & & & & & \\
1 & 303.1 & 0.247 & 3.75 & $8.167 \mathrm{E}-04$ & 75.04 \\
2 & 109.9 & 6.35 & -2.60 & 0.0578 & 699.4 \\
3 & 47.89 & 27.00 & -29.61 & 0.563 & $1,293.3$ \\
4 & 57.47 & & & & \\
\hline
\end{tabular}



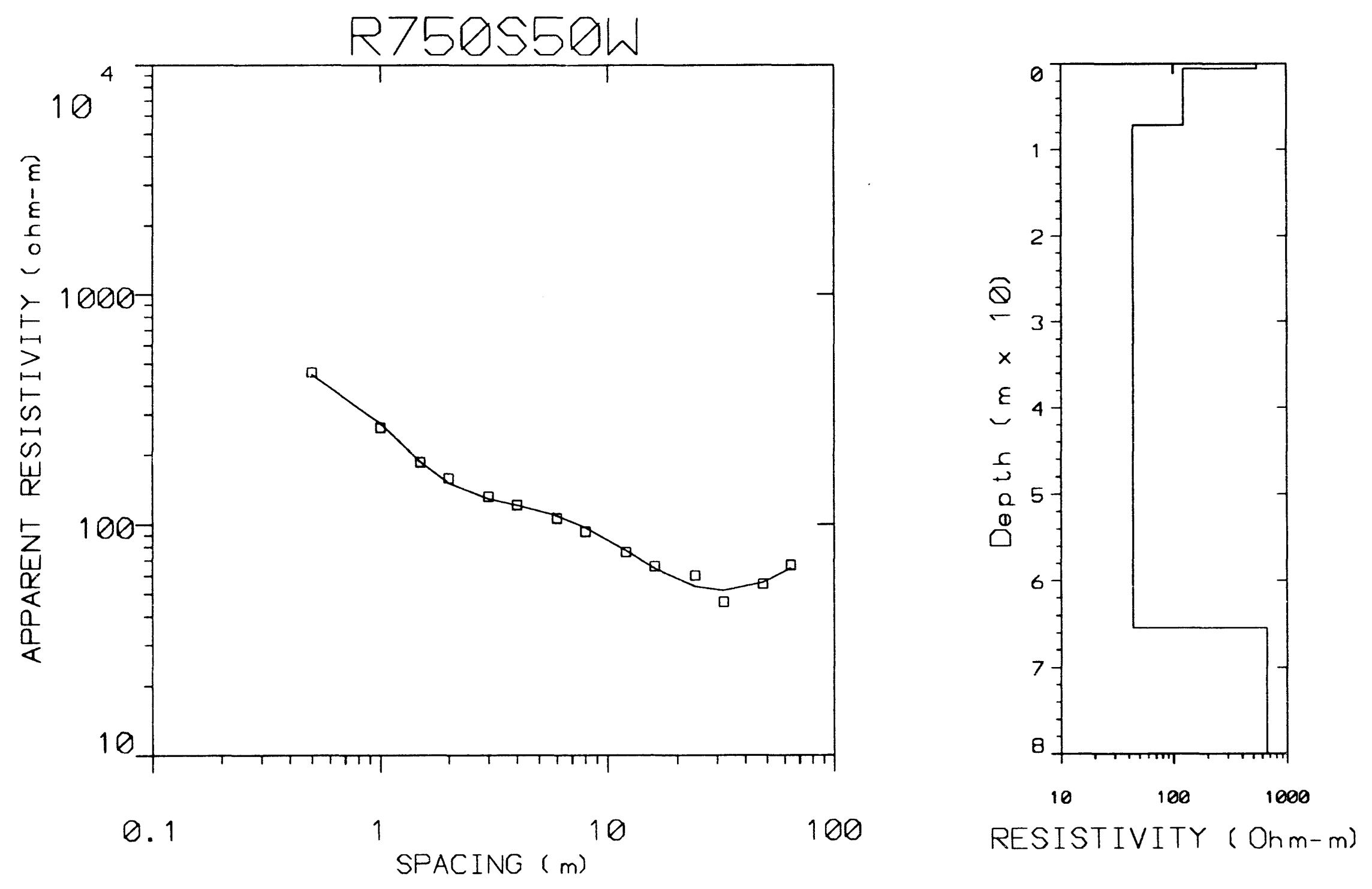

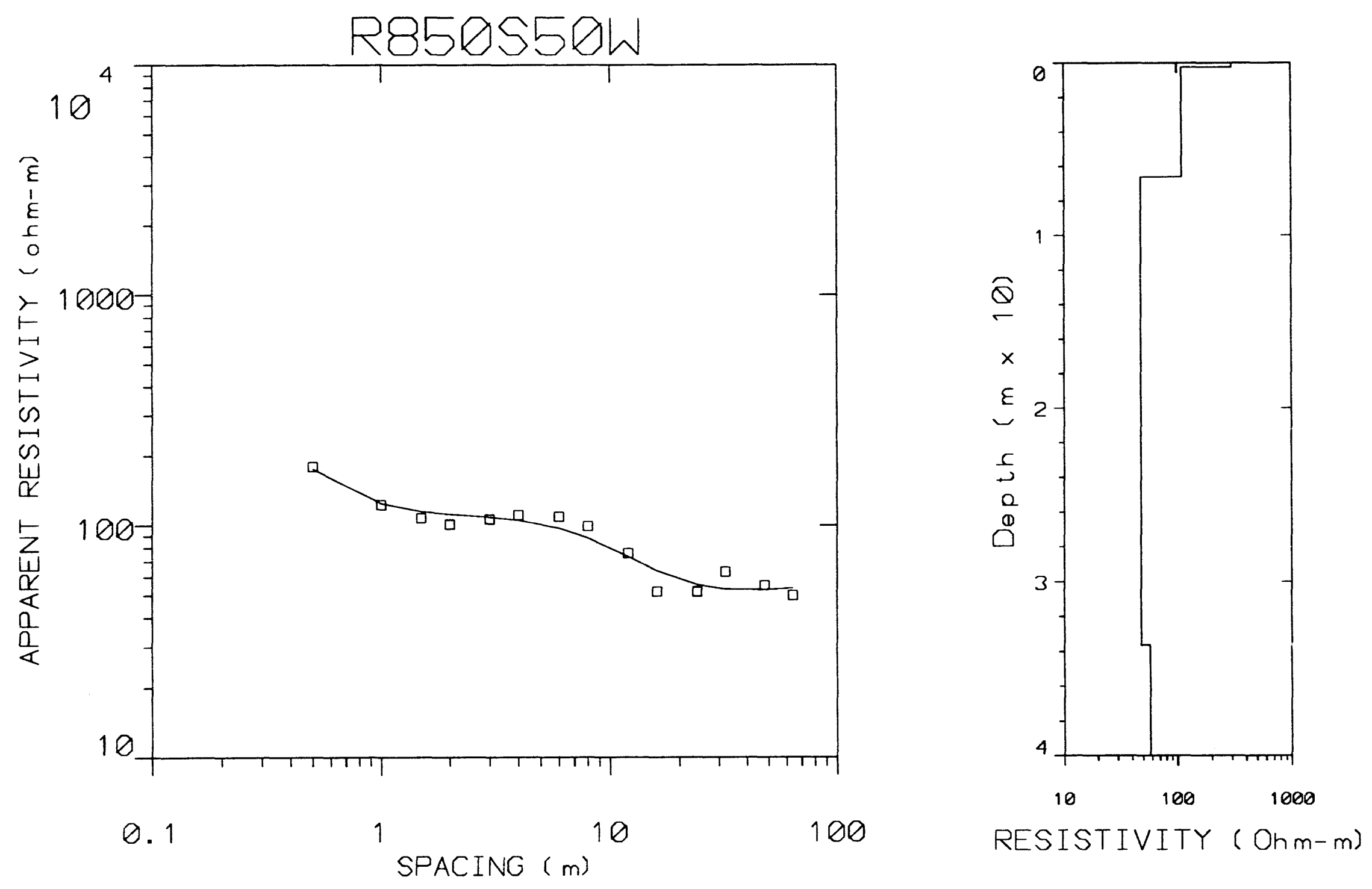
Appendix B:

Ground Penetrating Radar Profile Line Coordinates 


\section{APG-Beach Point Ground Penetrating Radar Profile Line Coordinates}

\begin{tabular}{|c|c|c|c|c|}
\hline \multirow[b]{2}{*}{ Line \# } & \multicolumn{2}{|c|}{ Start Coordinate } & \multicolumn{2}{|c|}{ End Coordinate } \\
\hline & South & West & South & West \\
\hline Lines $1-5$ & Misc. test & s over & drant line & \\
\hline 6 & 1050 & 00 & 1050 & 120 \\
\hline 7 & 1000 & -10 & 1000 & 130 \\
\hline 8 & 950 & -40 & 950 & 130 \\
\hline 9 & 900 & -30 & 900 & 100 \\
\hline 10 & 850 & -40 & 850 & 100 \\
\hline 11 & 800 & -30 & 800 & 140 \\
\hline 12 & 800 & -30 & 800 & 190 \\
\hline 13 & 000 & -20 & 000 & 10 \\
\hline 14 & 050 & -20 & 050 & 10 \\
\hline 15 & 100 & -20 & 100 & 00 \\
\hline 16 & 150 & -40 & 150 & 10 \\
\hline 17 & 200 & -30 & 200 & 40 \\
\hline 18 & 250 & -30 & 250 & 65 \\
\hline 19 & 300 & -20 & 300 & 80 \\
\hline 20 & 350 & -10 & 350 & 80 \\
\hline 21 & 400 & -20 & 400 & 100 \\
\hline 22 & 450 & -30 & 450 & 110 \\
\hline 23 & 500 & -30 & 500 & 130 \\
\hline 24 & 550 & -30 & 550 & 150 \\
\hline 25 & 600 & .40 & 600 & 140 \\
\hline 26 & 650 & -40 & 650 & 180 \\
\hline 27 & 700 & -40 & 700 & 180 \\
\hline 28 & 700 & -40 & 700 & 180 \\
\hline 29 & 750 & -40 & 750 & 150 \\
\hline 30 & 000 & 000 & 200 & 000 \\
\hline 31 & 150 & 000 & 400 & 000 \\
\hline 32 & 400 & 000 & 600 & 000 \\
\hline 33 & 600 & 000 & 800 & 000 \\
\hline 34 & 800 & 000 & 1000 & 000 \\
\hline 35 & 250 & 050 & 520 & 050 \\
\hline 36 & 650 & 050 & 850 & 050 \\
\hline 37 & 850 & 050 & 1050 & 050 \\
\hline 38 & 1000 & 050 & 1200 & 050 \\
\hline 39 & 860 & 000 & 860 & 180 \\
\hline 40 & 870 & 000 & 870 & 180 \\
\hline 41 & 880 & 000 & 880 & 210 \\
\hline 42 & 880 & 000 & 880 & 220 \\
\hline 43 & 890 & 000 & 890 & 160 \\
\hline 44 & 900 & 000 & 900 & 170 \\
\hline 45 & 650 & 010 & 800 & 010 \\
\hline 46 & 650 & 020 & 750 & 020 \\
\hline 47 & 650 & 030 & 750 & 030 \\
\hline 48 & 650 & 040 & 800 & 040 \\
\hline 49 & 650 & 060 & 800 & 060 \\
\hline 50 & 650 & 070 & 800 & 070 \\
\hline 51 & 650 & 080 & 800 & 080 \\
\hline 52 & 650 & 090 & 800 & 090 \\
\hline
\end{tabular}


APG-Beach Polnt Ground Penetrating Radar Proflle LIne Coordinates (Cont.)

\begin{tabular}{|c|c|c|c|c|}
\hline \multirow[b]{2}{*}{ Line \# } & \multicolumn{2}{|c|}{ Start Coordinate } & \multicolumn{2}{|c|}{ End Coordinate } \\
\hline & South & West & South & West \\
\hline 53 & 650 & 100 & 730 & 100 \\
\hline 54 & 650 & 110 & 730 & 110 \\
\hline 55 & 650 & 120 & 800 & 120 \\
\hline 56 & 650 & 130 & 800 & 130 \\
\hline 57 & 650 & 140 & 800 & 140 \\
\hline 58 & 650 & 150 & 800 & 150 \\
\hline 59 & 650 & 160 & 800 & 160 \\
\hline 60 & 650 & 170 & 800 & 170 \\
\hline 61 & 650 & 180 & 810 & 180 \\
\hline 62 & 500 & -10 & 650 & -10 \\
\hline 63 & 500 & -20 & 650 & -20 \\
\hline 64 & 500 & 10 & 650 & 10 \\
\hline 65 & 500 & 20 & 650 & 20 \\
\hline 66 & 500 & 30 & 650 & 30 \\
\hline 67 & 500 & 40 & 650 & 40 \\
\hline 68 & 500 & 50 & 610 & 50 \\
\hline 69 & 500 & 60 & 610 & 60 \\
\hline 70 & 500 & 70 & 650 & 70 \\
\hline 71 & 500 & 80 & 650 & 80 \\
\hline 72 & 500 & 90 & 650 & 90 \\
\hline 73 & 500 & 100 & 650 & 100 \\
\hline 74 & 500 & 110 & 650 & 110 \\
\hline 75 & 500 & 120 & 650 & 120 \\
\hline 76 & 500 & 130 & 650 & 130 \\
\hline 77 & 500 & 140 & 650 & 140 \\
\hline 78 & 350 & -10 & 500 & -10 \\
\hline 79 & 350 & 00 & 500 & 00 \\
\hline 80 & 350 & 10 & 500 & 10 \\
\hline 81 & 350 & 20 & 500 & 20 \\
\hline 82 & 350 & 30 & 500 & 30 \\
\hline 83 & 350 & 40 & 500 & 40 \\
\hline 84 & 350 & 50 & 500 & 50 \\
\hline 85 & 350 & 60 & 500 & 60 \\
\hline 86 & 350 & 70 & 500 & 70 \\
\hline 87 & 350 & 80 & 500 & 80 \\
\hline 88 & 350 & 90 & 500 & 90 \\
\hline 89 & 400 & 100 & 500 & 100 \\
\hline 90 & 400 & 110 & 500 & 110 \\
\hline 91 & 450 & 120 & 500 & 120 \\
\hline 92 & 200 & .20 & 300 & -20 \\
\hline 93 & 200 & -10 & 350 & -10 \\
\hline 94 & 200 & 00 & 350 & 00 \\
\hline 95 & 200 & 10 & 350 & 10 \\
\hline 96 & 200 & 20 & 350 & 20 \\
\hline 97 & 200 & 30 & 350 & 30 \\
\hline 98 & 200 & 40 & 350 & 40 \\
\hline 99 & 250 & 50 & 350 & 50 \\
\hline
\end{tabular}


APG-Beach Polnt Ground Penetrating Radar Proflle LIne Coordinates (Cont.)

\begin{tabular}{|c|c|c|c|c|}
\hline \multirow[b]{2}{*}{ Line \# } & \multicolumn{2}{|c|}{ Start Coordinate } & \multicolumn{2}{|c|}{ End Coordinate } \\
\hline & South & West & South & West \\
\hline 100 & 250 & 60 & 350 & 60 \\
\hline 101 & 250 & 70 & 350 & 70 \\
\hline 102 & 000 & -10 & 200 & -10 \\
\hline 103 & 000 & .20 & 200 & -20 \\
\hline 104 & 1730 & 00 & 1550 & 00 \\
\hline 105 & 1550 & 00 & 1350 & 00 \\
\hline 106 & 1050 & 190 & 960 & 190 \\
\hline 107 & 1050 & 180 & 900 & 180 \\
\hline 108 & 1050 & 170 & 900 & 170 \\
\hline 109 & 1050 & 160 & 900 & 160 \\
\hline 110 & 1050 & 150 & 900 & 150 \\
\hline 111 & 1050 & 140 & 900 & 140 \\
\hline 112 & 1050 & 130 & 900 & 130 \\
\hline 113 & 1050 & 120 & 900 & 120 \\
\hline 114 & 1050 & 110 & 900 & 110 \\
\hline 115 & 1050 & 100 & 900 & 100 \\
\hline 116 & 1050 & 90 & 800 & 90 \\
\hline 117 & 1050 & 80 & 800 & 80 \\
\hline 118 & 1050 & 70 & 800 & 70 \\
\hline 119 & 1050 & 60 & 800 & 60 \\
\hline 120 & 1050 & 50 & 800 & 50 \\
\hline 121 & 1050 & 40 & 800 & 40 \\
\hline 122 & 1050 & 30 & 800 & 30 \\
\hline 123 & 1050 & 20 & 800 & 20 \\
\hline 124 & 1050 & 10 & 800 & 10 \\
\hline 125 & 1000 & -10 & 800 & -10 \\
\hline 126 & 900 & 100 & 800 & 100 \\
\hline 127 & 900 & 110 & 800 & 110 \\
\hline 128 & 900 & 120 & 800 & 120 \\
\hline 129 & 900 & 130 & 800 & 130 \\
\hline 130 & 900 & 140 & 800 & 140 \\
\hline 131 & 900 & 150 & 800 & 150 \\
\hline 132 & 900 & 160 & 800 & 160 \\
\hline \multicolumn{5}{|c|}{$\begin{array}{l}\text { Lines } 106-132 \text { Collected with } 100-\mathrm{MHz} \text { transceiver in } \\
\text { monostatic mode with range }=150 \mathrm{~ns}\end{array}$} \\
\hline 133 & 800 & 50 & 650 & 50 \\
\hline 134 & 800 & 30 & 650 & 30 \\
\hline 135 & 800 & 70 & 650 & 70 \\
\hline 136 & 800 & 90 & 650 & 90 \\
\hline 137 & 800 & 190 & 800 & -30 \\
\hline 138 & 750 & 190 & 750 & -30 \\
\hline 139 & 700 & 170 & 700 & -50 \\
\hline 140 & 650 & 190 & 650 & -40 \\
\hline 141 & 000 & 000 & 1000 & 000 \\
\hline $\begin{array}{l}\text { Lines } 1 \\
\text { range }\end{array}$ & 1 Ccllec & th $300-$ & static an & as with \\
\hline
\end{tabular}


APG-Beach Point Ground Penetrating Radar Proflle Line Coordinates (Cont.)

\begin{tabular}{cccccc}
\hline & \multicolumn{2}{c}{ Start Coordinate } & & \multicolumn{2}{c}{ End Coordinate } \\
\cline { 2 - 3 } \cline { 5 - 6 } Line \# & South & West & & South & West \\
\hline 142 & 800 & 50 & & 650 & 50 \\
143 & 820 & 190 & & 800 & -30 \\
144 & 800 & 90 & & 650 & 90 \\
145 & 750 & 190 & & 750 & -30
\end{tabular}

Lines 142-145 Collected with $300-\mathrm{MHz}$ bistatic antennas with range $=300 \mathrm{~ns}$

\begin{tabular}{|c|c|c|c|c|}
\hline $\begin{array}{l}146 \\
147 \\
148 \\
149 \\
\text { Lines 146-149 } \\
\text { range }=300\end{array}$ & $\begin{array}{l}800 \\
800 \\
700 \\
000 \\
\text { Collected } \\
\text { ns }\end{array}$ & $\begin{array}{c}50 \\
30 \\
170 \\
000 \\
\text { with } 100-\mathrm{MHz}\end{array}$ & $\begin{array}{c}650 \\
650 \\
700 \\
1000 \\
\text { bistatic antenna }\end{array}$ & $\begin{array}{l}50 \\
30 \\
-50 \\
000 \\
\text { as with }\end{array}$ \\
\hline 150 & 585 & 0 & 585 & 100 \\
\hline 151 & 582.5 & 0 & 582.5 & 40 \\
\hline 152 & 580 & 0 & 580 & 100 \\
\hline 153 & 575 & 0 & 575 & 100 \\
\hline 154 & 570 & 0 & 570 & 100 \\
\hline 155 & 565 & 0 & 565 & 90 \\
\hline 156 & 560 & 0 & 560 & 90 \\
\hline 157 & 555 & 0 & 555 & 100 \\
\hline 158 & 550 & 0 & 550 & 100 \\
\hline 159 & 545 & 0 & 545 & 100 \\
\hline 160 & 540 & 0 & 540 & 100 \\
\hline 161 & 555 & 0 & 555 & 10 \\
\hline 162 & 552.5 & 0 & 552.5 & 10 \\
\hline 163 & 550 & 0 & 550 & 10 \\
\hline 164 & 547.5 & 0 & 547.5 & 10 \\
\hline 165 & 545 & 0 & 545 & 10 \\
\hline 166 & 542.5 & 0 & 542.5 & 10 \\
\hline 167 & 540 & 0 & 540 & 10 \\
\hline 168 & 537.5 & 0 & 537.5 & 10 \\
\hline 169 & 535 & 0 & 535 & 10 \\
\hline 170 & 532.5 & 0 & 532.5 & 10 \\
\hline 171 & 532.5 & 0 & 532.5 & 20 \\
\hline 172 & 530 & 0 & 530 & 20 \\
\hline 173 & 527.5 & 0 & 527.5 & 20 \\
\hline 174 & 525 & 0 & 525 & 20 \\
\hline 175 & 535 & 0 & 535 & 100 \\
\hline 176 & 540 & 80 & 540 & 100 \\
\hline 177 & 532.5 & 70 & 532.5 & 100 \\
\hline 178 & 537.5 & 70 & 537.5 & 100 \\
\hline 179 & 537.5 & 80 & 537.5 & 100 \\
\hline 180 & 530 & 70 & 530 & 100 \\
\hline 181 & 525 & 70 & 525 & 100 \\
\hline 182 & 520 & 70 & 520 & 100 \\
\hline 183 & 515 & 70 & 515 & 100 \\
\hline 184 & 510 & 70 & 510 & 100 \\
\hline
\end{tabular}


Appendix C:

Seismic Reflection Profiles 


\section{Appendlx C: Seismic Reflection Proflles}

Stacked seismic profiles for deep reflection lines are shown as Figures C.1 and C.2 for profiles BCHNS-DP and BCHEW-DP, respectively. A stacked seismic profile for the shallow reflection line on Beach Point Road (line BCHEW-SH) is shown as Figure C.3. Stacked seismic profiles for shallow reflection lines aligned with the geophysics survey coordinates on Beach Point Peninsula are shown as Figure C. 4 for profiles BCHNS000, BCHNS50A, BCHNS50B, and BCHNS100 and Figure C.5 for profiles BCHEW450, BCHEW650, and BCHEW 1000. $A$. stacked seismic profile for the shallow reflection line extending from monitoring wells CC-33 to CC-34 (line BCHXWELL) is shown in Figure C.6.

Line BCHXWELL (Figure C.6) uses relatively short offset and geophone spacings. The shortened recording parameters permit recognition of visible reflectors in the 10-40 ms range, corresponding to depths as shallow as 6-50 ft. The reflector at 10-15 ms likely corresponds with the water table at 6-12 ft depth. The reflector at about $30 \mathrm{~ms}$, or a depth of about $25 \mathrm{ft}$, corresponds with a sharp increase in the gamma count for the log of well CC-33 in the depth range 20-26 ft, suggesting the reflector is caused by the presence of a clay-rich layer that is continuous between the two wells, CC-33 and CC34.

A reflector at about $45 \mathrm{~ms}$ at the west edge of line BCHEW-SH along Beach Point Road (Figure C.3) corresponds with a depth of about $80 \mathrm{ft}$. The gamma log for well CC-12, located approximately $450 \mathrm{ft}$ west of the profile, indicates a significant increase in gamma count at $80 \mathrm{ft}$, suggesting that the reflector corresponds with the top of a clay-rich layer, $y_{1}$ obably the top of Cretaceous sediments. Another interesting set of features observed for BCHEW-SH is the presence of on-lapping or apparent cross-bedding above the 80 -ft reflector. The on-lap reflectors are prominent at distances of 630,690 , and $790 \mathrm{ft}$ and indicate cross-bed dipping toward the east.

Shallow reflection profile BCHNS50A (shown in Figure C.4, center right) was recorded along a south-to-north traverse along the 50W survey coordinate. The south end of the profile is located at coordinate $1000 \mathrm{~S}$. The north end of the profile is adjacent to the location of the University of Maryland bio-assay trailer. The profile was not extended farther north because of

noise (from pumping) associated with well CC-33, which was in continuous operation at the time of the survey.

Profile BCHNS50A images a reflecting horizon at approximately $60 \mathrm{ft}$ in depth (31-ms two-way travel time) which correlates with the lower Plsistocene P-K unconformity. Two other reflection wavelets are also imaged on the seismic section. Maximurn penetration depth is approximately $100 \mathrm{ft}$.

Figure C.5, top, represents shallow reflection profile BCHEW450, which was recorded along an east-to-west traverse along the geophysical coordinate $450 \mathrm{~S}$. As with profile BCHNS50A, the lower Pleistocene P-K unconformity was also imaged. The depth to this interface is slightly shallower than that shown on BCHNS50A. Like profile BCHEW-SH, the 
present profile shows on-lap or apparent cross-bedding dipping toward the east. The on-lap is slightly deeper (approximately $100 \mathrm{ft}$ deep) and is in Cretaceous rather than Pleistocene sediments. The on-lap reflectors are most prominent at about $25 \mathrm{E}$. 

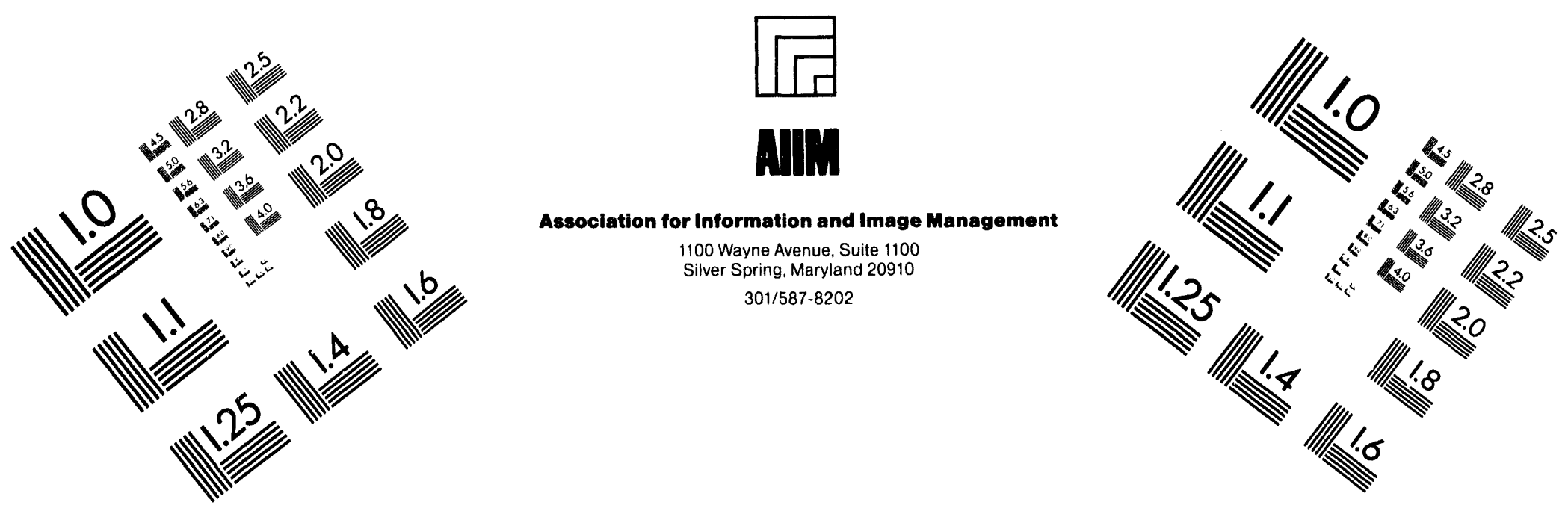

\section{Centimeter}

1 Inches
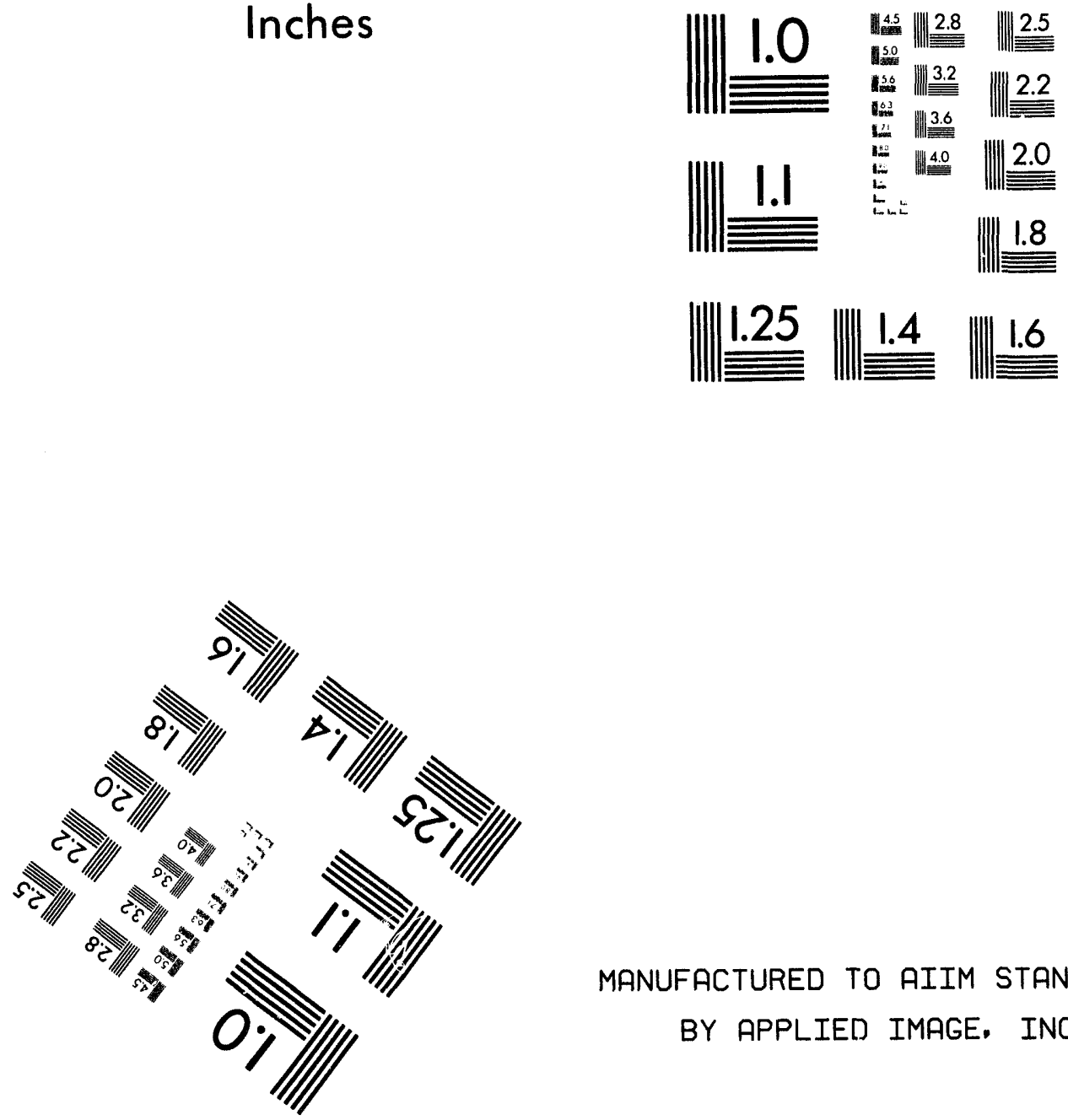

MANUFACTURED TO AIIM STANDARDS BY APPLIED IMAGE. INC.

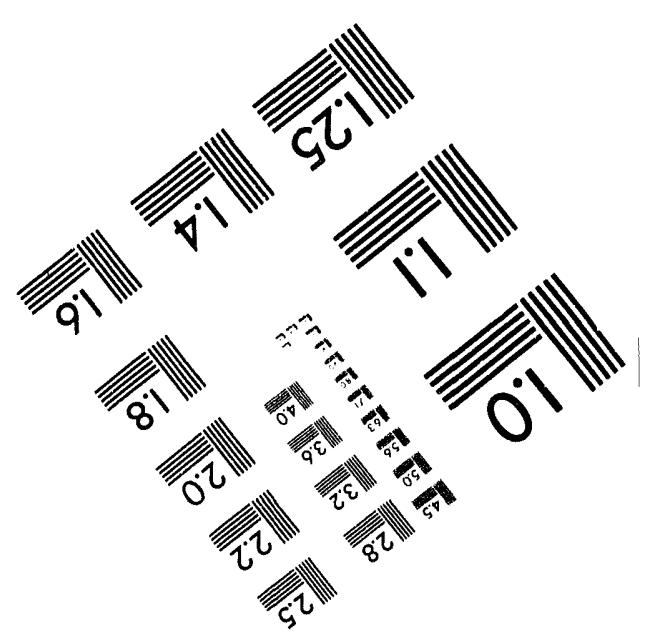



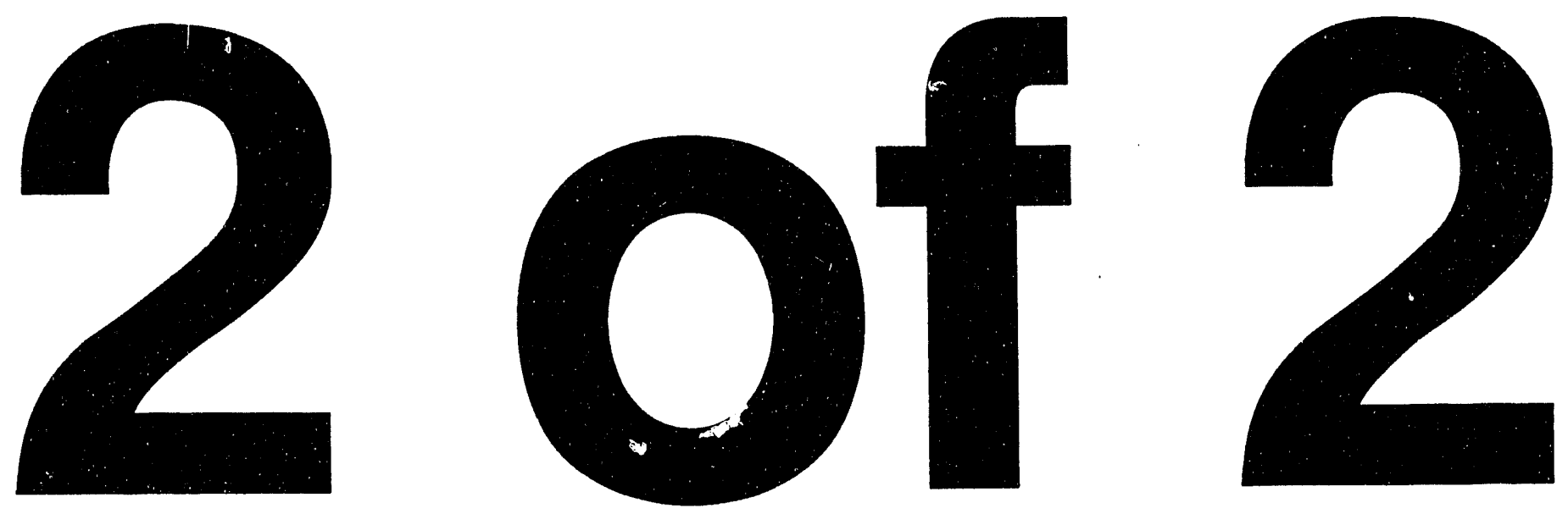


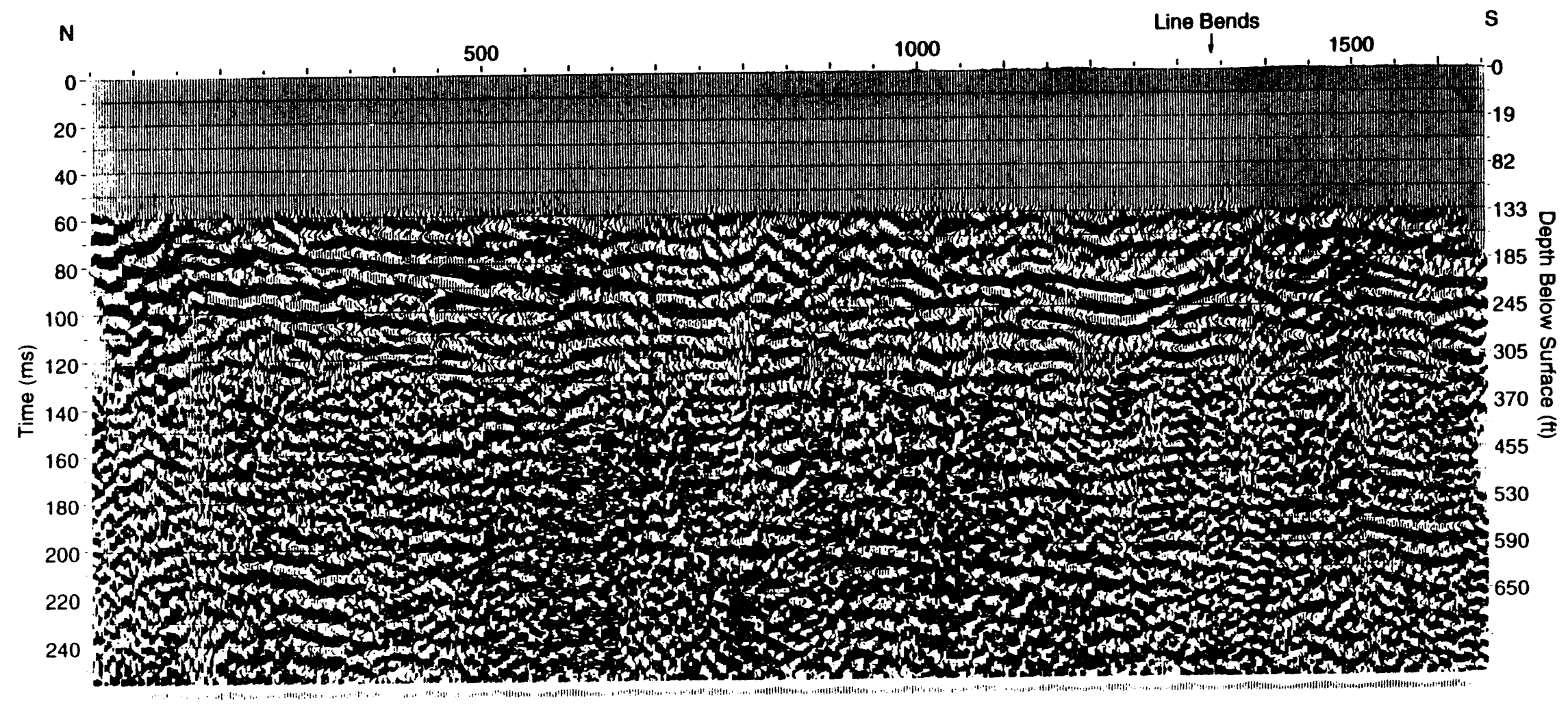

BCHNS-DP

FIGURE C.1 Stacked Seismic Section for BCHNS-DP 


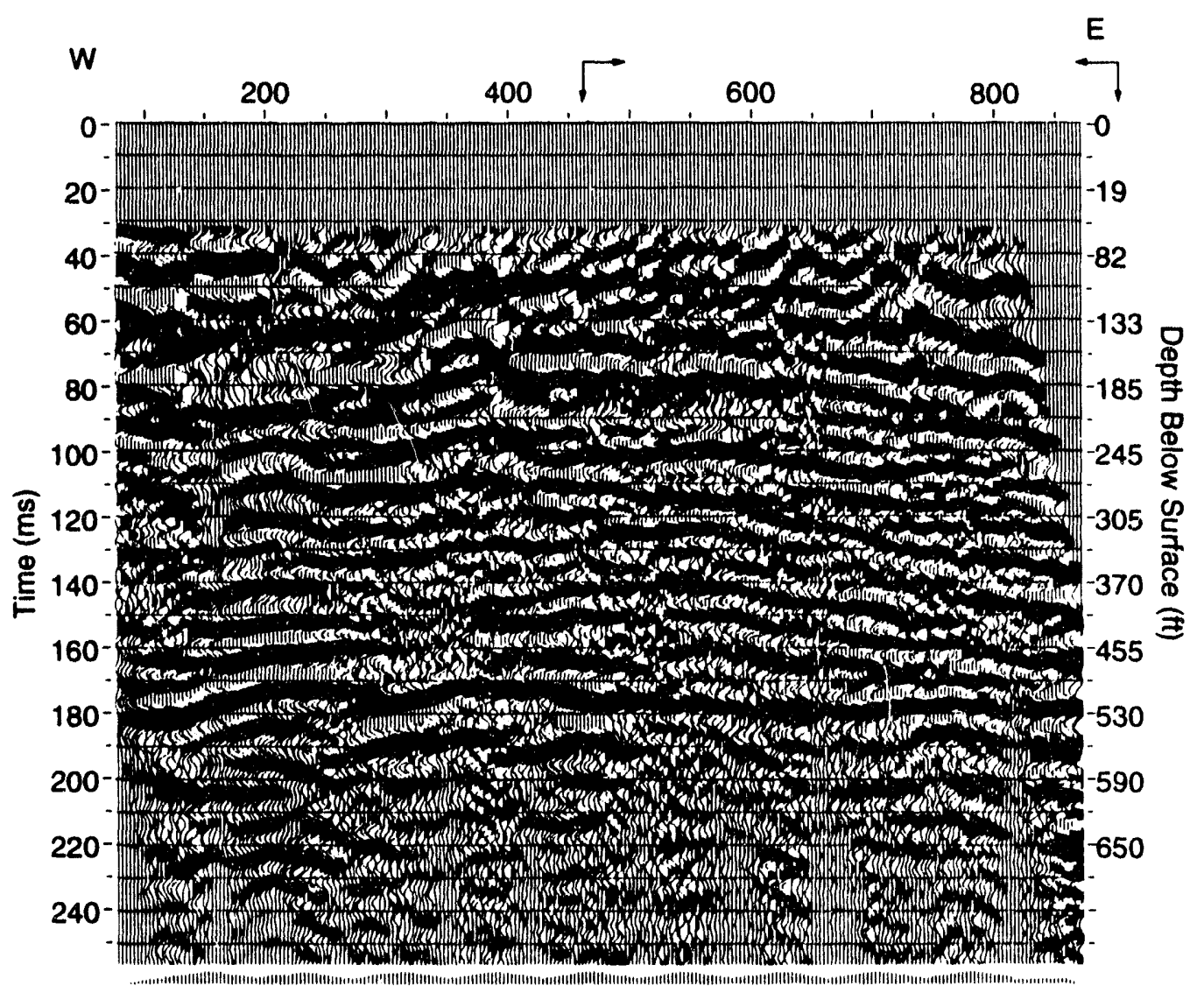

\section{BCHEW-DP}

FIGURE C.2 Stacked Seismic Section for BCHEW-DP

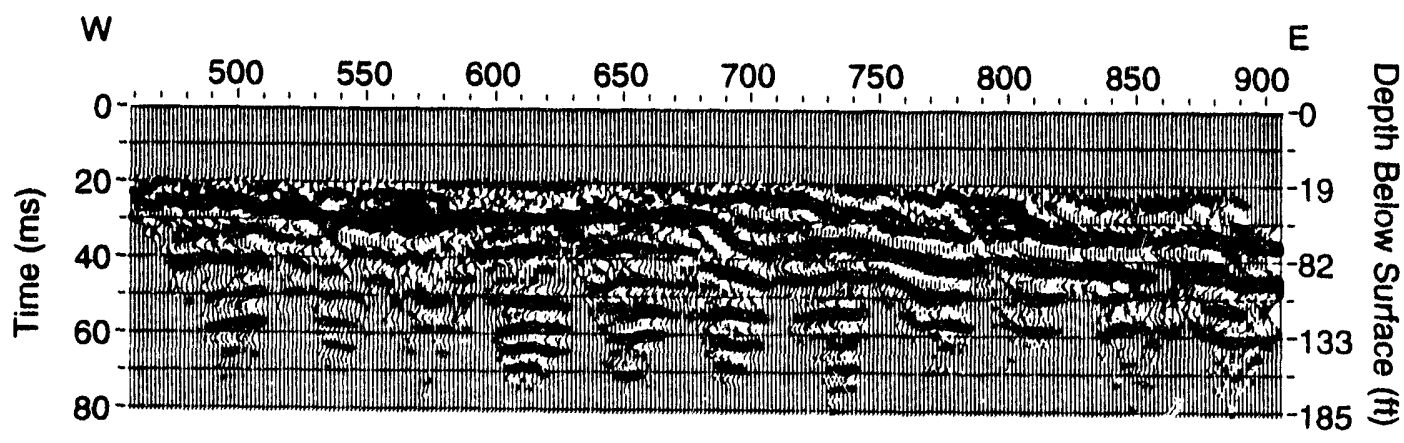

BCHEW-SH

FIGURE C.3 Stacked Seismic Section for BCHEW-SH 

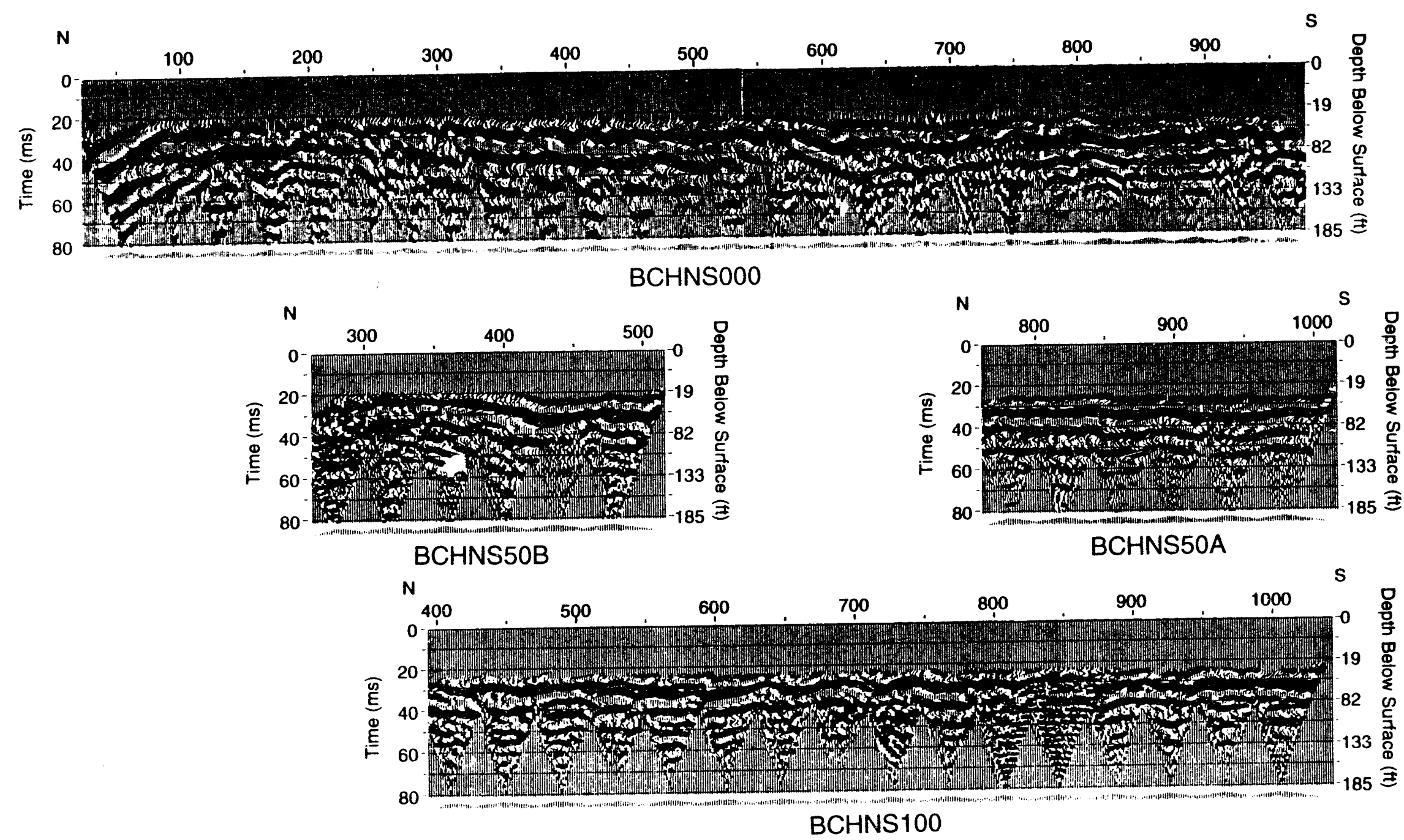

FIGURE C. 4 Stacked Seismic Sections for BCHNS000, BCHNS50B, BCHNS50A, and BCHNS100 

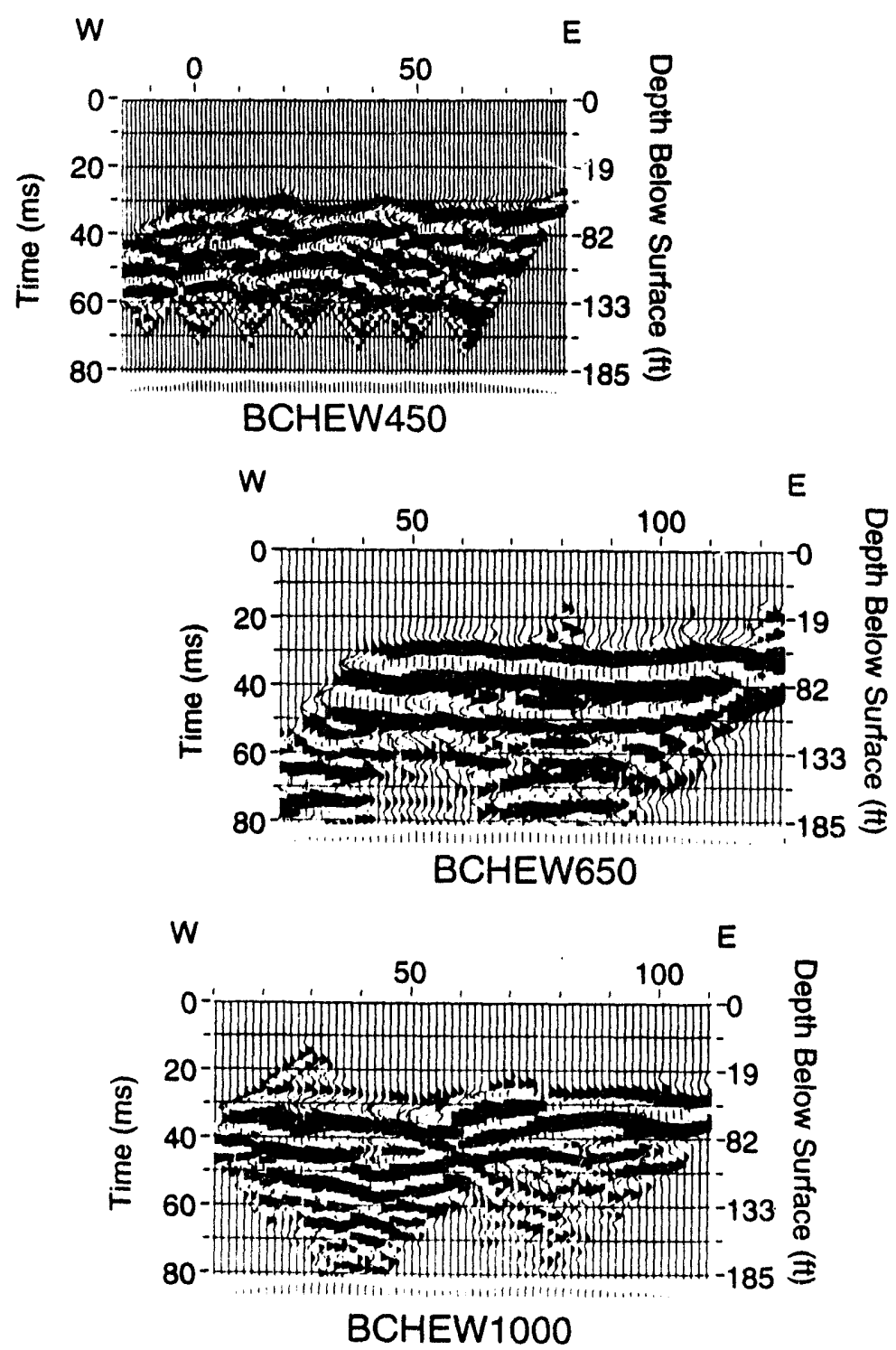

FIGURE C.5 Stacked Seismic Sections for BCHEW450, BCHEW650, and BCHEW 1000 


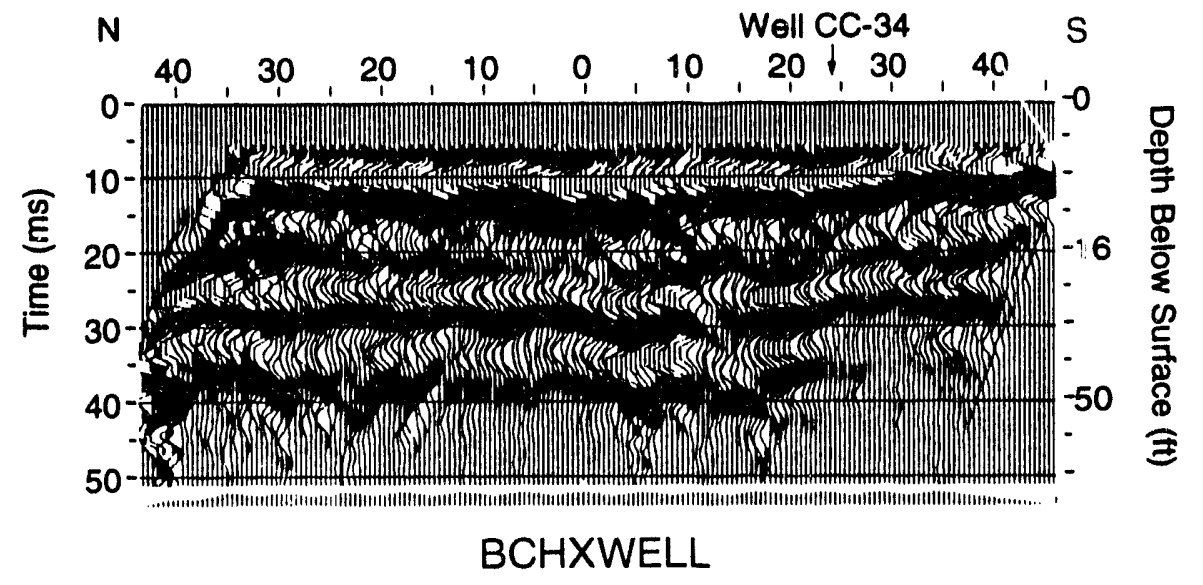

FIGURE C.6 Stacked Seismic Section for BCHXWELL 
Appendix D:

Area Magnetic Maps 


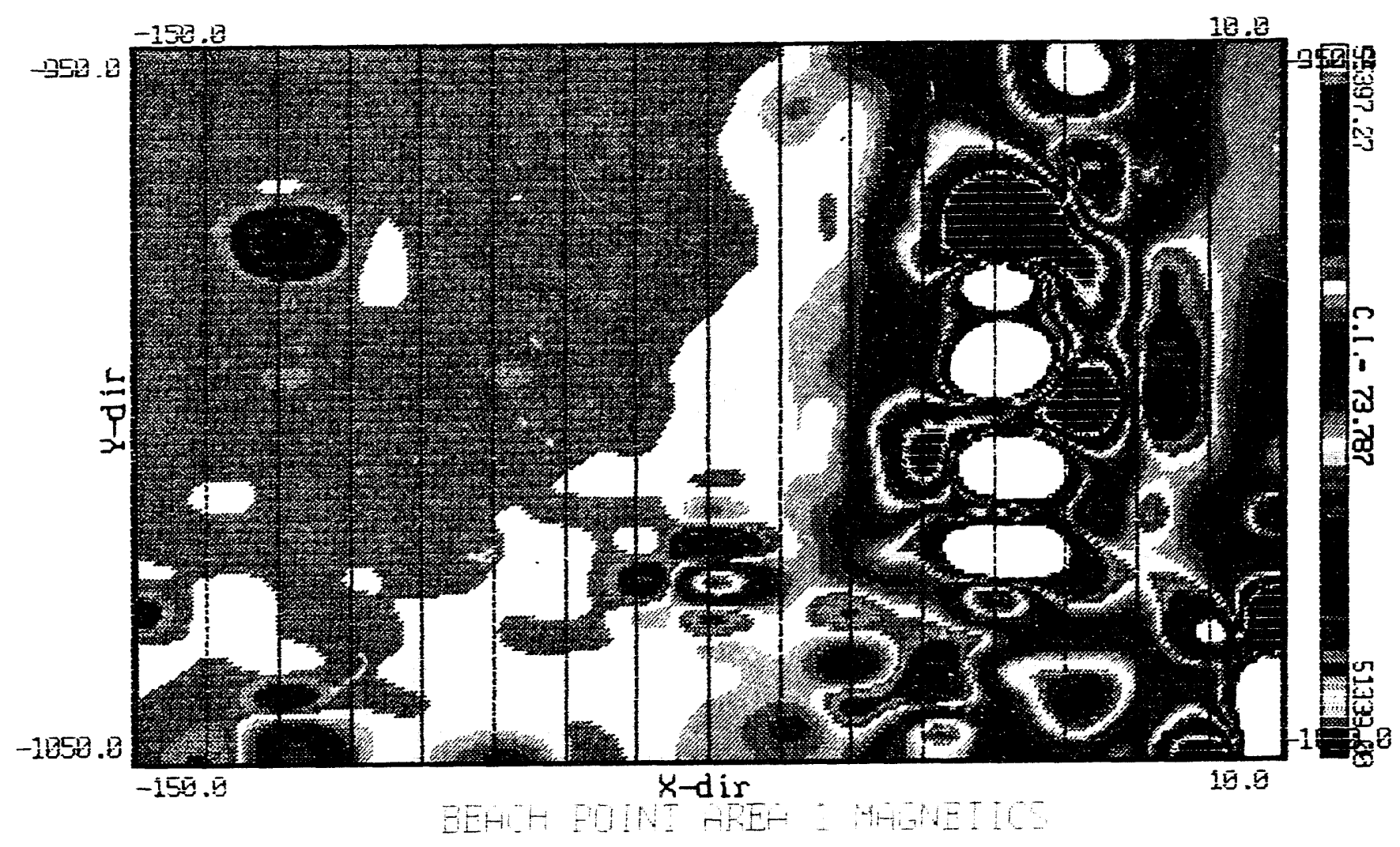

FIGURE D. 1 Beach Point Area 1 Magnetics (The southeastern two-thirds of the area, including anomalies along lines $70 \mathrm{~W}$ and $80 \mathrm{~W}$, is dominated by anomalies associated with road fill or by construction fill along the southeastern shore of Beach Point. The anomaly in the northwest quarter on Line $130 \mathrm{~W}$ is produced by surficial debris.) 


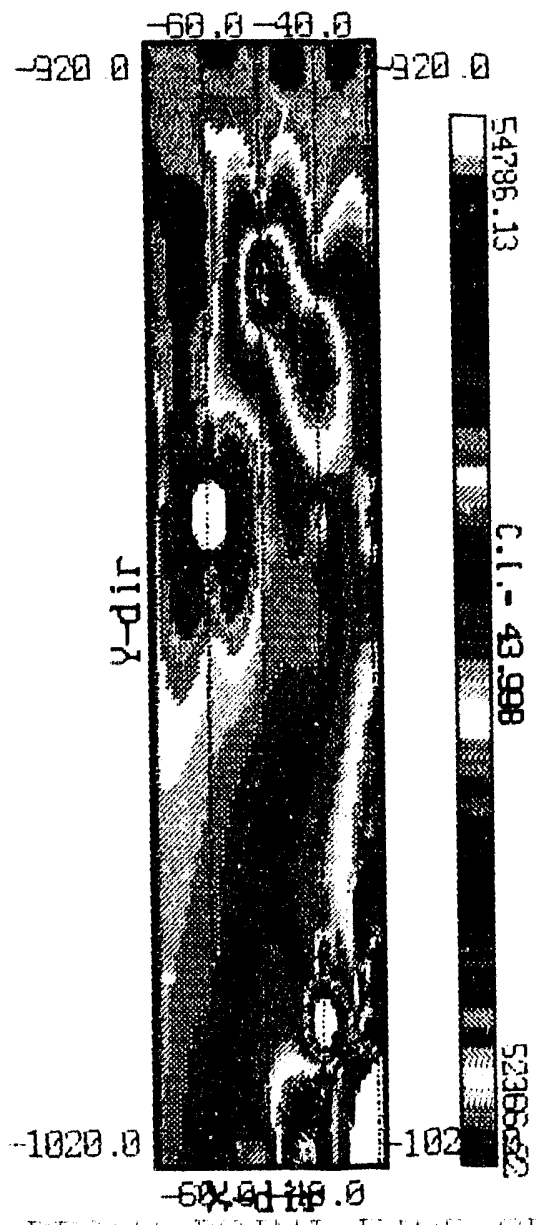

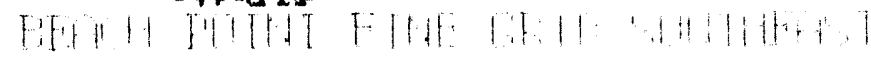

FIGURE D.2 Beach Point Fine Grid: Southeast (All anomalies are produced by road fill.) 


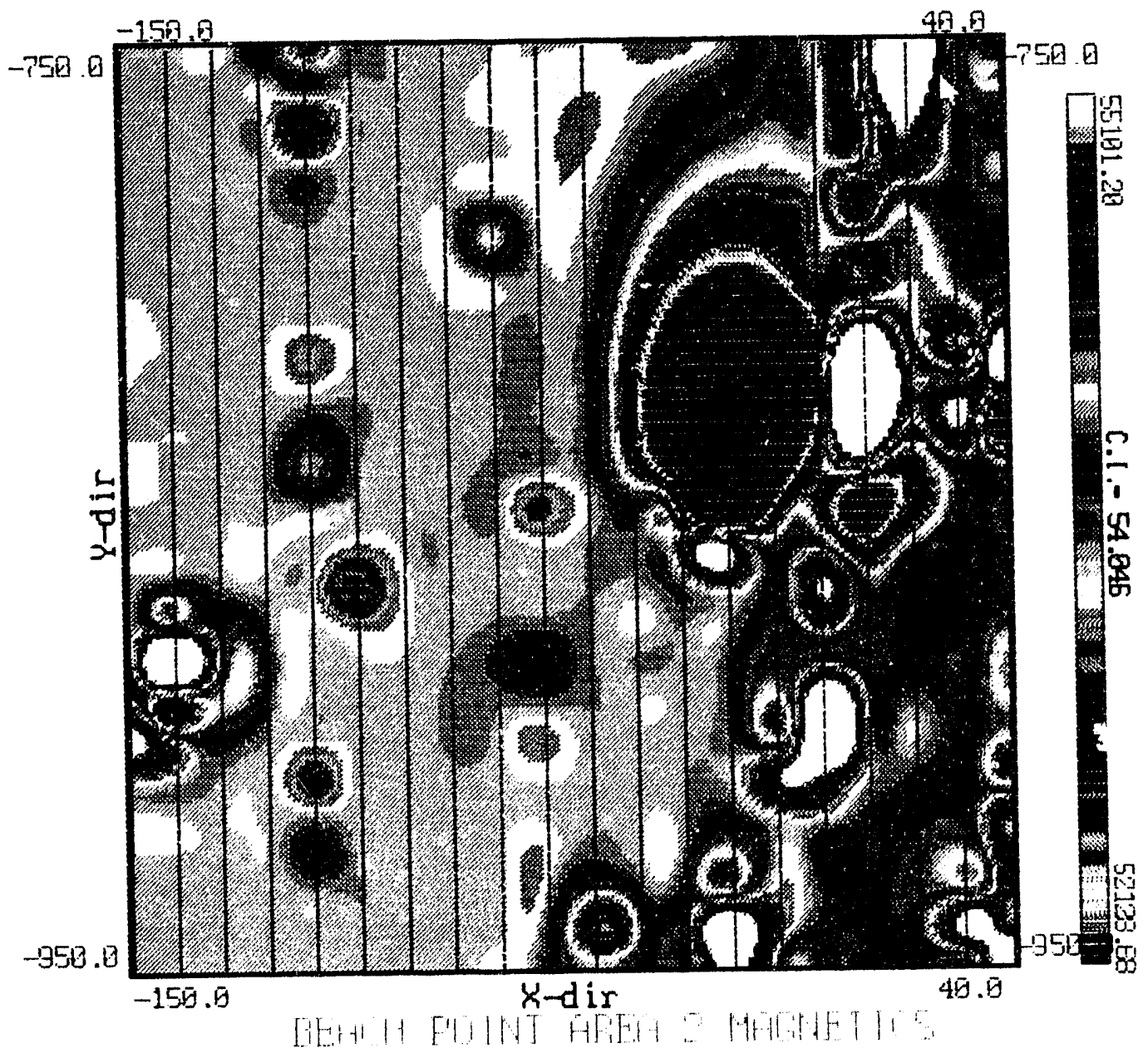

FIGURE D.3 Beach Point Area 2 Magnetics (Anomalies on the east are produced by road fill and shoreline stabilization fill. The large negative anomaly area and associated anomalies in the northeast quadrant are caused by the bio-assay trailer and by other surficial debris. Anomalies in the western half of the area are caused by unknown, buried sources, as listed in Table 4.) 


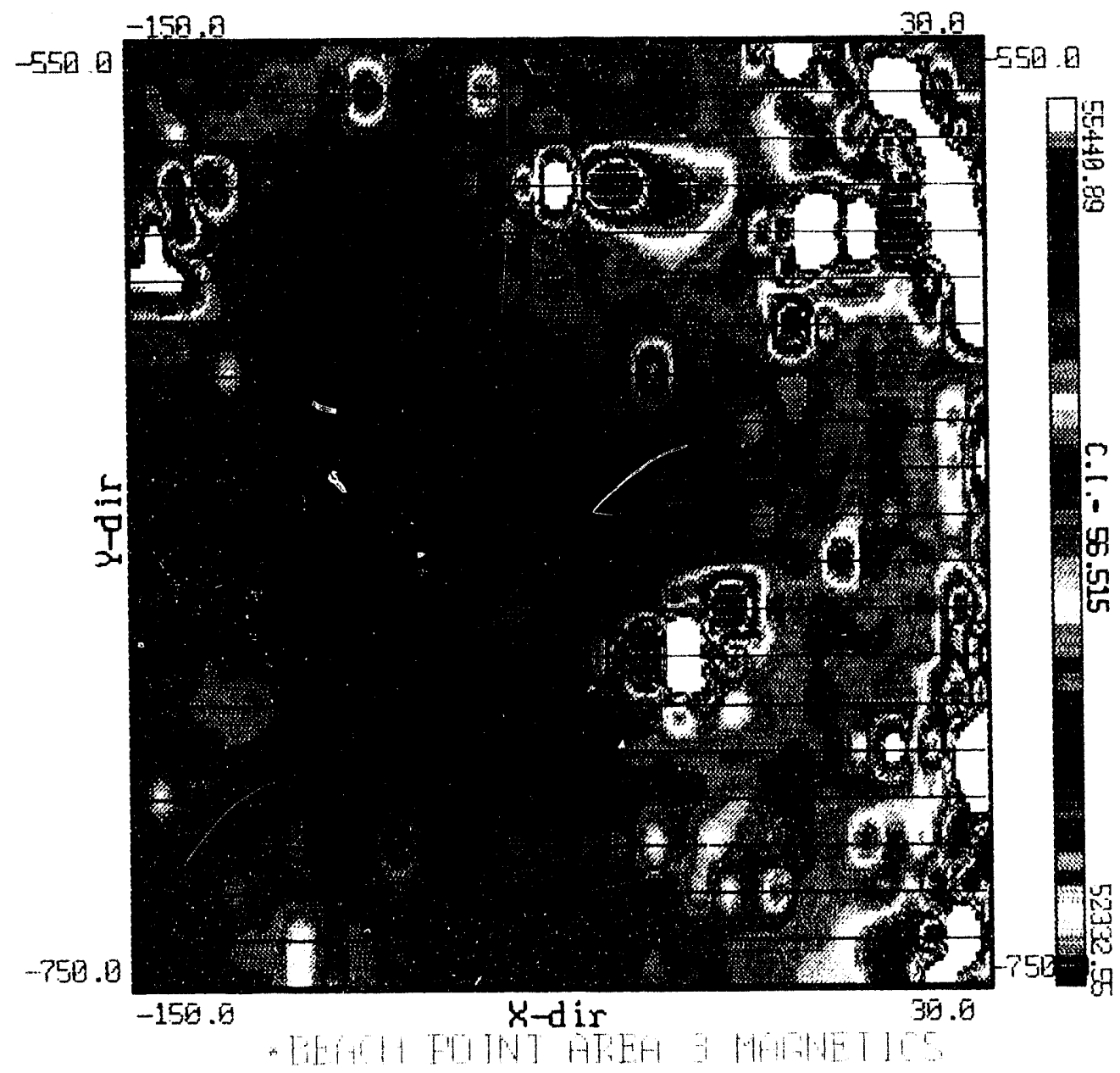

FIGURE D.4 Beach Point Area 3 Magnetics (Anomalies on the east are associated primarily with road fill. The source of an east-west string of anomalies along $720 \mathrm{~S}$ is unknown. The source of the large anomaly complex at $690 \mathrm{~S}-40 \mathrm{~W}$ is unknown. Anomalies in the northwest quarter are caused partially by surface debris. Anomalies in the north central area are associated with a concrete slab.) 


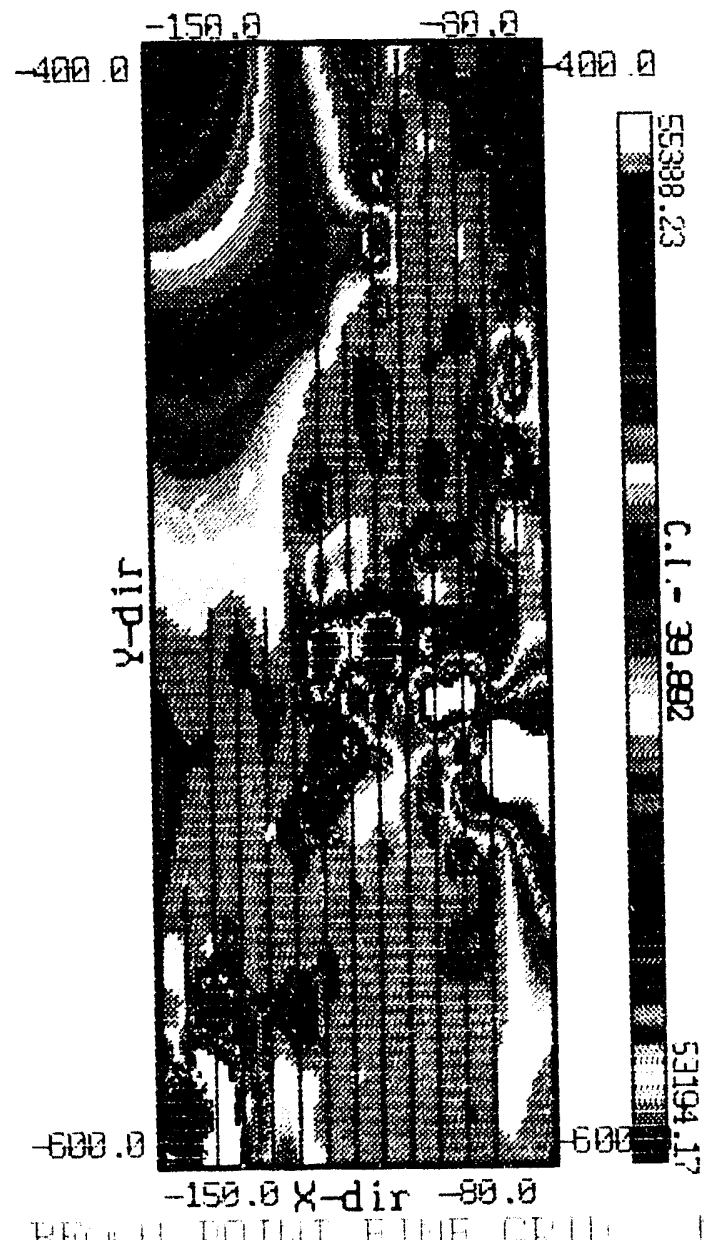

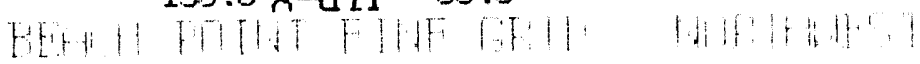

FIGURE D.5 Beach Point Fine Grid: Northwest (Anomalies are unexplained and are probably associated with trenches and activities during operation of the former building associated with the buried concrete slab.) 


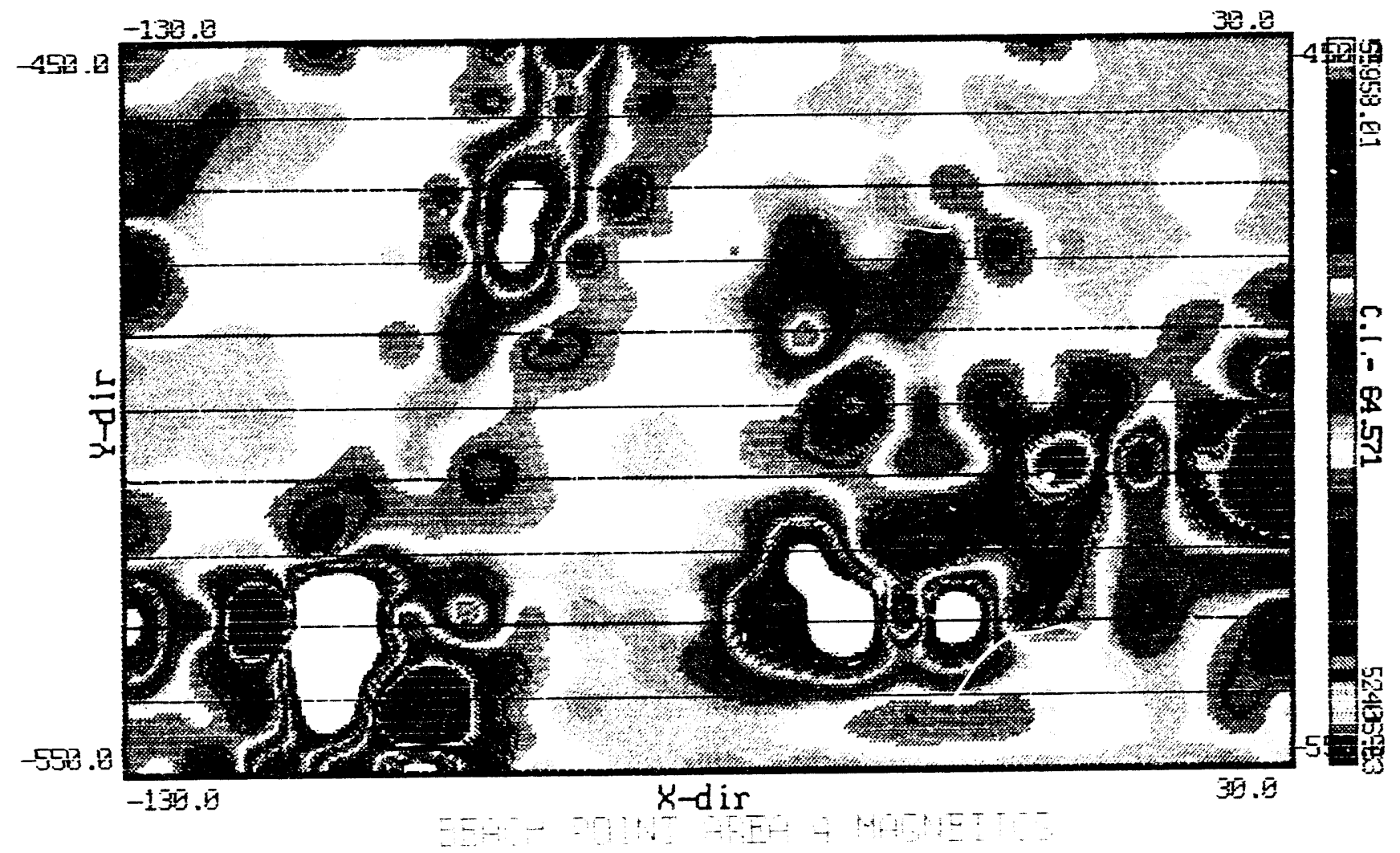

FIGURE D.6 Beach Point Area 4 Magnetics (Anomalies are unexplained and are probably associated with trenches, buried tanks, and activities during operation of the former building on the concrete slab.) 


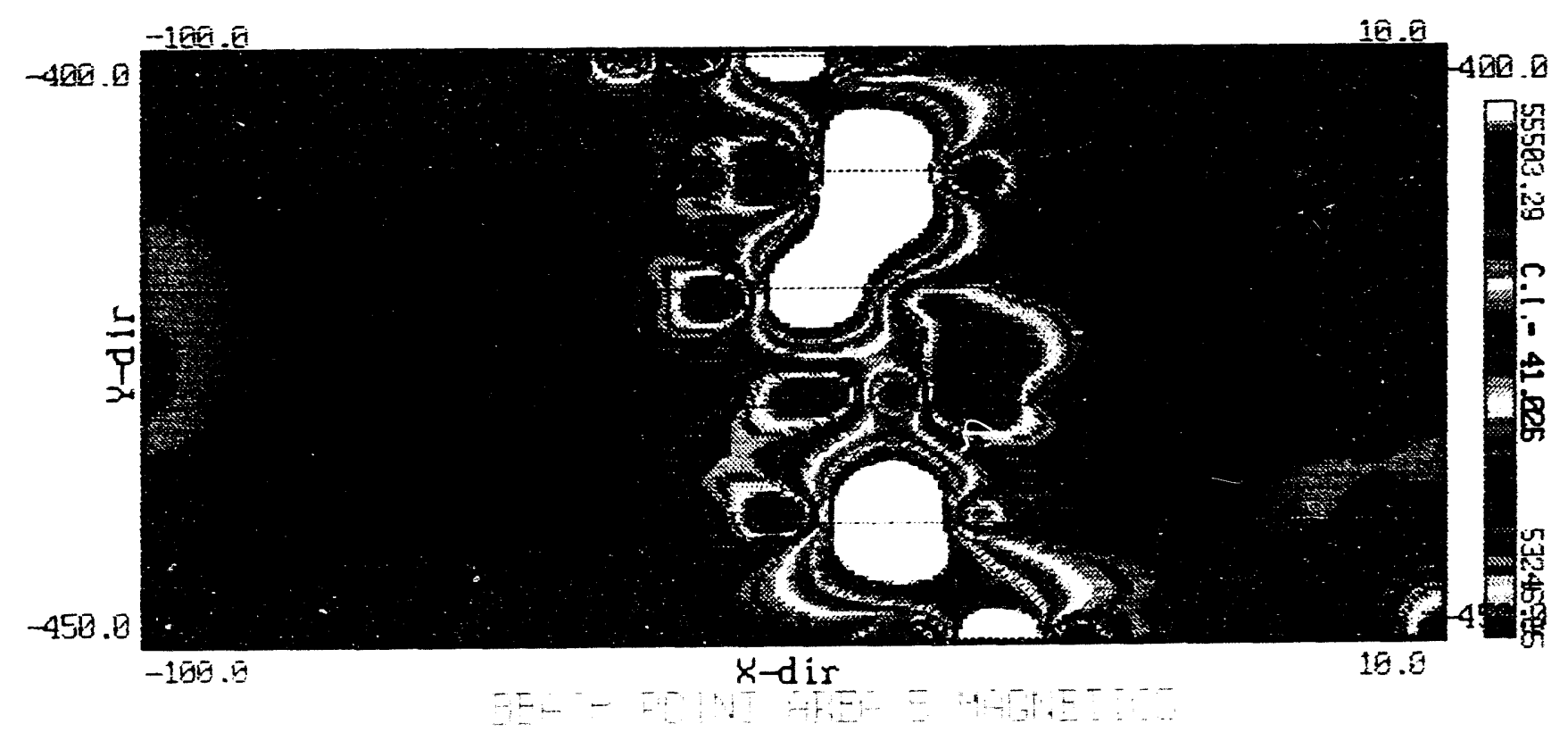

FIGURE D.7 Beach Point Area 5 Magnetics (All anomalies are associated with the access road fill.) 


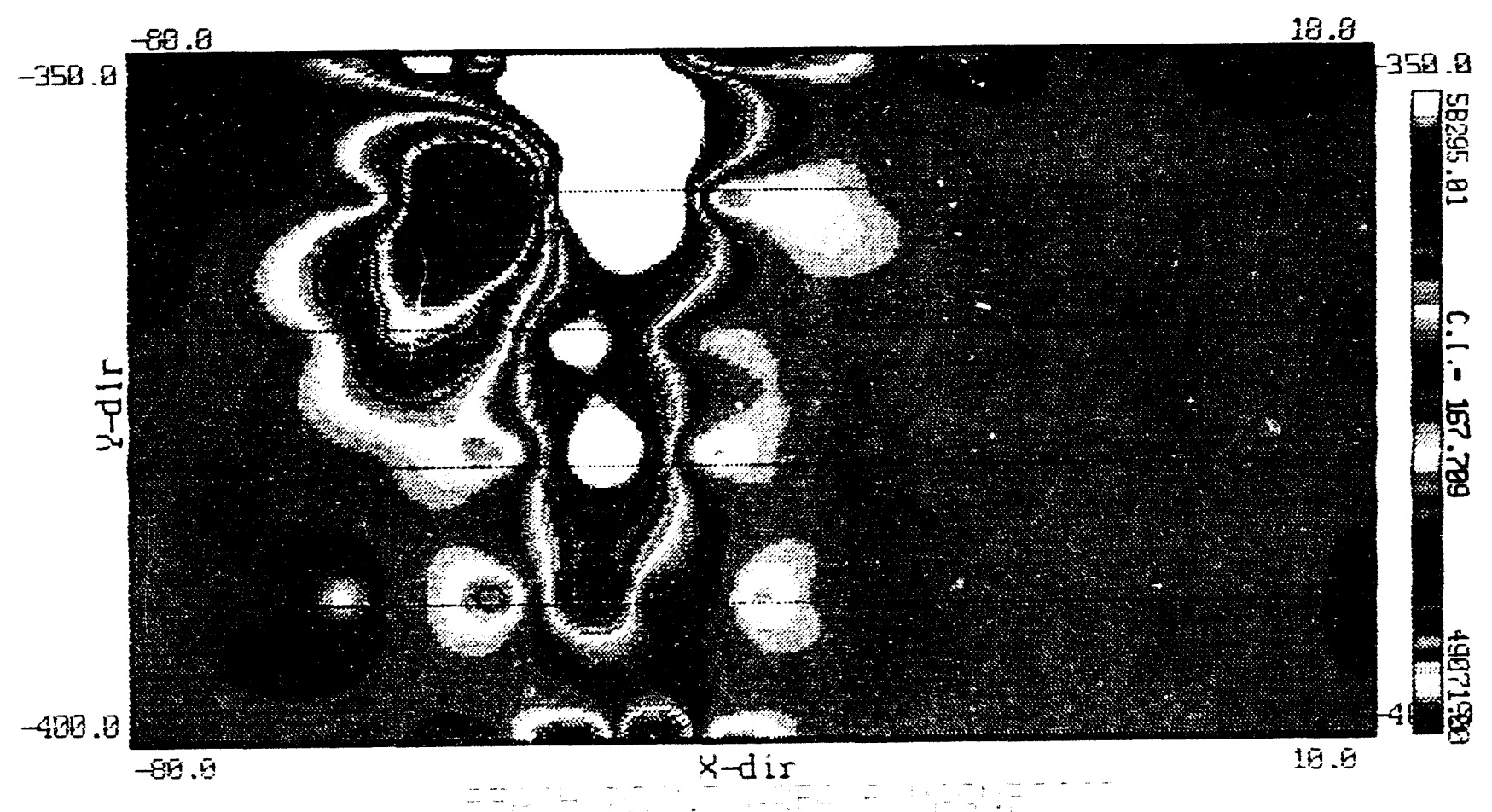

FIGURE D.8 Beach Point Area 6 Magnetics (Anomalies are caused primarily by road fill.) 


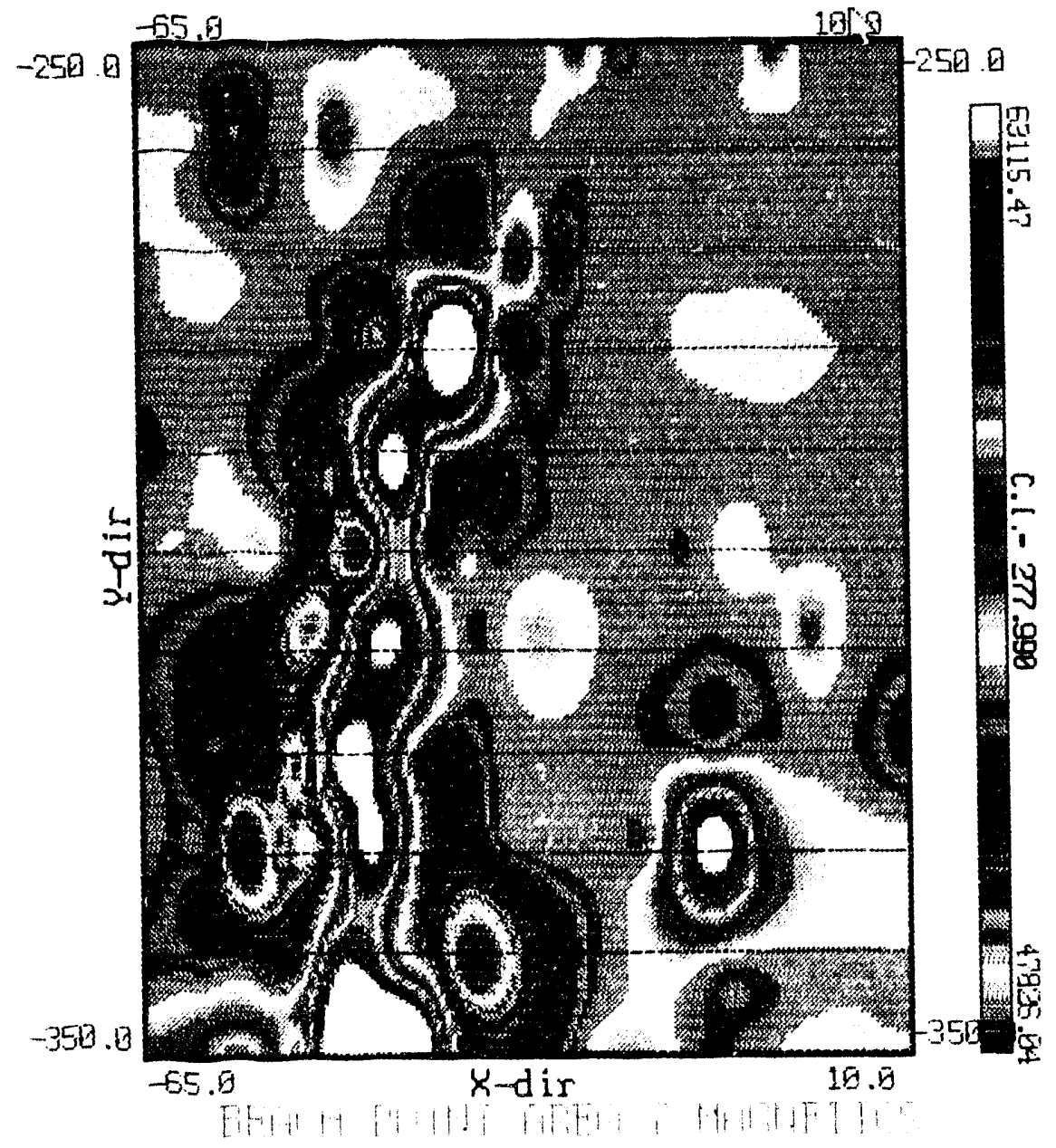

FIGURE D.9 Beach Point Area 7 Magnetics (Anomalies are caused by road fill.) 


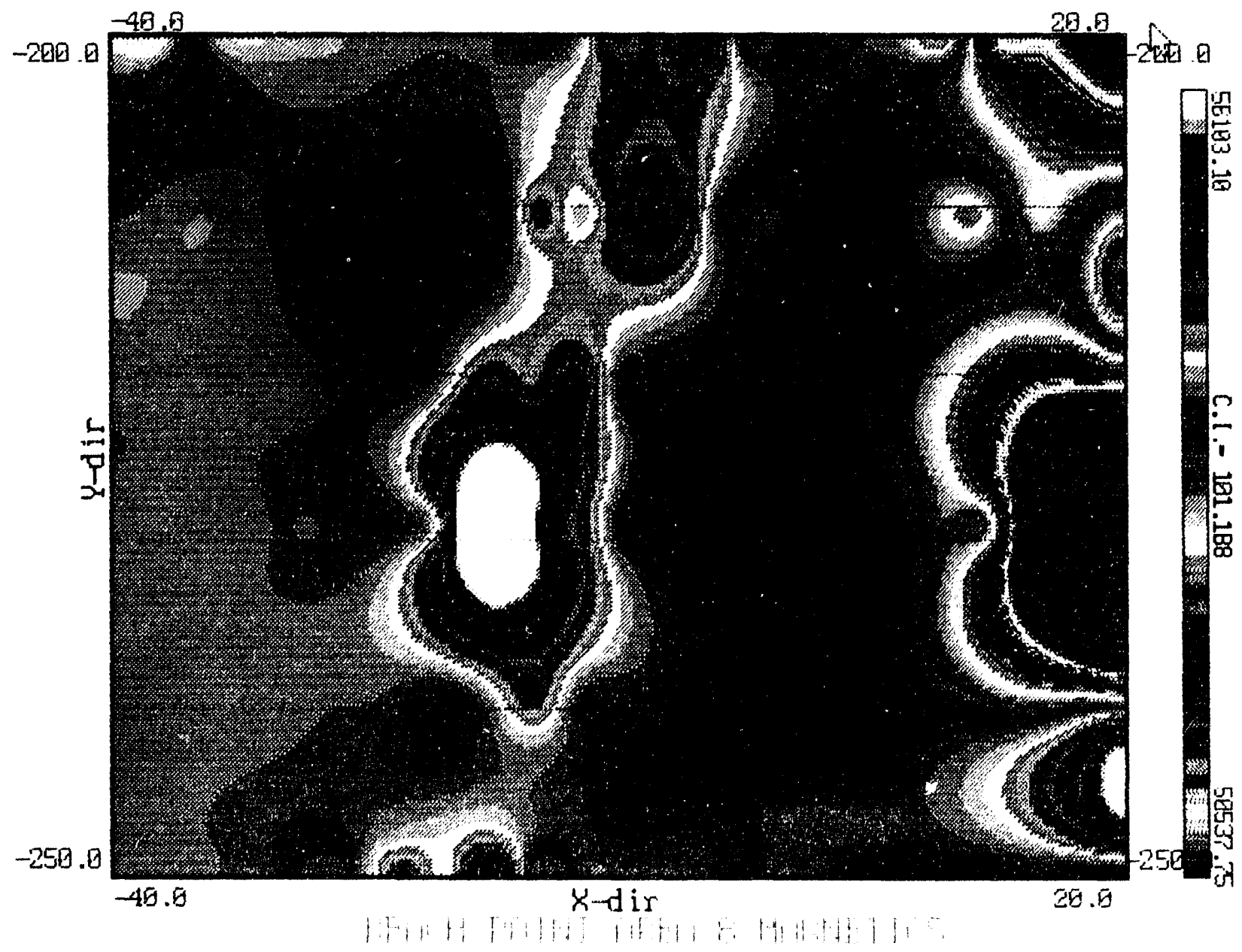

FIGURE D.10 Beach Point Area 8 Magnetics (Anomalies are caused by road fill.) 


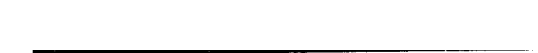




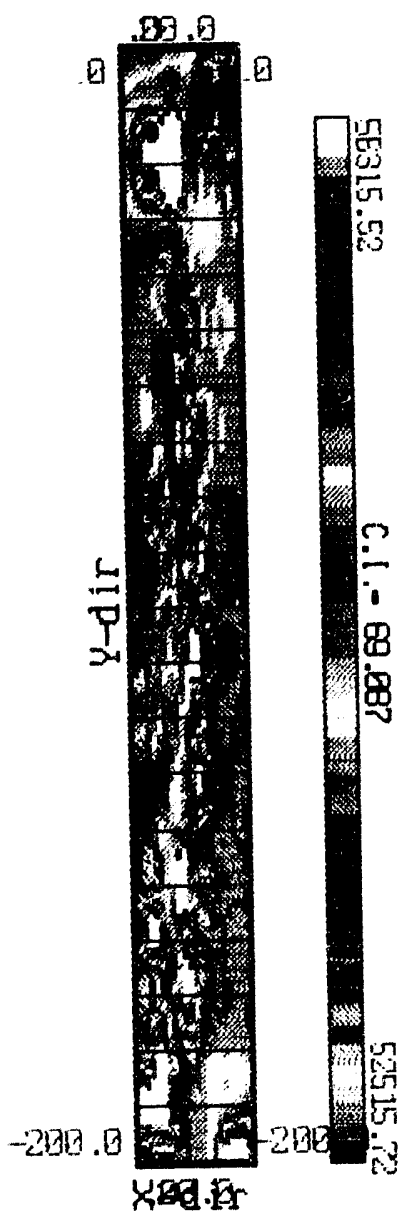

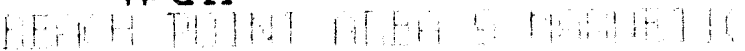

FIGURE D.11 Beach Point Area 9 Magnetics (Anomalies are caused by road fill.) 


\section{Distribution for ANL/ESD-23}

Internal

ANL Technical Publications Services

R. Weeks

N. Clodi (4)

R. Putnam

L.D. McGinnis (62)

\section{External}

U.S. Department of Energy Office of Scientific and Technical Information (12)

Manager, U.S. Department of Energy Chicago Field Office

ANL-E Libraries (2)

ANL-W Library 

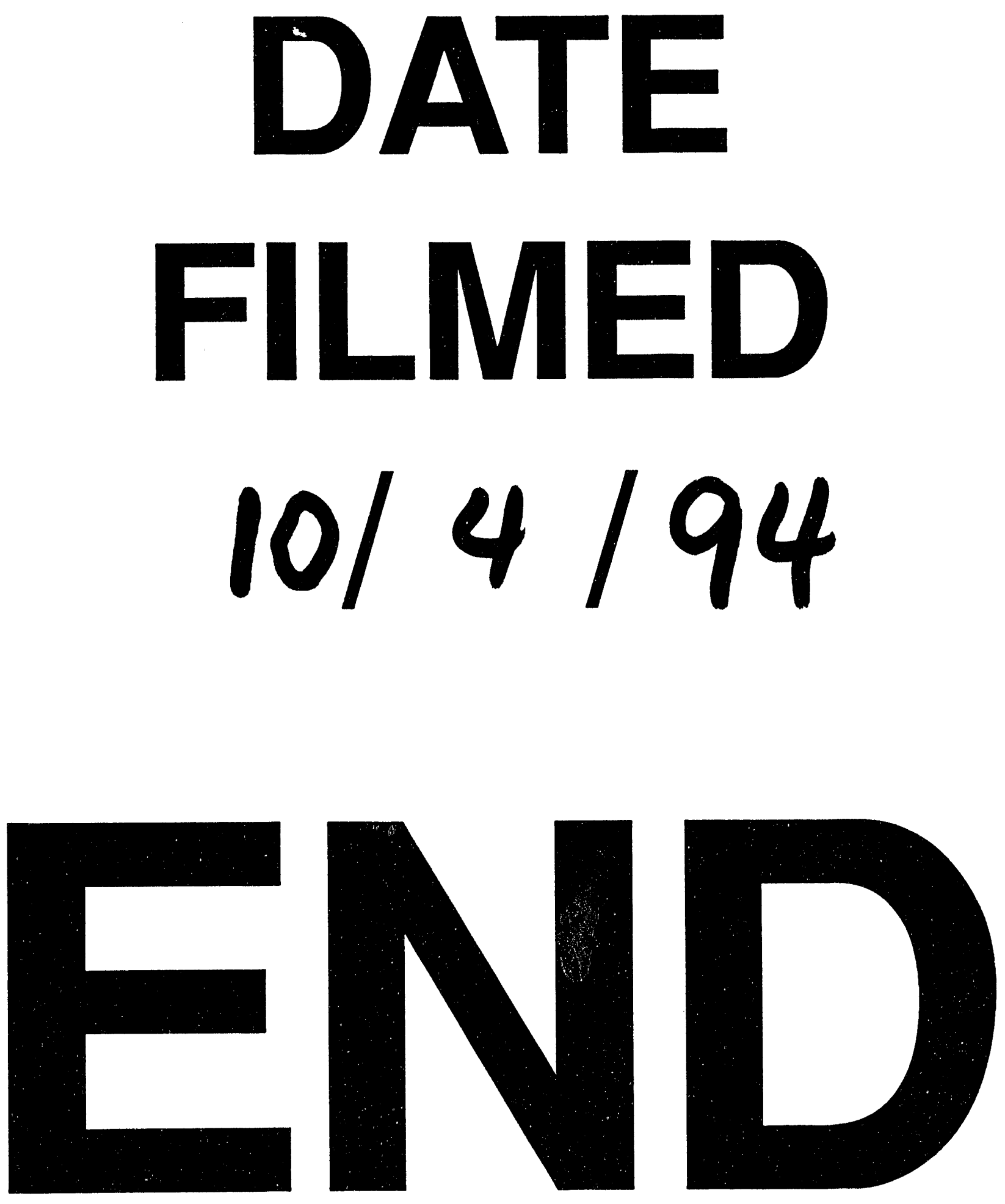


$$
\text { ( }
$$

